\title{
Economic Optimization of Campus Energy System Using Real Time Pricing
}

\author{
By \\ Maxime St-Jacques, B.Eng. \\ A thesis submitted to the Faculty of Graduate and Postdoctoral Affairs in \\ partial fulfillment of the requirements for the degree of
}

\section{Master of Applied Science}

Department of Mechanical and Aerospace Engineering Carleton University

Ottawa-Carleton Institute for Mechanical and Aerospace Engineering Ottawa, Ontario

August 2018

(C) 2018, Maxime St-Jacques 
The undersigned hereby recommends to the

Faculty of Graduate and Postdoctoral Affairs acceptance of the thesis

\title{
Economic Optimization of Campus Energy System Using Real Time Pricing
}

\author{
submitted by Maxime St-Jacques, B.Eng. \\ in partial fulfillment of the requirements for the degree of
}

Master of Applied Science

Professor Huseyin Gunay

Internal Examiner

Professor Cynthia Cruickshank

Member of Department

Professor Raphael St. Gelais

Member of Joint Institute

Professor Scott Bucking

Thesis Supervisor

Professor William O’Brien

Thesis Co-Supervisor

Professor Andrei Artemev

Graduate Chair

Department of Mechanical and Aerospace Engineering

Carleton University

Ottawa-Carleton Institute for Mechanical and Aerospace Engineering 


\section{Abstract}

This thesis aims to design a community energy system with controls optimizing for operational cost savings. This research treats electrical and thermal domains as an integrated system to find a global minimum cost of a community energy system. A proposed methodology to quantify an electric grid user's greenhouse gas (GHG) emission is presented and then demonstrated with a case study. The methodology is demonstrated using publicly available hourly timestamped generator data from the Independent Electricity System Operator (IESO) and the hourly electrical load of a campus building in 2015. This contribution shows that an increase in GHG emissions cost of 53\% can be seen when comparing annual versus hourly methodologies. The GHG quantification method is relevant throughout the thesis allowing the author to discuss the environmental effects of adding storage technologies to community energy systems. This methodology is an improvement over previously accepted annual methods of calculating GHG emissions as it considers electrical grid peak time and thus is relevant to any user of a mixed source electrical grid wanting to better quantify their emissions. Furthermore, an optimization methodology is presented to lower an electrical grid user's electrical bill through the implementation of a battery energy storage system. This cost optimization showcases with a case study demonstrating that optimizing to lower electrical costs has an added benefit of lowering GHG emissions and removing peak demand capacity from the grid. This optimization methodology is then expanded to also lowering a community energy systems gas bill by way of controlling an on-site generator, a battery energy storage system and a thermal energy storage system. The cost optimization methodology demonstrated with a university campus electrical and heat data resulted in an approximate yearly saving of 
$\$ 3.163 \mathrm{M}$ or $33 \%$ in operational costs. The results of these case studies are important to both end-consumers and utility companies as it creates a mutually beneficial situation in terms of costs and environment. 


\section{Acknowledgements}

I would first like to thank both Dr. Liam O'Brien and Dr. Scott Bucking for the opportunity and privilege to complete this thesis under their supervision. They allowed me to venture out into research that truly piqued my interest while guiding me to success. Their desire to excel into new territories and passionate conversations were invaluable throughout these past two years. For these and many more reasons, I am truly thankful.

I would also like to acknowledge all other professors in the Building Performance Research Centre who have all helped me in some way. Within these professors, I would like to give a special thank you to Dr. Cynthia Cruickshank for getting me more involved during my undergraduate and sparking my curiosity.

To the students of the Building Performance Research Centre, thank you all for your help and laughs. Specifically, to my office mate, Tareq Abuimara thank you for keeping me sane.

Thank you to both NSERC and NewEnergy for their support in some of my research. Additionally, thank you to Carleton University's facilities team and the IESO for providing much of the data required for this research.

This thesis would not exist if it wasn't for my family and close-knit group of friends who've all provided me with constant support and the joys of life.

I must thank my partner in crime, Erika Kall, for inspiring me to better myself every day and allowing me to work on my ideas. You keep life an adventure.

Finally, I would like to thank my dog, Baxter, for his unconditional love and constant company. 


\section{Table of Contents}

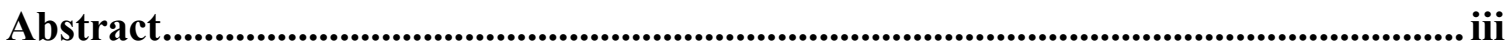

Acknowledgements ............................................................................................................. $\mathrm{V}$

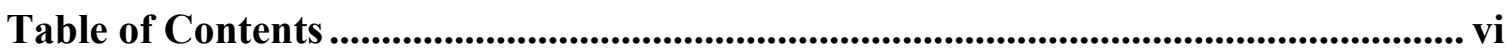

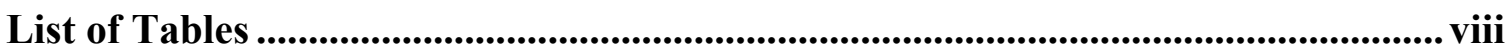

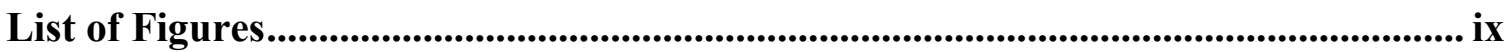

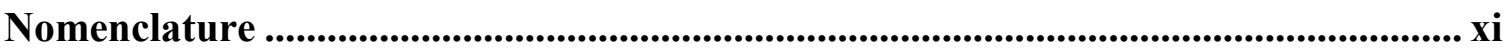

1 Chapter: Introduction .................................................................................................... 1

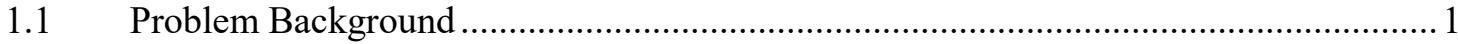

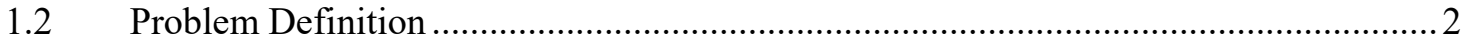

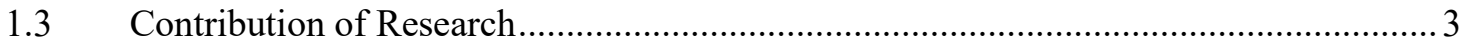

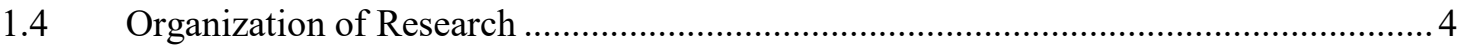

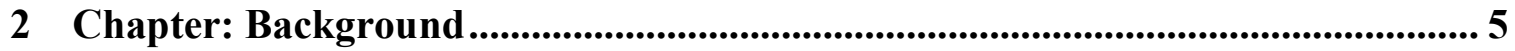

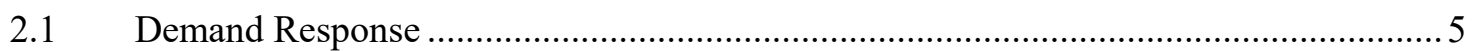

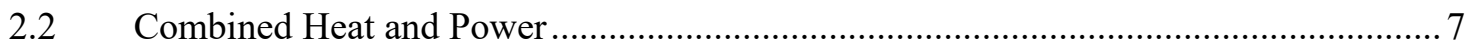

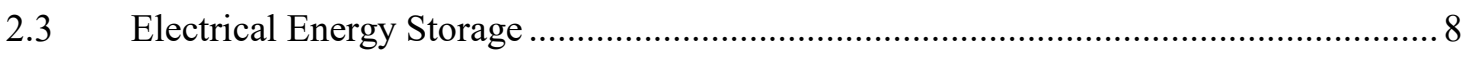

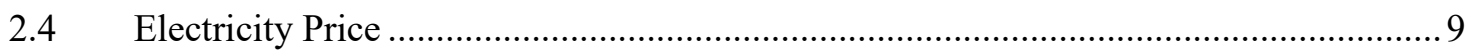

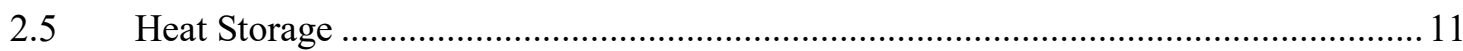

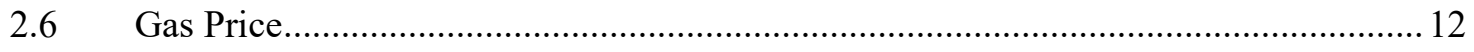

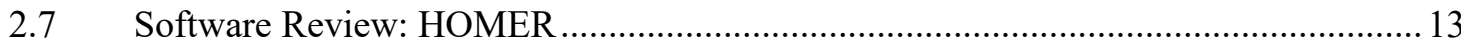

3 Chapter: GHG Emissions from Electrical Grid Use ......................................... 17

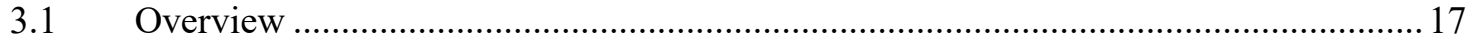

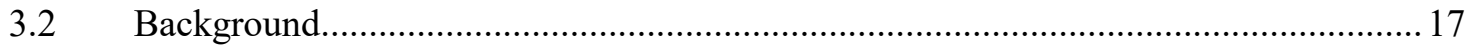

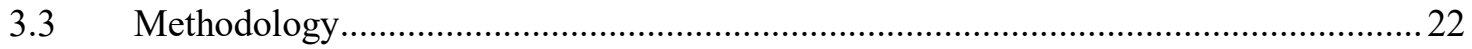

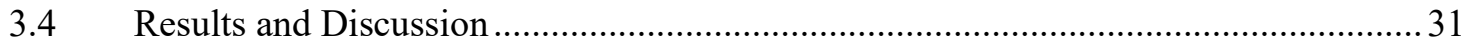

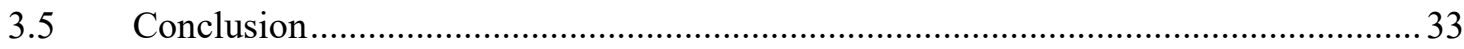

4 Chapter: Electrical Bill Minimization via Battery Energy Storage Systems ...... 35 


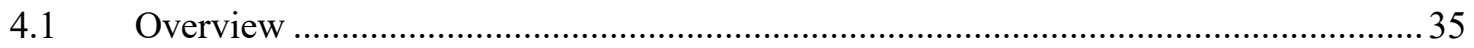

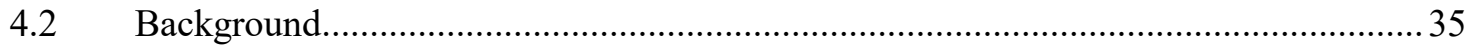

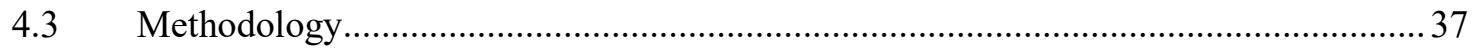

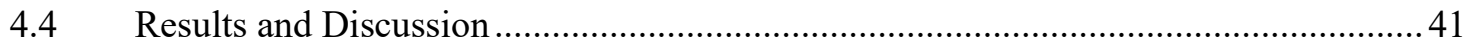

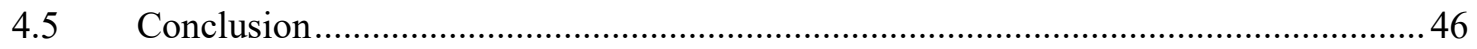

5 Chapter: Energy Bills Minimization via On-Site Generator and Storage ........... 47

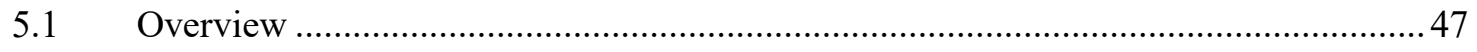

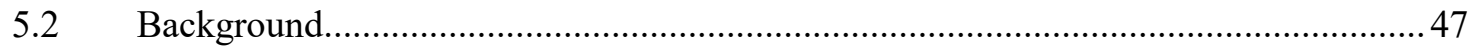

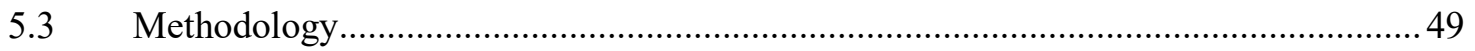

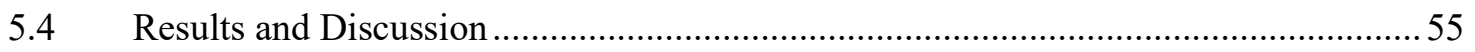

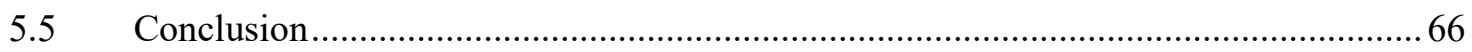

6 Chapter: Conclusions and Future Work ......................................................... 68

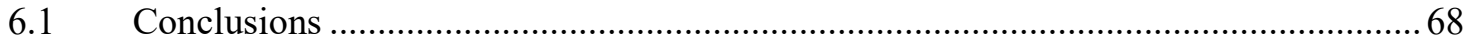

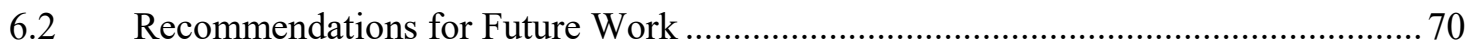

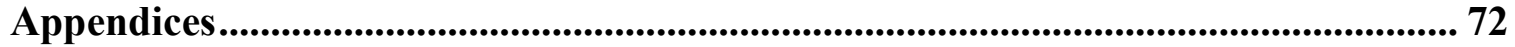

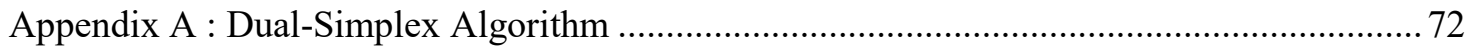

Appendix B : Carleton Eight Building Cluster Load Profile.................................................. 74

Appendix C : Carleton University Campus Load Data …................................................... 75

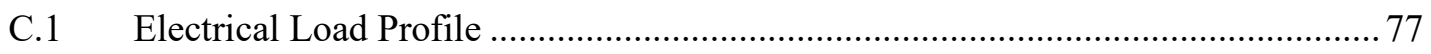

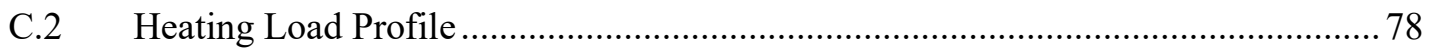

Appendix D : Carleton University’s Energy System Load ................................................. 79

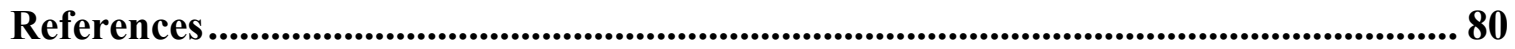




\section{List of Tables}

Table 2.1: Efficiencies, Heat to Power Ratios of CHPs [14]............................................ 8

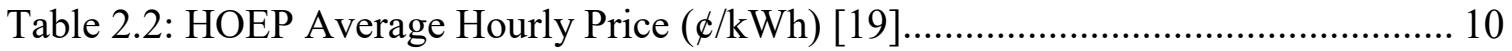

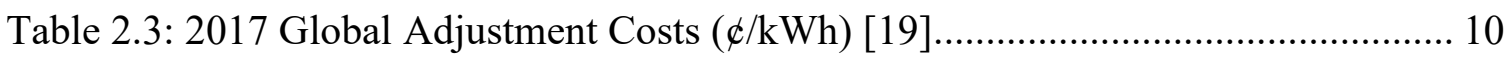

Table 2.4: Enbridge Nature Gas Price Structure [26] .................................................. 13

Table 2.5: OEB's Historical Price for Natural Gas for Enbridge Gas Distribution [27] .. 13

Table 3.1: Yearly emission factor for Canada and select provinces (t CO2e/ GWh) [37] 19

Table 3.2: Hourly emission factors for USA (t CO2e/GWh) [44].................................... 21

Table 3.3: General information of Ontario's electrical zones .......................................... 24

Table 3.4: Energy mix of Canadian provinces in 2014 .................................................. 27

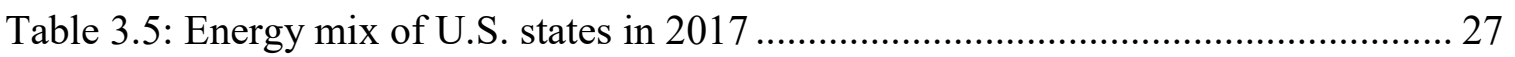

Table 3.6: Ontario electricity generator's life cycle GHG emissions in 2008 .................. 27

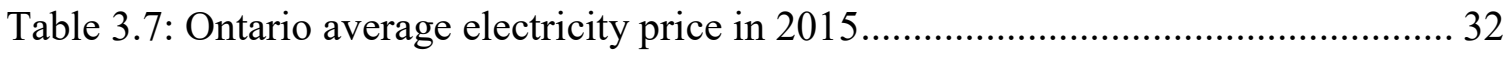

Table 3.8: GHG costs depending on model ................................................................ 32

Table 3.9: GHG sensitivity based on model assumptions ............................................... 33

Table 4.1: BESS Model Linear Program Constraints ....................................................... 38

Table 4.2: BESS Model Linear Program Nomenclature ……………………………..... 39

Table 4.3: Hydro Ottawa's Rates under 5,000 kW Peak [63] ........................................... 40

Table 4.4: Hydro Ottawa's Rates over 5,000 kW Peak [63] ............................................ 40

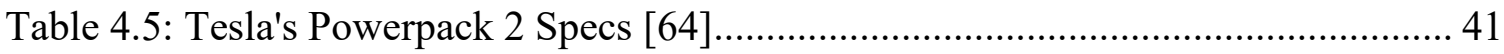

Table 4.6: 2015 Minimized Electrical Bills ...................................................................... 42

Table 4.7: 2015 Minimized Peak Demand ...................................................................... 43

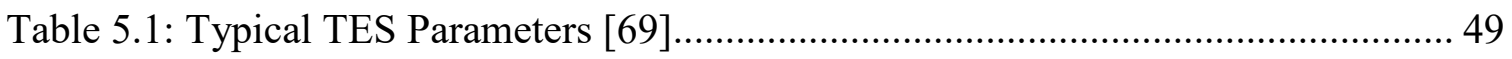

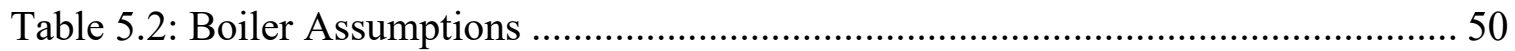


Table 5.3: CHP System Parameters [71] …………………...................................... 51

Table 5.4: CES Linear Program Constraints.............................................................. 52

Table 5.5: CES Linear Program Nomenclature .............................................................. 54

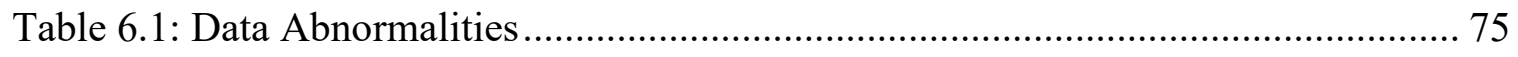

\section{List of Figures}

Figure 1.1: 345 kV Integrated North American Power Lines Map [9] ............................ 2

Figure 2.1: IESO Supply Mix and HOEP Price in January 2015 ..................................... 6

Figure 2.2: Hydro Ottawa's Time of Use Rates [13] f.................................................. 7

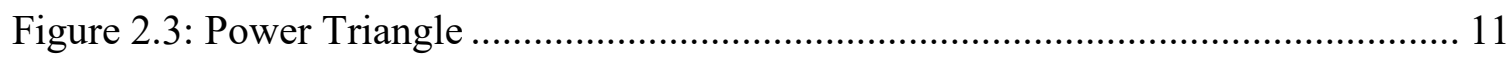

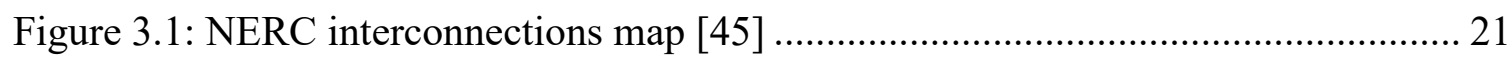

Figure 3.2: Physical boundaries of Ontario's electrical zones ........................................ 25

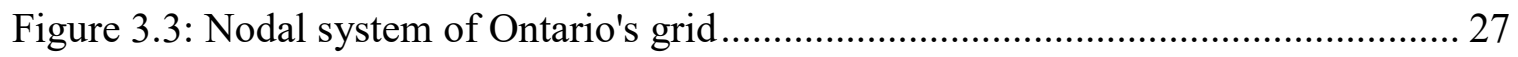

Figure 3.4: Richcraft Hall yearly load profile heat map ................................................. 30

Figure 3.5: Average annual daily profile of Richcraft Hall ............................................ 30

Figure 3.6: Average monthly profile of Richcraft Hall ................................................... 31

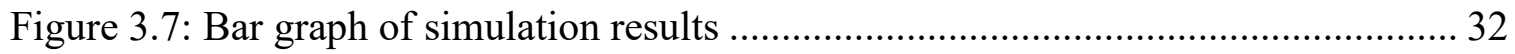

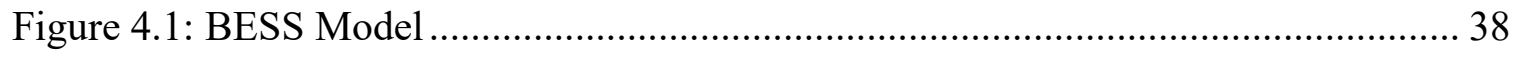

Figure 4.2: Electricity Charge 2015-2016 ………………............................................. 41

Figure 4.3: BESS Charge/Discharge Histogram.......................................................... 44

Figure 4.4: BESS Simple Payback versus Cost of BESS ............................................... 45

Figure 4.5: Bill Savings and Simple Payback Dependent on Amount of Powerpacks..... 45

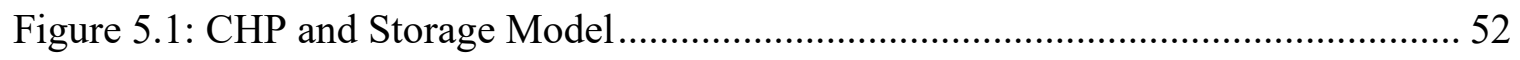

Figure 5.2: Campus Hourly Demand from Grid in CHP Model...................................... 56 
Figure 5.3: Average Weekday Campus Demand from Grid in CHP Model ................... 56

Figure 5.4: CHP Hourly Electrical Output from CHP Model .................................... 57

Figure 5.5: Campus Hourly Demand from Grid in CHP + BESS Model ...................... 58

Figure 5.6: Average Weekday Campus Demand from Grid in CHP + BESS Model ...... 58

Figure 5.7: Auxiliary Boiler Hourly Heat Output in CHP Model ................................ 59

Figure 5.8: CHP Hourly Waste Heat in CHP Model .................................................. 59

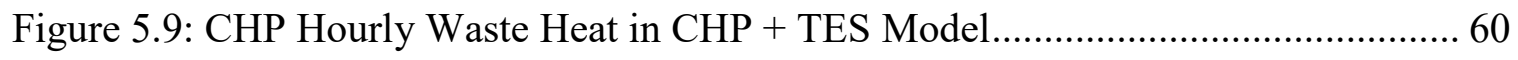

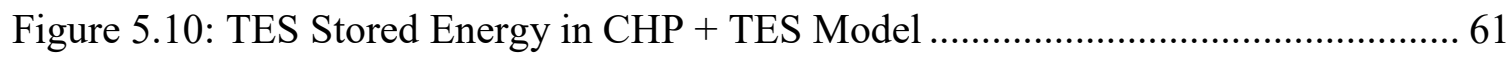

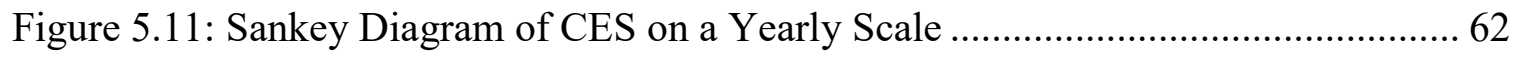

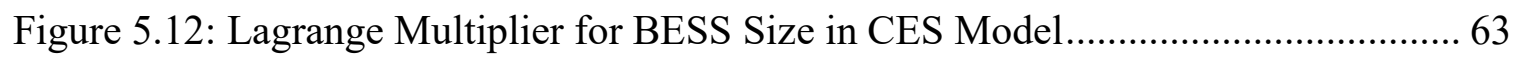

Figure 5.13: Lagrange Multiplier for BESS Charge Rate in CES Model........................ 63

Figure 5.14: Lagrange Multiplier for BESS Discharge Rate in CES Model .................... 64

Figure 5.15: Lagrange Multiplier for CHP Capacity in CES Model .............................. 64

Figure 5.16: Sensitivity Analysis of TES Size for Operational Savings ....................... 65

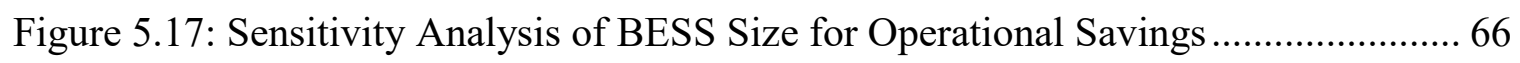

Figure 6.1: Logic Map to Calculate Simplex Problem ................................................ 73

Figure 6.2: Carleton University Eight Building Cluster Stacked Load Profile ............... 74

Figure 6.3: Raw vs Interpolated Hourly Electrical Data........................................... 77

Figure 6.4: Raw vs Interpolated Hourly Heating Data ........................................... 78

Figure 6.5: Carleton University Hourly Timestep Load Profile in 2016 ....................... 79 


\section{Nomenclature}

\begin{tabular}{|c|c|}
\hline Abbreviations & Full Name \\
\hline BESS & Battery Energy Storage System \\
\hline CES & Community Energy System \\
\hline $\mathrm{CHP}$ & Combined Heat and Power \\
\hline $\mathrm{CO}_{2 \mathrm{e}}$ & Carbon Dioxide Equivalent \\
\hline CPP & Critical Peak Pricing \\
\hline DER & Distributed Energy Resource \\
\hline $\mathrm{DHN}$ & District Heating Network \\
\hline DLC & Directly Controllable Load \\
\hline DR & Demand Response \\
\hline EDRP & Emergency Demand Response Program \\
\hline EES & Electrical Energy Storage \\
\hline $\mathrm{EF}$ & Emission Factor \\
\hline EM & Energy Mix \\
\hline EPA & United States Environmental Protection Agency \\
\hline GA & Global Adjustment \\
\hline GHG & Greenhouse Gas \\
\hline HOEP & Hourly Ontario Energy Price \\
\hline IESO & Independent Electricity System Operator \\
\hline LDC & Local Distribution Company \\
\hline LHS & Latent Heat Storage \\
\hline LR & Linear Regression \\
\hline NERC & North American Electric Reliability Corporation \\
\hline OEB & Ontario Energy Board \\
\hline PCM & Phase Change Material \\
\hline RTP & Real Time Pricing \\
\hline SHS & Sensible Heat Storage \\
\hline SVM & Support Vector Machine \\
\hline TCHS & Thermochemical Heat Storage \\
\hline TDV & Time-dependent Valuation \\
\hline TES & Thermal Energy Storage \\
\hline TOU & Time-of-use \\
\hline
\end{tabular}




$\begin{array}{ll}\text { Symbols } & \text { Full Name } \\ \phi & \text { Cents } \\ \$ & \text { Dollars } \\ \Phi & \text { Heat Transfer Rate } \\ \mathrm{K} & \text { Heat Transfer Coefficient } \\ \Delta \mathrm{t} & \text { Temperature Difference } \\ \sum & \text { Sum Of } \\ i & \text { Timestep Index } \\ j & \text { Technology Source } \\ A & \text { Inequality Matrix } \\ \text { Aeq } & \text { Equality Matrix } \\ b & \text { Inequality Vector } \\ b e q & \text { Equality Vector } \\ f & \text { Objective function } \\ x & \text { Solution Vector } \\ & \\ \mathrm{Units} & \text { Full Name } \\ \mathrm{t} & \\ \mathrm{tCO} & \text { Tonne } \\ \mathrm{M} & \text { Tonnes of Carbon Dioxide Equivalent } \\ \mathrm{k} & \text { Million }(\$) \\ \mathrm{Mt} & \text { Thousand }(\$) \\ \mathrm{kV} & \text { Megatonne } \\ \mathrm{kW} & \text { Kilovolt } \\ \mathrm{MW} & \text { Kilowatt } \\ \mathrm{kWh} & \text { Megawatt } \\ \mathrm{kWh} & \text { Kilowatt-hour } \\ \mathrm{GWh} & \text { Kilowatt-hour equivalent } \\ \mathrm{lbs} & \text { Gigawatt-hour } \\ \mathrm{klbs} & \text { Pounds } \\ \mathrm{m}^{3} & \text { 1000 Pounds } \\ \mathrm{MMBTU} & \text { Meter Cubed } \\ \mathrm{K} & \text { One Million British Thermal Units } \\ { }^{\circ} \mathrm{C} & \text { Kelvin } \\ & \text { Degrees Celsius } \\ & \end{array}$




\section{Chapter: Introduction}

\subsection{Problem Background}

The Intergovernmental Panel on Climate Change states that human influence on the climate system is clear and the recent climate changes caused have had impacts on both humans and their surrounding natural systems [1]. The international community has spoken by having 174 of 197 parties ratified for the Paris Agreement which has the aim to strengthen the global response to the threat of climate change [2]. These countries, including Canada, have individualistic goals to reduces their greenhouse gas (GHG) emissions from 1990 levels. Not taking in account the production of fossil fuels, the electricity sector in Canada is responsible for $79 \mathrm{Mt} \mathrm{CO}_{2} \mathrm{e}$ in 2015 [3], of much emissions are caused by peaking plants which are GHG-intensive generators that also require expensive operational and investments costs $[4,5,6]$. Peaking plants are often activated when system-wide peak demands are needed causing an increase in electrical price. In the most populated province of Canada, Ontario, the base load is met largely by nuclear and hydro power whereas peaks loads are mostly met with natural gas-fired powerplants.

Using renewable energy will lower the use of fossil fuels therefore lowering greenhouse gas (GHG) emissions of the grid. The problem with renewable energy arises from its intermittent nature. Incorporating a higher share of renewable technologies into the grid is motivated by old infrastructure requiring high repair or replacement costs, lowering cost in renewable technologies, stricter environmental requirements, tougher carbon policies, consumer's push for GHG-free energy, and deployment of smarter grids with new services allowing new income opportunities for utilities [7]. Active research around smart grids have been underway since 2008 to remedy some of these situations, 
however, grid-wide implementations have yet to be implemented.

The American Society of Civil Engineers' 2013 report card gave the USA's energy system a lowly grade of $\mathrm{D}+$ meaning poor and at risk. This low grade is mostly due to America's aging electrical grid, some of which originated in the 1880s [8]. The Canadian counterpart does not report on its energy infrastructure; however, similar rating is expected due to its interconnected nature as seen in Figure 1.1 [9]. This causes further issues as it is believed that up to $80 \%$ of all grid failures begin at the distribution level [10].

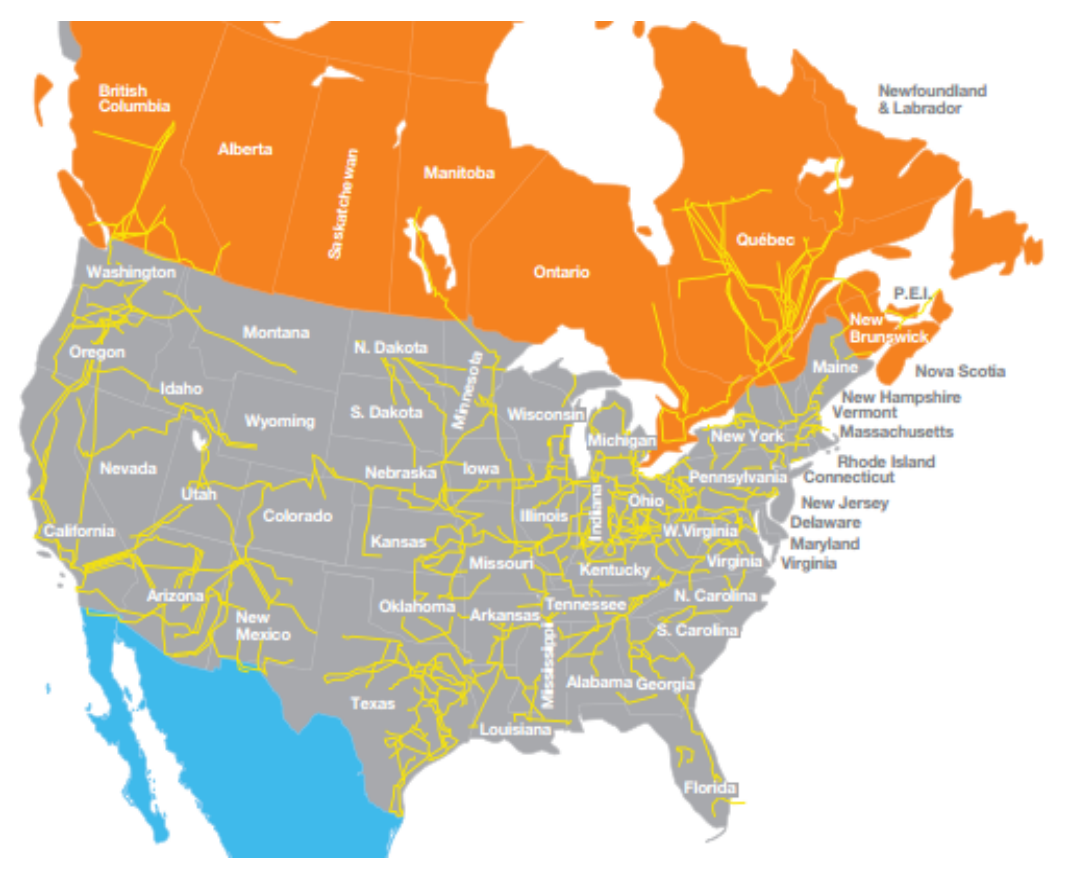

Figure 1.1: 345 kV Integrated North American Power Lines Map [9]

\subsection{Problem Definition}

The trend of increasing world-wide urbanization indicates that city systems will play an important role in our collective carbon-free future. Presently, our cities are based on outdated technologies which are susceptible to grid outages from increasingly frequent severe weather events such as the recent 2012 Toronto flooding and 2013 Ontario Ice Storm. An important problem to be solved in the coming decade will be the creation of 
urban environments which are resilient to grid outages and can provide essential services to homes and businesses. Furthermore, Ontario's peak demand growth is outpacing total electricity use growth [4]. This peak demand is causing hikes in price of electricity due to the increasing need to invest in peaking equipment. When the decision is made to install peaking plants, there's a missed opportunity in comparing to distributed generators. Both unnecessary redundancies and efficiencies can occur as these peaking plants are siloed from other technologies to optimize energy use. This is especially relevant to any large grid consumer such as a university campus.

\subsection{Contribution of Research}

This research aims to design a community energy system (CES) with a holistic modelling approach to consider integrated supply (energy sources), demand (energy users), storage, and collaborative management and control. This collaborative management and control are demonstrated via linear optimization, finding a global minimum cost for the entire system instead of local minima for individualistic resources. The linear optimization is solved using dual simplex technique which meets demand while making the best action for every hourly timestep.

This research could help any large electricity and natural gas users to lower their operational cost with the added benefit of lowering peak demands which in turn lowers needed grid capacity. Moreover, this research could help users in lowering GHG emissions. This research also presents a method to calculate GHG emissions from electrical grid use which was published as a conference paper by the author. The methodology moves towards representing a temporal and spatial sensitive carbon content of electrical grid usage. 


\subsection{Organization of Research}

Chapter 2 provides general background knowledge required via a literature review on various subjects such as demand response, combined heat and power, energy prices, and energy storage. Additional literature reviews are at the beginning of following chapters.

Chapter 3 presents a novel approach to calculating GHG emissions from electrical grid use via publicly available generator data and applies it to a case study of a university campus building.

Chapter 4 presents a linear programming methodology to minimize an end user's monthly electrical bill using electrical storage. The methodology is demonstrated using a campus case study of an eight-building cluster.

Chapter 5 presents a linear programming methodology minimizing energy cost over a year while meeting both heating and electrical demands and is demonstrated with a case study of a whole university campus.

Chapter 6 presents conclusions and discusses future work. 


\section{Chapter: Background}

This chapter presents background knowledge for this thesis with additional literature reviews provided at the beginning of Chapter $3-5$. This thesis focuses on a system-level; therefore, is broad in subject matter and thus distributed.

\subsection{Demand Response}

A recent literature review on distributed energy resources (DER) concluded that significant economic returns can be achieved by the deployment of all DER via several value streams such as demand response, electricity exports, outage resiliency, and local energy markets [5]. For this thesis, we will be concentrating on demand response.

Demand response (DR) is defined as the changes in energy usage by end-use customers from their normal consumption patterns in response to changes in the price of time $[4,11][11,4]$. When a DER is connected to the grid, DR can achieve economic benefits whereas when islanded, the DER could utilize DR for security and stability of the grid [12]. DR enables the reduction of high-peak hour capacity demand from peaking devices which are expensive to avoid operational and investment costs [5, 4]. As seen in Figure 2.1, the Hourly Ontario Energy Price (HOEP) supplied by the Independent Electricity System Operator (IESO) goes up considerably when the supply mixture utilizes more of the GHG-intensive natural gas peaking stations. 


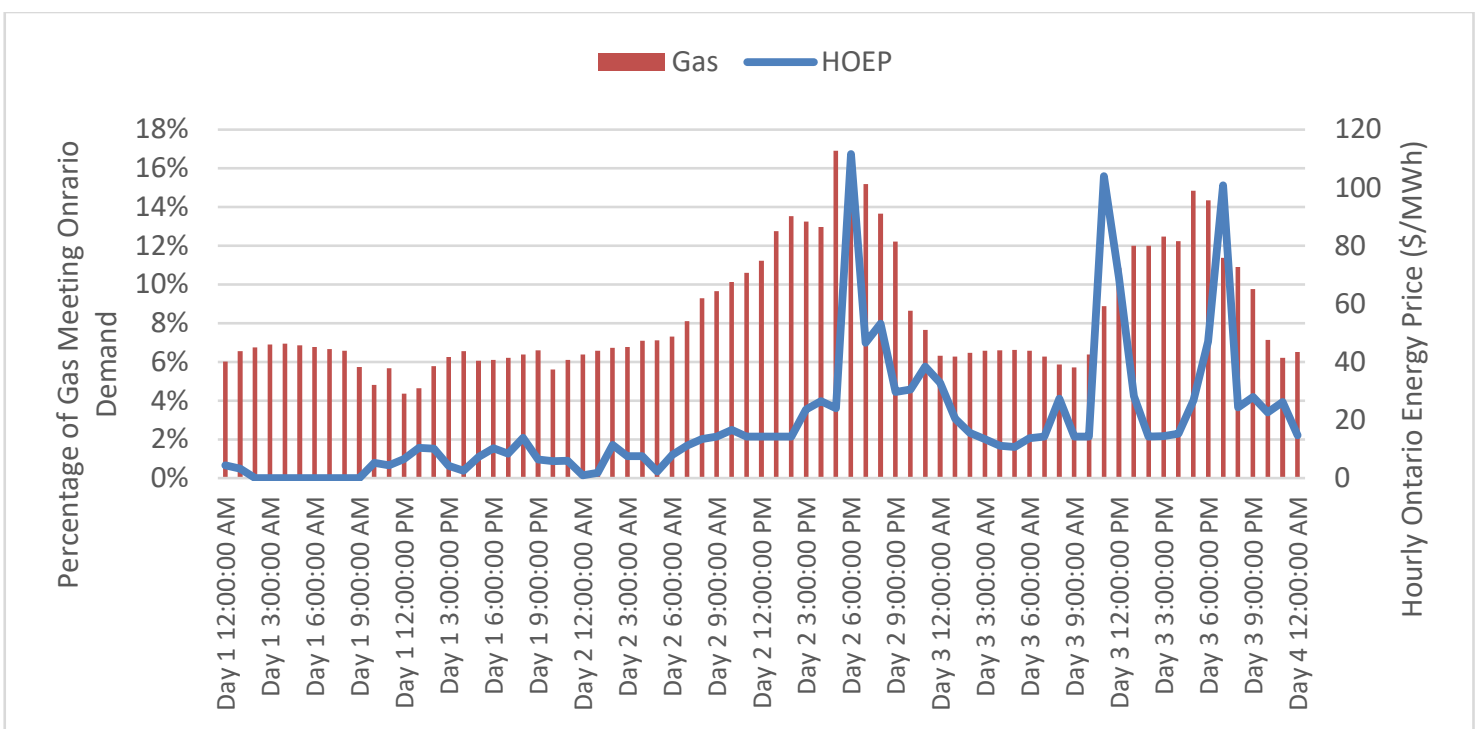

Figure 2.1: IESO Supply Mix and HOEP Price in January 2015

DR is separated in two major categories: price-based programs and event-based programs. Price-based DR programs are a passive tool requiring no direct requests from the utility that rely on changing end user behaviors. This can be seen as Time-of-Use (TOU) rates that vary energy rates by daily periods with fixed predetermined pricing as seen in Figure 2.2, Critical Peak Pricing (CPP) which utilizes pre-specified extreme rates for peak hours, and Real Time Pricing (RTP) changing rates to reflect the wholesale price of electricity on a day-ahead or hour-ahead basis. Alternatively, event-based programs rewards end users for reducing loads when requested. This request can be forecasted as seen in buyback programs where end users bid on load reductions in wholesale markets or the request can be timely as seen in Emergency Demand Response Programs (EDRP) where end users receive payment for load reductions to avoid potential high cost related to unserved high-priority loads. Moreover, event-based programs can be activated without the end user's knowledge through Directly Controllable Loads (DLC) where incentives are paid for the utility to have direct control on end user's loads such as air-conditioning [5]. 
The widespread participation of DR programs in power markets has the potential to generate systemic economic benefit. While they are technically viable for the grid, there economic potential varies greatly dependent on the local utility, onsite devices, and the ratio from peak to base load. DERs utilizing these programs can contribute to reducing average wholesale prices while also adding resiliency to peak pricing [5]. Furthermore, the potential of these programs grows in DERs environments which could allow a system controller more freedom to vary rates at a higher frequency and price range resulting in being one of the strongest revenue opportunities for CES.

\section{Prices effective November 1, 2016}

\section{Off-Peak: 8.7 cents/kWh $\quad$ Mid-Peak: 13.2 cents/kWh $\quad$ On-Peak: 18.0 cents/kWh}

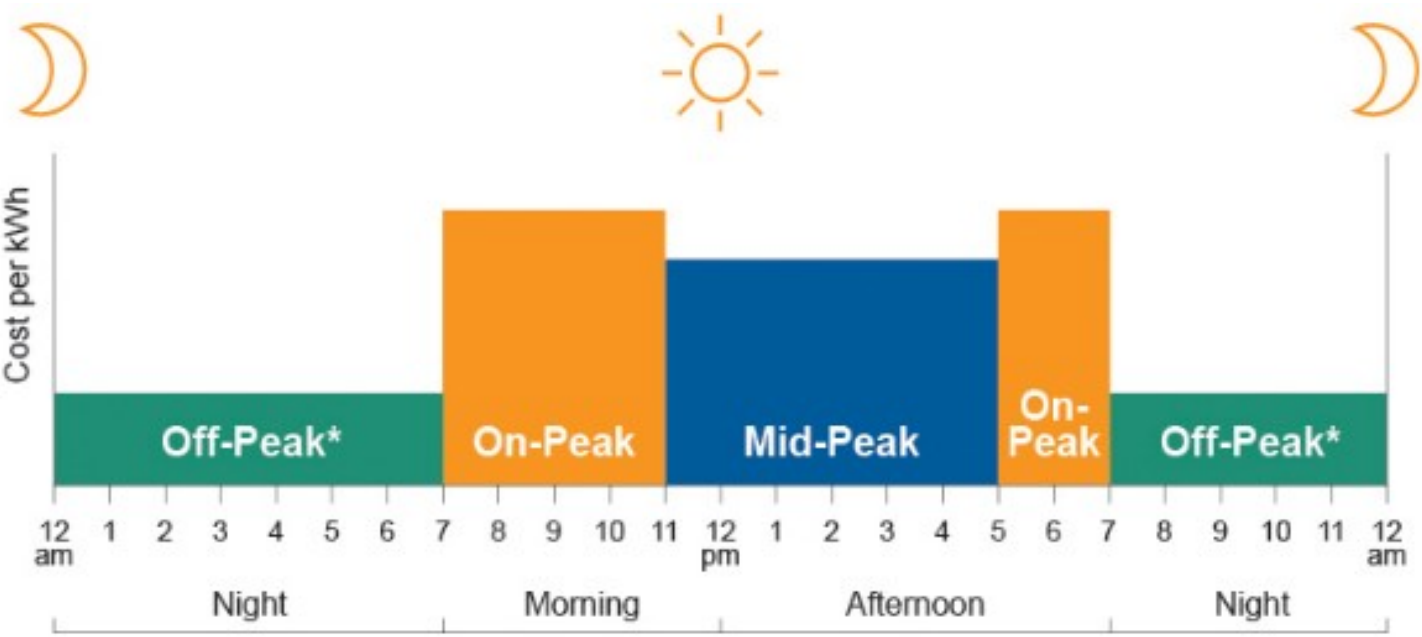

*Including weekends and holidays

Figure 2.2: Hydro Ottawa's Time of Use Rates [13]

\subsection{Combined Heat and Power}

Combined Heat and Power (CHP) plants are DERs defined as the simultaneous production of electrical and thermal energy from a single fuel [14]. In the EU, CHP plants have been recognized as the most efficient fossil-fueled energy source [15]. CHP plants 
work for baseline operation where auxiliary boiler systems are used to supply the peak thermal demand [16]. CHP come in different technologies such as steam turbines, gas turbines, reciprocating engine, combined cycle gas turbine, and newer technologies. These different technologies have different inherent efficiencies as shown in Table 2.1.

Table 2.1: Efficiencies, Heat to Power Ratios of CHPs [14]

\begin{tabular}{|l|l|l|l|}
\hline Cogeneration System & $\begin{array}{l}\text { Electrical Energy } \\
\text { Output (\%) }\end{array}$ & $\begin{array}{l}\text { Overall Efficiency } \\
(\%)\end{array}$ & $\begin{array}{l}\text { Heat to Power } \\
\text { Ratio }\end{array}$ \\
\hline Back-pressure steam turbine & $14-28$ & $84-92$ & $4-22$ \\
\hline Condensing steam turbine & $22-40$ & $60-80$ & $2-10$ \\
\hline Gas turbines & $24-42$ & $70-85$ & $1.3-2$ \\
\hline Reciprocating engine & $33-53$ & $75-85$ & $0.5-2.5$ \\
\hline Combined cycle gas turbine & $34-55$ & $69-83$ & $1-1.7$ \\
\hline Fuel Cells & $40-70$ & $75-85$ & $0.33-1$ \\
\hline Microturbines & $15-33$ & $60-75$ & $1.3-2$ \\
\hline
\end{tabular}

\subsection{Electrical Energy Storage}

Electrical energy storage (EES) is an effective tool to access the value streams especially in the areas of improving grid reliability and utilization. Although EES is widely implemented via pumped hydroelectric storage, where it holds $99 \%$ of worldwide storage capacity on a grid-wide scale, battery energy storage systems (BESS) are seen to be the "holy grail" for utilities and other stakeholders [17]. Their compact size makes them ideal for distributed systems giving a better load shifting opportunity on a minute scale for power ratings from $1 \mathrm{~kW}$ to $10 \mathrm{MW}$ [17]. BESS are often differentiated as electrochemical batteries such as Lead-acid, Li-ion batteries, Na-based batteries, and Redox-Flow Batteries. 
Due to their ability to deliver energy while also providing high specific power and its recent commercialization success by companies such as Panasonic and Tesla, this thesis will concentrate on Li-ion batteries.

\subsection{Electricity Price}

Electrical bills are often separated in three sub-charges; a fixed charge, an energy use section (e.g., kWh) where the customer is charged for energy use based on the time of consumption, and a demand section where the customer is charged by the peak power (e.g., $\mathrm{kW}$ ) seen on your feeder for that month.

Real time pricing (RTP) is unknown far in advance and reflects the real market cost of delivering electricity. A previous RTP pilot of over 1000 households in Illinois averaged to approximately $0.05 \$ / \mathrm{kWh}$ but with spikes of over $0.35 \$ / \mathrm{kWh}$ [4].

In Ontario, the IESO publishes both the current market price and their projected price. The market price is named HOEP for Hourly Ontario Energy Price. HOEP specifies the charge to non-residential electrical users in $\$ / \mathrm{kWh}$ for reaching a peak demand over 50 $\mathrm{kW}$ within a given month in Ontario [13]. HOEP is the average of twelve market clearing prices set every five minutes [18]. Table 2.2 gives average weighted HOEP prices to give a better sense of scale. Furthermore, there is a global adjustment (GA) cost added onto the HOEP price that covers the cost of building new electricity infrastructure, maintaining existing resources, and conservation programs [18]. GA is a flat rate applied to all electricity consumption for a given month and is published ten business days after the end of the given month. However, an end user can use the IESO's GA estimates, for which the first estimate is published on the last business day of the preceding month and the second estimate for a given month is published on the last business day of that month [18]. The 
extra costs generated by GA have often been blamed on renewables in recent years but come mostly from long term nuclear and natural gas plants contracts. For the month of June $2018,37 \%$ of GA costs was attributed to nuclear and natural gas programs. Table 2.3 gives an example of GA prices seen in Ontario. Household owners may not be aware of these charges as the IESO charges local distribution companies (LDC) who then recuperate the cost from their customer base via flat rates or more commonly from charges in TOU pricing.

Table 2.2: HOEP Average Hourly Price $(\boldsymbol{c} / \mathrm{kWh})[19]$

\begin{tabular}{|l|l|l|l|l|l|l|l|l|l|l|l|l|l|}
\hline Year & Average & Jan & Feb & Mar & Apr & May & Jun & Jul & Aug & Sep & Oct & Nov & Dec \\
\hline 2018 & 2.16 & 3.21 & 1.90 & 1.72 & 2.97 & 1.31 & 1.83 & & & & & & \\
\hline 2017 & 1.55 & 2.16 & 2.11 & 2.60 & 1.11 & 0.32 & 0.59 & 1.36 & 1.73 & 2.31 & 0.88 & 1.40 & 2.06 \\
\hline
\end{tabular}

Table 2.3: 2017 Global Adjustment Costs ( $/ \mathbf{k W h})[19]$

\begin{tabular}{|l|l|l|l|l|l|l|l|l|l|l|l|l|}
\hline 2017 & Jan & Feb & Mar & Apr & May & Jun & Jul & Aug & Sep & Oct & Nov & Dec \\
\hline $1^{\text {st }}$ estimate & 6.69 & 10.56 & 8.41 & 6.87 & 10.62 & 11.95 & 10.65 & 11.50 & 12.74 & 10.21 & 11.16 & 8.39 \\
\hline $2^{\text {nd }}$ estimate & 8.68 & 8.43 & 6.89 & 10.22 & 12.78 & 12.56 & 10.20 & 10.48 & 9.90 & 11.97 & 9.67 & 9.67 \\
\hline Actual Rate & 8.23 & 8.64 & 7.14 & 10.78 & 12.31 & 11.85 & 11.28 & 10.11 & 8.86 & 12.56 & 9.70 & 9.21 \\
\hline
\end{tabular}

It should be noted that some customers deemed "Class A" can reduce their GA costs by reducing their demand during Ontario's top five peak hours within a given year [20]. Due to large year-to-year variations and complications in tracking province wide yearly peaks, this thesis will concentrate on "Class B" customers who pay full HOEP and GA prices. 
In power engineering, alternating current from the electrical grid can be separated in real, reactive, and apparent power as seen in Figure 2.3. Real power, also known as active power, is the value in Watts seen on electrical bills. Reactive power expressed in VoltAmpere Reactive is created when current and voltage are not in phase and does not transfer any net energy to the load. Apparent power expressed in Volt-Ampere is the root-meansquare of the current multiplied by the root-mean-square of the voltage. Moreover, the power factor is an angle representing the ratio of real power to apparent power and is used in power generation to signify the quality of the electrical power. A power factor can be deemed lagging where the load is seen as inductive or leading where the load is seen as capacitive. The power factor is important in electrical bills as customers are penalized if it drops under the value of 0.9 for leading or 0.9 for lagging. Due to investments in power factor corrections, all case studies in this thesis will assume to always be in the proper range and therefore not penalized for these instances.

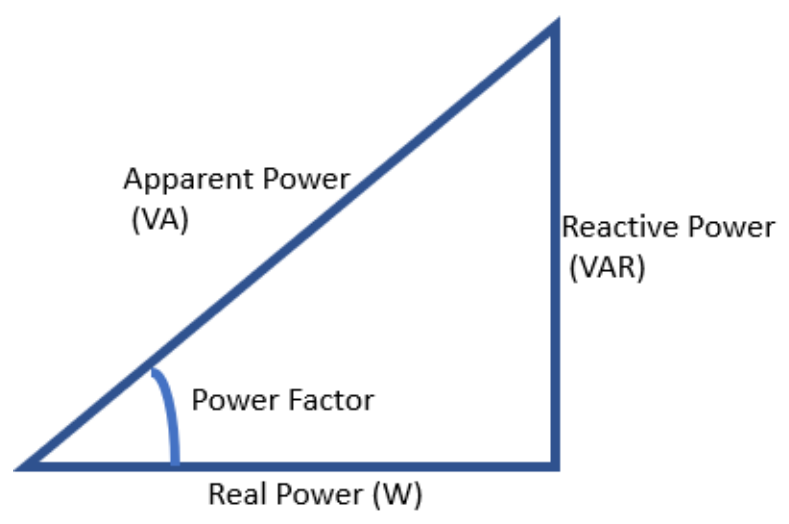

Figure 2.3: Power Triangle

\subsection{Heat Storage}

Thermal energy storage (TES) can be utilized to take advantage of waste heat recovery from industrial processes. TES decouples electrical and heat production from 
CHP systems allowing to meet peak demands in both instances [21, 22]. When electrical prices are high, but heat demand is low, the heat produced by the CHP can be utilized to charge the TES. Tveit and al. notes that during summer periods, heat demand can be so low that the CHP plant must be shut down [22]. A long-term TES may be able to extend CHP operation time.

TES can be separated in sensible heat storage (SHS), latent heat storage (LHS), and thermochemical heat storage (TCHS). SHS stores thermal energy as a function of a materials specific heat, change in temperature, and volume of storage material. Thermal energy is stored by rising a materials temperature with an injected heat [23]. LHS is considered the most promising technique for TES utilizing phase change materials (PCM). Latent heat storage has high energy storage density and constant working temperature but suffers in energy charging rates and limited cycles [24]. TCHS is a reversible physiochemical phenomenon to store thermal energy chemically [23].

Other TES techniques may be employed such as using a preexisting district heating network (DHN) as storage. Basciotti et al. notes that such technique is limited by the DHN capacity, however, has the advantage of no added capital costs [25]. Applying the methodology to a case study from [25], daily heating peaks were reduced by up to $15 \%$ and a fuel cost reduction of $2 \%$.

\subsection{Gas Price}

Gas price can be separated in multiple sections as seen in Table 2.4, however, can be simplified in a form of a fixed charge and volume charge. 
Table 2.4: Enbridge Nature Gas Price Structure [26]

\begin{tabular}{|c|c|c|}
\hline \multicolumn{2}{|l|}{ Monthly Charges } & Monthly Rates: April 1, 2018 \\
\hline \multicolumn{2}{|l|}{ Customer Charge } & $70 \$$ \\
\hline \multicolumn{2}{|c|}{ Gas Supply Charge } & $9.2496 \not / \mathrm{m}^{3}$ \\
\hline \multicolumn{2}{|c|}{ Transportation to Enbridge } & $4.7525 \phi / \mathrm{m}^{3}$ \\
\hline \multirow[t]{6}{*}{ Delivery Charge } & First $500 \mathrm{~m}^{3}$ & $10.35 \phi / \mathrm{m}^{3}$ \\
\hline & Next $1050 \mathrm{~m}^{3}$ & $8.2392 \notin / \mathrm{m}^{3}$ \\
\hline & Next $4500 \mathrm{~m}^{3}$ & $6.7611 \notin / \mathrm{m}^{3}$ \\
\hline & Next $7000 \mathrm{~m}^{3}$ & $5.8114 \phi / \mathrm{m}^{3}$ \\
\hline & Next $15250 \mathrm{~m}^{3}$ & $5.3894 \not / \mathrm{m}^{3}$ \\
\hline & Over $28300 \mathrm{~m}^{3}$ & $5.2834 \phi / \mathrm{m}^{3}$ \\
\hline
\end{tabular}

For historical rates, the Ontario Energy Board's (OEB) commodity price from Table 2.5 will be used to replace Gas Supply Charge and Cost Adjustment from Table 2.4.

Table 2.5: OEB's Historical Price for Natural Gas for Enbridge Gas Distribution [27]

\begin{tabular}{|l|l|l|l|}
\hline Date & Commodity Price $\left(\phi / \mathrm{m}^{3}\right)$ & $\begin{array}{l}\text { Gas Cost Adjustment } \\
\left(\phi / \mathrm{m}^{3}\right)\end{array}$ & Effective Price $\left(\phi / \mathrm{m}^{3}\right)$ \\
\hline Apr 2018 & 9.4452 & -0.2106 & 9.2346 \\
\hline Jan 2018 & 10.0943 & 0.5556 & 10.6499 \\
\hline Oct 2017 & 9.8252 & 0.7328 & 10.5580 \\
\hline Jul 2017 & 12.0636 & 0.3609 & 12.4245 \\
\hline
\end{tabular}

\subsection{Software Review: HOMER}

Energy planners are required to navigate many technologies and systems when designing community energy systems (CES). Deciding on what technologies to use in a 
CES depends on the cost-effectiveness but also efficiency and availability. Although many software tools exist such as Modelica and TRNSYS, the most popular for this application is HOMER. HOMER (Hybrid Optimization of Multiple Electric Renewables), originally developed at the National Renewable Energy Lab (NREL), aims to aid decision makers in navigating multiple technology choices [28]. HOMER includes an equation-based energy model but also an optimization and sensitivity tool that can explore both grid-connected and off-grid technologies. HOMER can determine which components perform best in the system design, what size of equipment should be used and what configurations are favorable. The difficulty of solving such a problem is the sheer number of solutions available. HOMER's optimization and sensitivity analysis algorithms aim to simplify the selection of many possible system configurations by focusing only on those which appear to work best. The scope of this section is limited to a high-level overview of the tool's capabilities and deficiencies, not the optimization or sensitivity analysis functionality.

HOMER performs three main tasks: system simulation, optimization and sensitivity analysis. Not all features will be discussed. In the system design, HOMER models one combination of the district energy system and determines life cycle performance using cost and energy indicators. This is done by comparing, on an hourly basis, the district system generation capacities and district electrical and thermal energy demands, and fuel costs. The technical constraints are imposed depending on the district design requirements, such as the number of operational hours for power generators, load following or constant operation, and whether the district is grid connected or islanded. Based on the economic and technical constraints, HOMER calculates the cost of generation from the different technologies and compares it to the cost of purchasing from the grid on an hourly basis. 
When the district demand is met, the surplus energy generation is sold to the grid on different hourly rates based on the grid needs. In the optimization stage, the software repeats the system simulation for many different system configurations until it determines the configuration that meet the technical constraints with the lowest life-cycle cost. Finally, a sensitivity analysis is performed by repeating optimizations under a range of input variables to determine the effect of changes in the uncontrolled variables such as fuel cost, solar gain and wind speed.

HOMER solves a series of linear equations using a timestep method [29]. Timesteps can be as low as one-minute and up to 60 minutes. HOMER can model many forms of renewables including solar, wind, hydro and biogas. Loads, both thermal and electrical can be deferrable or primary. Deferrable loads can be met any time within a projected time horizon. Primary loads must be met at a specific time and cannot be deferred. Battery storage uses a state-based time-step method. This ensures that physical limitations such as the depth of discharge and charge/discharge characteristics are properly modelled. The further capabilities of the tool are described here: http://homerenergy.com/HOMER-Profeatures.html.

HOMER does have several limitations. With respect to the value streams described earlier, demand response strategies are limited, and local energy markets are not quantified fully within HOMER. Similarly, more complicated control strategies such as model predictive control (MPC) or other advanced approaches are not presently implemented in the tool. Thus, HOMER results may not fully quantify the value of a CES. A recently developed MATLAB extension, which may be executed at every timestep or at the end of a simulation period, is intended to circumvent some of these limitations. However, this new 
addition to HOMER is not well documented and there is a sparsity of exemplar implementations.

Given the provided features, HOMER remains as the most feature rich decisionmaking tool available to CES planners. Although the tool is not feature complete, it serves the purpose of demonstrating and modelling methodology for CES decision making.

This thesis will use many lessons learnt from the use and techniques applied by HOMER but will utilize MATLAB solely with custom scripts. The reason for this decision stems from a lack of control in decision making and the simplification of hourly loads. HOMER is an early design tool and as such lacks in control strategies and decision making when hourly data is available. Furthermore, creating a MATLAB custom script will allow the thesis to analyze control maneuvers of storage devices for cost savings on a more granular scale.

This thesis will present a custom software approach to calculating an electrical grid user's GHG emissions and lowering operational costs of a CES's assets. 


\section{Chapter: GHG Emissions from Electrical Grid Use}

This chapter was published as a conference paper [30]:

(M. St-Jacques, S. Bucking and W. O'Brien, "Quantification of high temporal and spatial scale GHG emissions from electricity generation: method and case study," in eSim 2018, Montréal, 2018.)

\subsection{Overview}

This chapter presents a method to quantify greenhouse gas (GHG) emissions of an electrical grid user via generator data using hourly timesteps. This method allows energy modellers to more accurately calculate GHG emissions on an hourly basis. This is an improvement over current method that calculate on an annual basis which may lead to significantly different emission calculations for buildings with temporal electrical load variations. The proposed methodology is relevant for any mixed electrical grid and is demonstrated using Ontario data. A case study of a university building is utilized to show the difference between annual and hourly emission calculations. Furthermore, this chapter discusses the use of a federal, provincial, and municipal geographic frame of reference when segmenting the electrical grid. The current case study demonstrates an increase in GHG emissions costs of 53\% when comparing annual versus hourly methods at the provincial level.

\subsection{Background}

The Government of Canada is moving forward with carbon pricing [31]. In 2015, Environment and Climate Change Canada reported that 11\% of Canada's greenhouse gas (GHG) emissions came from the electricity sector, the fourth largest source after oil and gas sector, and transportation sector [32]. Historically, the electrical grid's carbon footprint 
has been calculated via an emission factor (EF) converting electricity use (GWh) into tonnes of carbon dioxide emissions equivalent $\left(\mathrm{t}^{\left.\mathrm{CO}_{2 \mathrm{e}}\right)}\right.$. For this chapter, all GHG emissions will be presented in carbon dioxide equivalent $\left(\mathrm{CO}_{2 \mathrm{e}}\right) \cdot \mathrm{CO}_{2 \mathrm{e}}$ is an equivalency measure of the amount of carbon dioxide needed to produce similar greenhouse effects from other sources such as sulfur oxides and nitrogen oxides [31].

The United States Environmental Protection Agency (EPA) defines EFs as representative values that relates the quantity of a pollutant released into the atmosphere with an activity associated with the release of that pollutant [33]. The electrical grid energy mix is the main source of information to dictate EFs. The Independent Electricity System Operator (IESO) reports that approximately $71 \%$ of Ontario electric generation infrastructure has zero GHG emissions sources. Much of generation in Ontario is from nuclear stations and hydro dams [34]. The rest of the electricity generation is mostly from the combustion of fossil fuel which emits carbon dioxide $\left(\mathrm{CO}_{2}\right)$, water $\left(\mathrm{H}_{2} \mathrm{O}\right)$, methane $\left(\mathrm{CH}_{4}\right)$, and nitrous oxide $\left(\mathrm{N}_{2} \mathrm{O}\right)$ [35] with a fraction from renewables such as solar and wind.

EFs have historically been calculated using two methods. Equation 3.1, is the average mass of GHG emissions ( $\mathrm{t} \mathrm{CO}_{2 \mathrm{e}}$ ) from producing one unit of electricity (GWh) [35]. For instance, to calculate the $\mathrm{EF}(\mathrm{t} \mathrm{CO} 2 \mathrm{e} / \mathrm{GWh})$ of a province, the values for emissions from generation (t CO2e/year) and electrical generation are those of within that province (GWh/year).

$$
E F=\frac{G H G \text { emissions from electricity generation }}{\text { Total electricity generation }}
$$

Equation 3.1

Equation 3.1 introduces some error into emission factors by neglecting transmission and distribution losses, neglecting supply differences from one province to another, and 
under-estimates GHG emissions. The overall transmission and distribution losses for Ontario is estimated to be 6\% [35]. The second method to calculate EFs, defined in Equation 3.2, [35] considers GHG emissions from only fossil fuel power plants.

$$
E F=\frac{G H G \text { emissions from fossil fuel plants }}{\text { Total electricity generation from fossil power plants }}
$$

Equation 3.2

Equation 3.2 considers transmission and distribution losses but often overestimates GHG emissions and is used often to inflate numbers for electricity savings. Farhat et al. note that the difference between methods can be substantial with the Ontario value from Equation 3.1 being $199 \mathrm{t} \mathrm{CO}_{2 \mathrm{e}} / \mathrm{GWh}$ and the value from Equation 3.2 being $862 \mathrm{t} \mathrm{CO}_{2 \mathrm{e}} / \mathrm{GWh}$ for the period of 2004-2006 [35].

Environment Canada utilizes a simplified emissions estimation method based on fuel consumption from the electricity generation sector [36]. Fuel-based methods only estimate an annual average, which does not properly represent the energy mix variation seen hourly in Ontario. Table 3.1 shows the EFs published by Environment Canada each year [37].

Table 3.1: Yearly emission factor for Canada and select provinces (t $\mathrm{CO} 2 \mathrm{e} / \mathrm{GWh}$ ) [37]

\begin{tabular}{|l|l|l|l|l|l|l|}
\hline Location & 2010 & 2011 & 2012 & 2013 & 2014 & 2015 \\
\hline Canada & 210 & 180 & 180 & 160 & 150 & 152 \\
\hline Ontario & 140 & 100 & 100 & 80 & 40 & 43 \\
\hline Quebec & 3.0 & 2.6 & 3.3 & 2.5 & 1.6 & 1.8 \\
\hline Manitoba & 2.8 & 3.8 & 3.4 & 3.2 & 3.5 & 4 \\
\hline
\end{tabular}

Equation 3.3 is the currently accepted method of calculating $\mathrm{CO}_{2 \mathrm{e}}$ emissions from grid-purchased electricity where an $\mathrm{EF}$ is applied to the quantity of electricity consumed 
$[38,39,3]$. Equation 3.3 is used to calculate the emissions based on the value of EF that is calculated using Equation 3.1.

The limitations of Environment Canada's method are that it does not consider the timing at which the electricity was consumed. In Ontario, the base load is met largely with nuclear and hydro power whereas the peak loads are mostly met with natural gas-fired powerplants. This translates to peak load times having higher EFs and higher costs. Using $1 \mathrm{kWh}$ of electricity early morning when total market load is lowest is less carbon intensive than using $1 \mathrm{kWh}$ of electricity in the afternoon when demand is higher.

$$
\begin{gathered}
\text { CO2e Emissions }(\mathrm{t} \mathrm{CO2e})= \\
\text { Purchased Electricity }(\mathrm{GWh}) \times \mathrm{EF}\left(\frac{\mathrm{t} \mathrm{CO} 2 \mathrm{e}}{\mathrm{GWh}}\right)
\end{gathered}
$$

Equation 3.3

California's Energy Efficiency for Residential and Non-residential Buildings adopted time-dependent valuation (TDV) to promote the reduction of peak demand [40]. The California Energy Commission states that the concept behind TDV is that energy efficiency measure savings should be valued differently depending on which hours of the year the savings occur, to better reflect the actual costs of energy to consumers, to the utility system, and to society [41]. As of 2017, the Government of Canada does not utilize TDV. The implementation of TDV in California reported EFs on an hourly basis, however, it was implemented on a yearly basis ignoring daily, monthly, and seasonal variations. Most of California is in ASHRAE climate zone 3 (warm), whereas Ontario is in zone 6 (cold) and zone 7 (very cold) which can cause more of a seasonality discrepancy in EFs [42, 43]. Similarly, Zivin et al. developed a methodology which estimated the emissions of electrical demand across the United States and found substantial variations dependant on locations and times of day [44]. Table 3.2 shows the large variance found in the study with some 
sample hour and locations [44]. Figure 3.1 displays the regions defined by the North American Electric Reliability Corporation (NERC) [45].

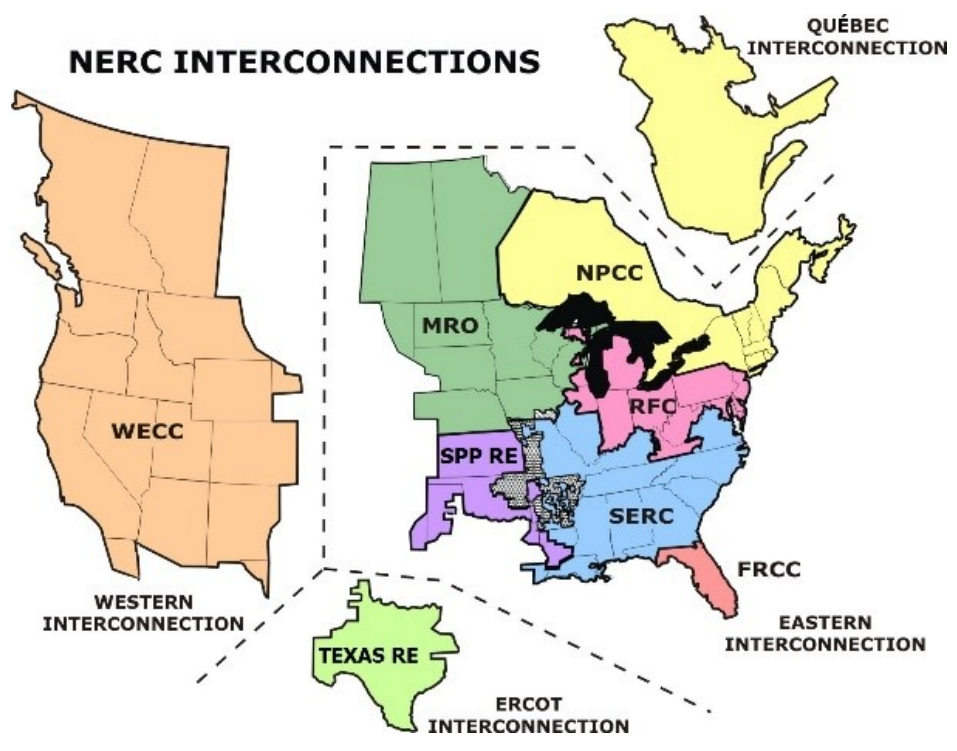

Figure 3.1: NERC interconnections map [45]

Table 3.2: Hourly emission factors for USA (t CO2e/GWh) [44]

\begin{tabular}{|l|l|l|l|l|}
\hline Hour & NPCC & Eastern & Western & USA \\
\hline 12 AM & 530 & 695 & 420 & 640 \\
\hline 4 AM & 730 & 735 & 400 & 680 \\
\hline 8 AM & 620 & 605 & 340 & 585 \\
\hline $12 \mathrm{PM}$ & 760 & 635 & 440 & 600 \\
\hline 4 PM & 700 & 595 & 400 & 555 \\
\hline 8 PM & 555 & 590 & 405 & 545 \\
\hline
\end{tabular}

With a lack of emission data on Ontario's generation stations, Gordon et al. created a method to produce seasonal EFs with TDV to replace the annual method [36]. Their results demonstrated a large difference between EFs throughout the year. They recommended that better accuracy could be reached by creating monthly EFs. The 
Canadian Energy Research Institute use dispatch models with 25 time-slices representing a peak demand period, and a reference day in each season split into six daily demand slices [46]. Moreover, optimal accuracy in emission calculations requires hourly precision as emission intensities of large-scale electrical grids change by the hour [38].

This chapter is intended to demonstrate the limitation of using EFs to calculate an Ontario electricity user's carbon dioxide emission by comparing different methods used in the past and a proposed data-driven method utilizing public data available from the Independent Electricity System Operator (IESO). Previous annual methods may under or over-estimate GHG emissions due to simplifications in daily, monthly, and seasonal variability while also using too large of a frame of reference.

This chapter lays out a methodology that reports an electric grid user's carbon footprint by using hourly generator data to calculate the local energy mix and applying it to the hourly electrical load. Furthermore, this chapter demonstrates the large difference from a federal, provincial and municipal view of the problem. This new approach allows energy modellers to more accurately quantify GHG emissions using simulation results or measured energy use data.

\subsection{Methodology}

The methodology proposed to calculate an electrical user's carbon emissions will be completed with four frames of reference. These frames of reference were chosen to showcase the case study buildings' actual location and another municipal location which has a higher GHG intensive grid.

1. Federal: Canada

2. Provincial: Ontario

3. Municipal: Ottawa 


\section{Municipal: London}

The federal frame of reference will be utilized as a reference case. In this instance, Equation 3.3 will be utilized using the 2015 EF from Table 3.1 to be processed through MATLAB $[37,38]$. To compare the difference utilizing energy production with EFs versus utilizing lifecycle GHG intensity (t CO2e/GWh) with Energy Mix (EM) model and the by-the-hour model,

Equation 3.4 is processed through MATLAB to calculate EM models. The annual energy mix model is implemented on a yearly basis, thus ignoring hourly variances, with $j$ representing the ' $N$ ' generator types (i.e. solar, wind, hydro, etc.).

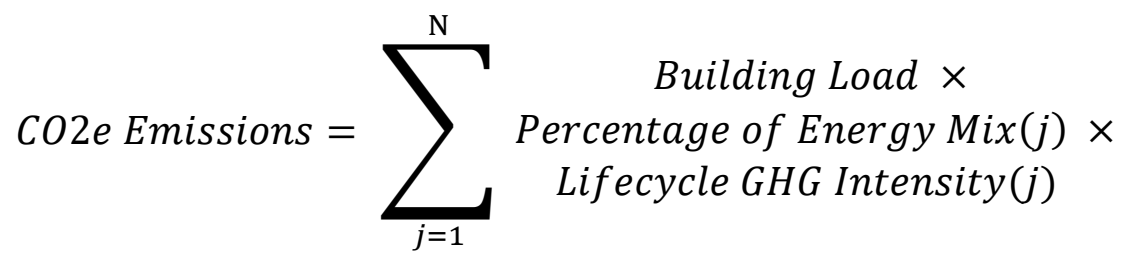

For the provincial models, IESO's generator energy output and capability data was used. This data was utilized to present the energy output of all 159 generating facilities with a minimum output capability of $20 \mathrm{MW}$ or more in Ontario. The generators were separated into the following categories; solar, wind, biofuel, natural gas, hydro, nuclear, and coal.

For the municipal models, IESO's Zonal Map data was used, which segments Ontario into 10 local regions: Bruce, East, Essa, Niagara, Northeast, Northwest, Ottawa, Southwest, Toronto, and West. Figure 3.2 shows the physical boundaries of these sections. Table 3.3 gives general information on these regions out of province connections and resources from the IESO. There are five additional sections created to simulate the import and export of electricity from Ontario to surrounding regions: Manitoba, Michigan, Minnesota, New York, and Québec. 
Table 3.3: General information of Ontario's electrical zones

\begin{tabular}{|l|l|l|}
\hline Zone & Import/Export Connections & Ratio of Peak Supply to Peak Demand \\
\hline Bruce & $\mathrm{n} / \mathrm{a}$ & Much higher than peak demand \\
\hline East & Québec and New York & Exceed peak demand \\
\hline Essa & $\mathrm{n} / \mathrm{a}$ & Much less than peak demand \\
\hline Niagara & New York & Much higher than peak demand \\
\hline Northeast & Québec & Exceeds peak demand \\
\hline Northwest & Manitoba and Minnesota & Generally, exceeds peak demand \\
\hline Ottawa & Québec & Much less than peak demand \\
\hline Southwest & n/a & Generally, balanced with peak demand \\
\hline Toronto & n/a & Less than peak demand \\
\hline West & Michigan & Generally, exceeds peak demand \\
\hline
\end{tabular}

Using the data provided and the map shown in Figure 3.2, a model was created separating each region into nodes with a sink representing the areas demand and multiple sources representing the various generators in the area [47]. Several assumptions were made to reconcile energy accounting. First, each node answers its demand if possible with the generators within their area. Second, any excess or deficit energy from a node is then transformed into their export or needed import. Once electricity is generated, there is no access to data on its exact path and ultimately which load it serves. 


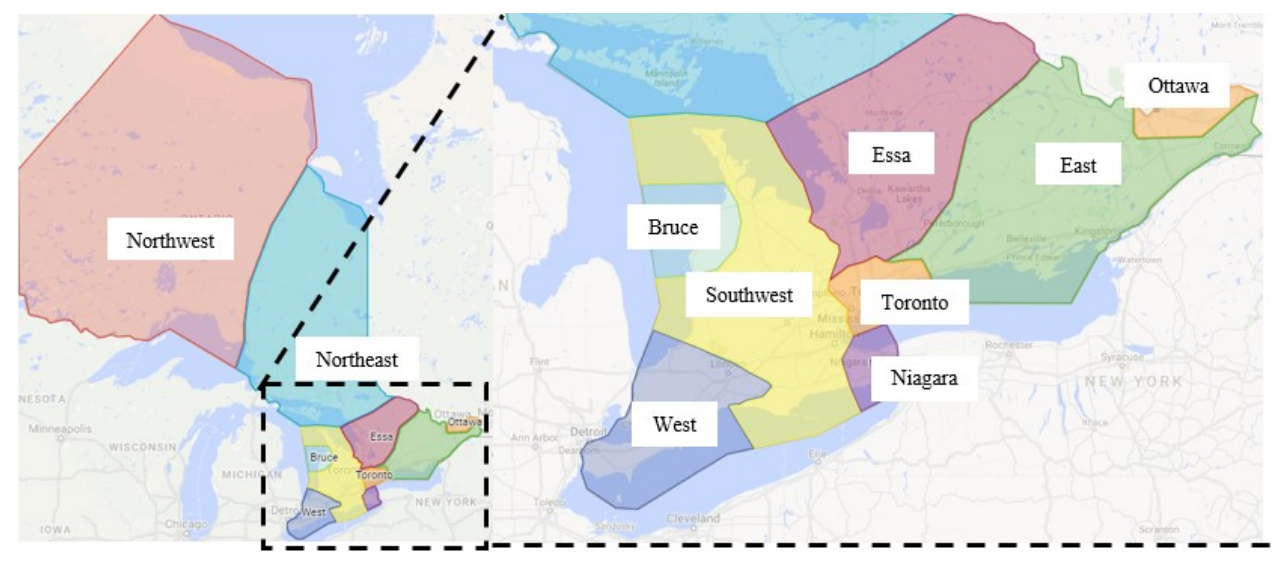

Figure 3.2: Physical boundaries of Ontario's electrical zones

Thus, thirdly, due to the uncertainty of which generator serves which load, a modelling assumption was made where the local load is met in the following order of technologies:

1. Solar

2. Wind

3. Biofuel

4. Natural Gas

5. Hydro

6. Nuclear

7. Coal

The order that the load is met uses renewables first due to their intermittent nature and to reward jurisdictions that have invested in these technologies, whereas, hydro and nuclear generators are utilized towards the end of the list as they typically meet Ontario's base load. This is a reasonable assumption because the grid does not have built-in storage and generators can be throttled. Furthermore, coal is used last as it is only seen in minimal amounts from imports. The implications of this order are discussed in the Results section of the case study.

Due to discrepancies in sources and sinks due to system losses and embedded generation, an additional node was added to balance the system making 16 nodes total. The balance node was added as a bidirectional connection with the Bruce node to isolate it from the whole system as Bruce does not import and only exports to the Southwest node. 
Furthermore, the balance node is assumed to only import or export nuclear energy to simplify the model. The balance node represents on average $1 \%$ of the Ontario demand. The final directional nodal model can be seen in Figure 3.3 where the blue nodes represent the local zones of Ontario whereas the white nodes represent the out-of-province zones; finally, the grey node represents the balance node.

The by-the-hour model creates an energy mix percentage from the generator output and capability data from the IESO. For imports, Table 3.4 and Table 3.5 provide the energy mix for neighbouring Canadian Provinces and U.S. States [48, 34, 49]. Table 3.4 is also used for the EM models at the federal and provincial frame of reference.

For each $\mathrm{kWh}$ of electricity produced from a certain technology, a lifecycle GHG EF will be applied. The lifecycle GHG EF used for all nodes comes from a study in Ontario by Mallia et al. and shown in Table 3.6 [50].

A linear program solver calculates the energy trading between nodes. MATLAB is used for its linear program and spare matrix solving abilities. MATLAB's built-in function of linprog solves Equation 3.5 with a dual-simplex algorithm explained in Appendix A where $f, x, b, b e q$ are vectors, and $A$ and $A e q$ are matrices [51].

$$
\min f^{T} x: A * x \leq b, A e q * x=b e q
$$

Equation 3.5 


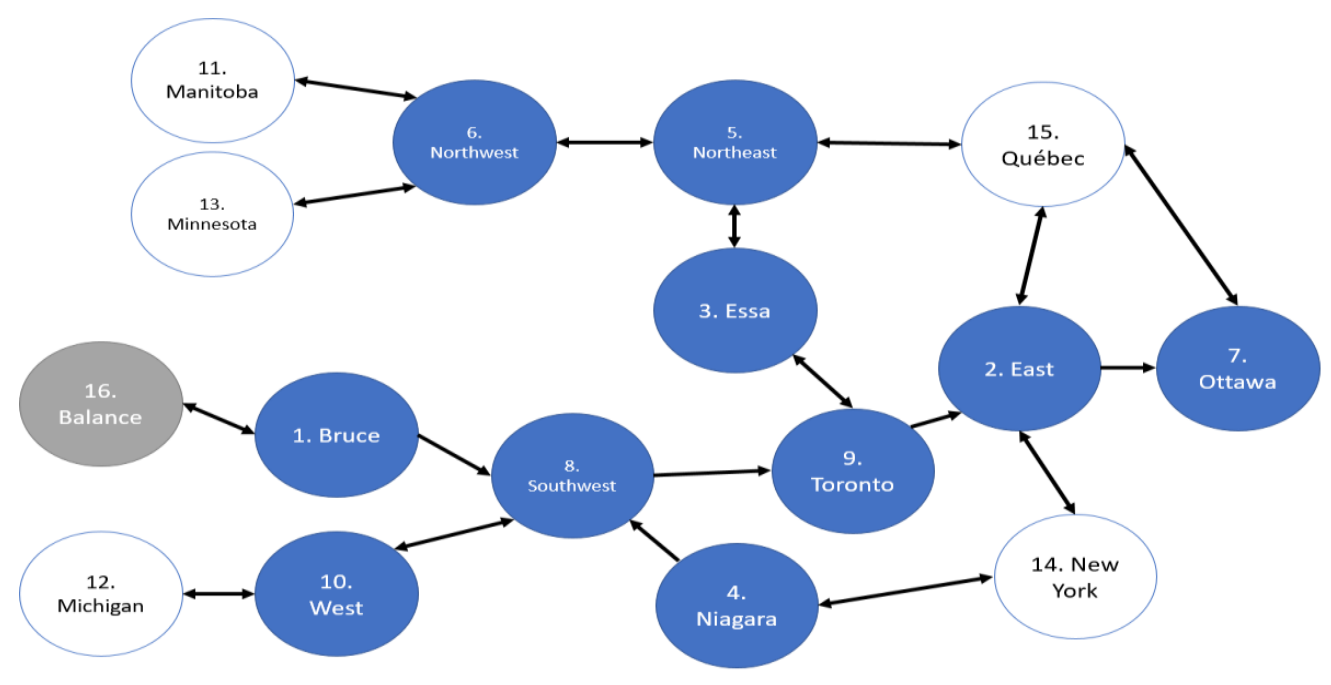

Figure 3.3: Nodal system of Ontario's grid

Table 3.4: Energy mix of Canadian provinces in 2014

\begin{tabular}{|l|l|l|l|l|l|}
\hline Location & Natural Gas & Coal & Nuclear & Hydro & Non-hydro Renewables \\
\hline Canada & $10.2 \%$ & $9.5 \%$ & $15.9 \%$ & $59.3 \%$ & $5.1 \%$ \\
\hline Ontario & $10 \%$ & $\mathrm{n} / \mathrm{a}$ & $60 \%$ & $24 \%$ & $6 \%$ \\
\hline Quebec & $\mathrm{n} / \mathrm{a}$ & $\mathrm{n} / \mathrm{a}$ & $\mathrm{n} / \mathrm{a}$ & $97 \%$ & $3 \%$ \\
\hline Manitoba & $\mathrm{n} / \mathrm{a}$ & $\mathrm{n} / \mathrm{a}$ & $\mathrm{n} / \mathrm{a}$ & $98 \%$ & $2 \%$ \\
\hline
\end{tabular}

Table 3.5: Energy mix of U.S. states in 2017

\begin{tabular}{|l|l|l|l|l|l|}
\hline Location & Natural Gas & Coal & Nuclear & Hydro & Non-hydro Renewables \\
\hline Michigan & $21 \%$ & $42 \%$ & $28 \%$ & $2 \%$ & $7 \%$ \\
\hline Minnesota & $12 \%$ & $38 \%$ & $22 \%$ & $2 \%$ & $26 \%$ \\
\hline New York & $36 \%$ & $1 \%$ & $33 \%$ & $25 \%$ & $5 \%$ \\
\hline
\end{tabular}

Table 3.6: Ontario electricity generator's life cycle GHG emissions in 2008

\begin{tabular}{|l|l|}
\hline Type of Generation & Lifecycle GHG Intensity $\left(\mathrm{t} \mathrm{CO}_{2 \mathrm{e}} / \mathrm{GWh}\right)$ \\
\hline Coal & 1,069 \\
\hline Natural Gas & 497 \\
\hline Hydro & 22 \\
\hline Wind & 11 \\
\hline Nuclear & 5 \\
\hline
\end{tabular}


For simplification, two different linear programs were solved to estimate the amount of energy from each technology that is being transferred between nodes. The first linear program is a simplification in the model where we want to know how much energy is being moved from one node to another and drop the knowledge from what source it is coming from. Except for four node interconnections, all other interconnections are bidirectional giving us a total of 32 connections where energy can be transferred between nodes. Therefore, $f$ is a $1 \times 32$ vector of ones, $b$ is a $32 \times 1$ vector of zeros, and $A$ is a negative identity matrix of $32 \times 32$ to put the restrictions of no negative flows. Equation 3.6 is the balance node notation to create the equality constraints for Equation 3.7. For Aeq a 16x32 matrix, each node is balanced using the connections as shown in Figure 3.3 where a "1" represents outbound from the node and "-1" represents incoming into the node.

Once solved, the second linear program, considering the seven sources of energy, are specified using the $x$ vector of the previous linear program, Equation 3.8 through Equation 3.10. Similarly, to the previous problem, $f$ is a $1 \times 329$ vector of ones, $b$ is a $329 \times 1$ vector of zeros, and $A$ is a negative $329 \times 329$ identity matrix to put the restrictions of no negative flows. The Aeq in this case is a $152 \times 329$ matrix where each node is balanced using the connections as shown in Figure 3.3 split into seven lines to represent each technology source. Therefore, Equation 3.11 demonstrates the equality constraint of the linear program. Once the linear program is solved for all timesteps, Equation 3.12 is used to calculate the total GHG emissions of the by-the-hour energy mix model where $i$ represents the hourly timestep and $j$ represents the generator type (e.g., solar, wind, hydro, etc.). 
Node Generation - Node Demand $=$

$$
\text { EExport Connections - SImport Connections }
$$

Equation 3.6

$$
\begin{gathered}
\text { Aeq } * x=\text { beq } \rightarrow \\
{\left[\begin{array}{ccccc}
1 & 1 & \cdots & 0 & -1 \\
0 & 0 & \cdots & 0 & 0 \\
\vdots & \vdots & \ddots & \vdots & \vdots \\
0 & 0 & \cdots & 1 & 0 \\
0 & -1 & \cdots & 0 & 1
\end{array}\right] *\left[\begin{array}{c}
x_{1-8} \\
x_{1-16} \\
\vdots \\
x_{15-7} \\
x_{16-1}
\end{array}\right]=\left[\begin{array}{c}
\text { Bruce Generation }- \text { Bruce Demand } \\
\text { East Generation }- \text { East Demand } \\
\vdots \\
\text { Quebec Export }- \text { Quebec Import } \\
\sum_{\text {Node }=1}^{15} \text { beq }(1, \text { Node }) *-1
\end{array}\right]} \\
x_{a-b}=\text { Solar }_{a-b}+\text { Wind }_{a-b}+\text { Biofuel }_{a-b}+\text { Natural Gas }_{a-b}+\text { Hydro }_{a-b} \\
+ \text { Nuclear }_{a-b}+\text { Coal }_{a-b}
\end{gathered}
$$$$
\text { Node Technology } j \text { Export }=
$$$$
\text { Node Technology j Import }+\sum \text { Export Technology j Connections }
$$

Equation 3.9

- SImport Technology j Connections

$$
\begin{aligned}
& \text { Node Import }=\sum_{j=1}^{7} \text { Node Technology } j \text { Import } \\
& \text { Aeq } * x=b e q \rightarrow \\
& {\left[\begin{array}{ccccc}
0 & 0 & \cdots & 0 & 0 \\
0 & 0 & \cdots & 0 & 0 \\
\vdots & \vdots & \ddots & \vdots & \vdots \\
0 & 0 & \cdots & 0 & 0 \\
0 & 0 & \cdots & 0 & 0
\end{array}\right] *\left[\begin{array}{c}
\text { Bruce Solar Import } \\
\text { Bruce Wind Import } \\
\vdots \\
\text { Québec Nuclear Import } \\
\text { Québec Coal Import } \\
\text { Solar }_{1-8} \\
\text { Wind }_{1-8} \\
\vdots \\
\text { Nuclear }_{16-1} \\
\text { Coall }_{16-1} \\
\end{array}\right]=\left[\begin{array}{c}
x_{1-8} \\
x_{1-16} \\
\vdots \\
x_{15-7} \\
x_{16-1} \\
\text { Bruce Solar Export } \\
\text { Bruce Wind Export } \\
\vdots \\
\text { Québec Nuclear Export } \\
\text { Québec Coal Export } \\
\text { Bruce Import } \\
\text { East Import } \\
\vdots \\
\text { New York Import } \\
\text { Québec Import }
\end{array}\right]}
\end{aligned}
$$

Equation 3.11 
CO2e Emissions $\left.=\sum_{i=1}^{8760} \sum_{j=1}^{7} \begin{array}{c}\text { Load }(i) \times \\ \text { Percentage of Energy Mix }(i)(j) \times \\ \text { Lifecycle GHG Intensity }(j)\end{array}\right) \quad$ Equation 3.12

Electrical load data of Richcraft Hall (formerly River Building) from the Carleton University's campus was used to demonstrate the proposed methodology [52]. Similarly, building performance simulation could be used. This building was chosen due to its large energy swings as seen in its yearly load profile (Figure 3.4) with an August peak hourly demand of 1,012 kWh and average hourly demand of $310 \mathrm{kWh}$. Figure 3.5 shows the average daily load profile of Richcraft Hall which will help demonstrate how daily variances can cause differences between a flat yearly EF and the by-the-hour model [53]. Figure 3.6 shows seasonal variance in the building which follows Ontario's summer peak.

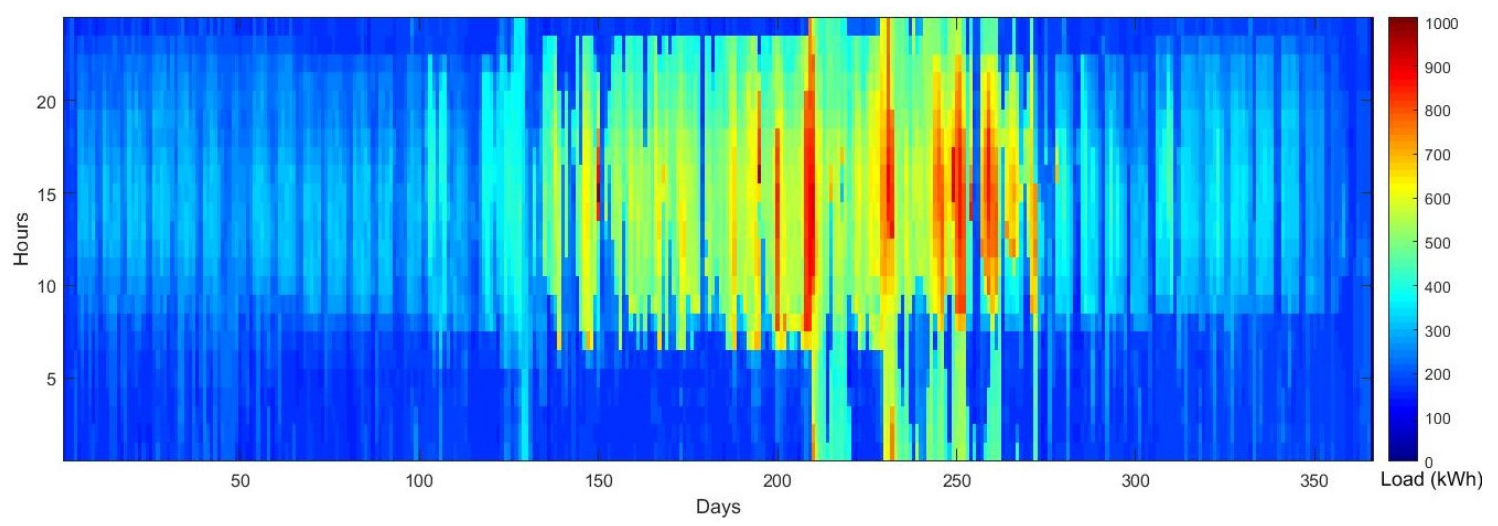

Figure 3.4: Richcraft Hall yearly load profile heat map

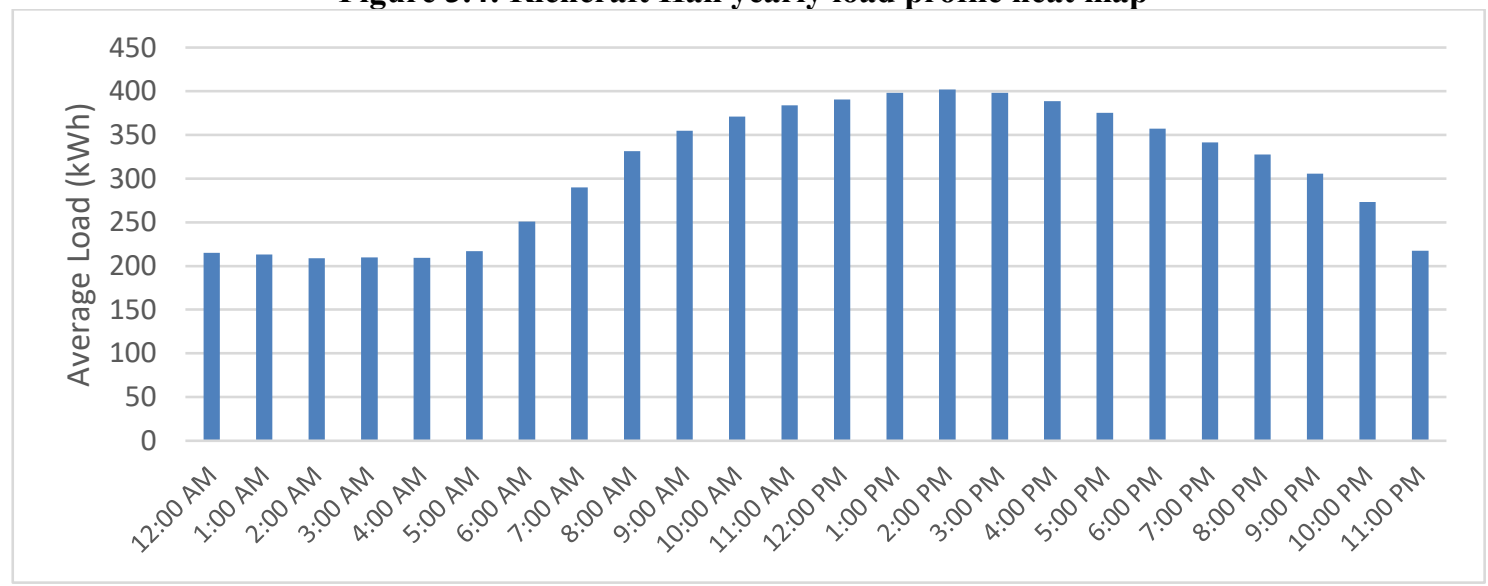

Figure 3.5: Average annual daily profile of Richcraft Hall 


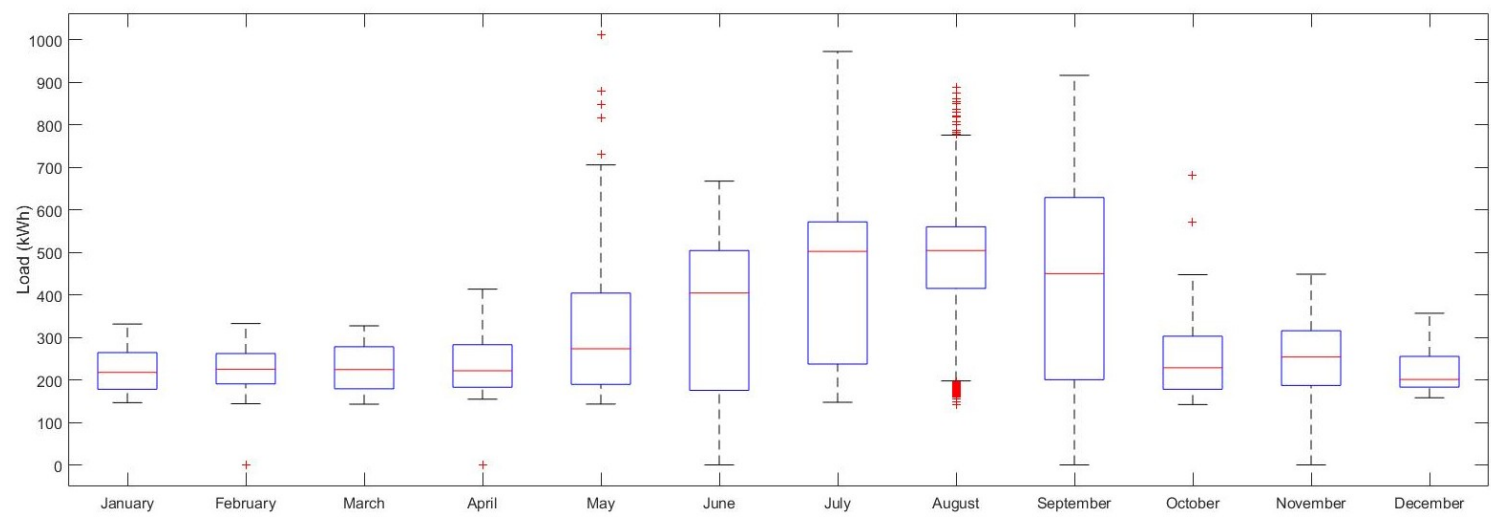

Figure 3.6: Average monthly profile of Richcraft Hall

The electrical load used in this chapter comes from a submeter of a real-world building, however, any hourly electrical load data from a building simulation could be used.

\subsection{Results and Discussion}

Figure 3.7 demonstrates the results of the amount of $\mathrm{CO}_{2 \mathrm{e}}$ emitted by the Richcraft Building's electrical load using EF (Equation 3.3), EM (Equation 3.4) and by-the-hour model (Equation 3.12) in our four frames of reference of Canada, Ontario, Ottawa, and London.

We reduce the case study to economic factors to give a sense of scale to the issue for ease of comprehension. To relate this to monetary values, we assume the Government of Canada imposes the 2022 proposed carbon pricing of $\$ 50 / t \mathrm{CO}_{2 \mathrm{e}}$ [31]. IESO's average electrical pricing data for 2015 from Table 3.7 was used to calculate the potential yearly bill seen for these buildings loads [54]. It is approximated that Richcraft Hall had a yearly electrical bill of $\$ 284,000$ in 2015 . Table 3.8 shows the economic results of the simulation. 
Table 3.7: Ontario average electricity price in $\mathbf{2 0 1 5}$

\begin{tabular}{|l|l|}
\hline & Average Price in 2015 (cents/kWh) \\
\hline Hourly Ontario Energy Price (HOEP) & 2.36 \\
\hline Global Adjustment (GA) & 8.11 \\
\hline Total Price & 10.47 \\
\hline
\end{tabular}

As shown in Table 3.8, the EF method estimates a much lower carbon cost than the EM and by-the-hour method. Furthermore, the two-municipal frame of reference shows that there is a large difference dependant on the location of the load. Looking at the Ontario model, there is an increase of 53\% in costs when comparing a flat EF model to the proposed by-the-hour model.

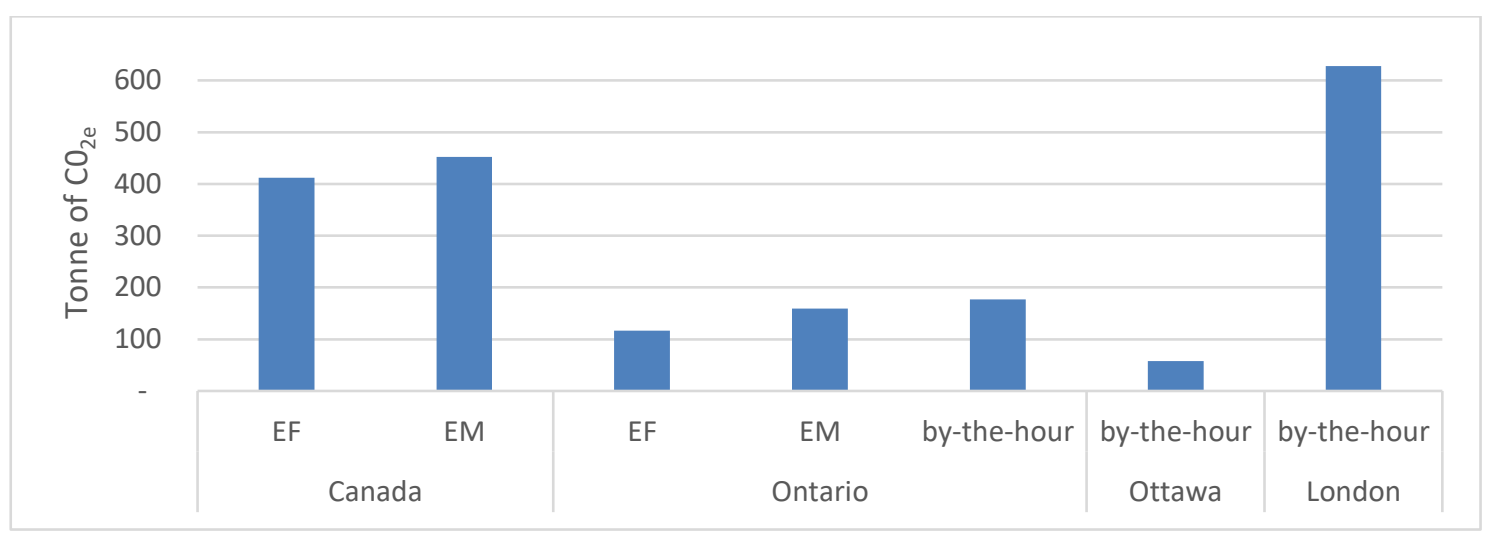

Figure 3.7: Bar graph of simulation results

Table 3.8: GHG costs depending on model

\begin{tabular}{|l|l|l|l|}
\hline Frame of Reference & Carbon Model & Approximate Carbon Cost & $\%$ Increase on Electricity Cost \\
\hline Canada & EF & $\$ 20,600$ & $7.25 \%$ \\
\cline { 2 - 4 } & EM & $\$ 22,600$ & $7.96 \%$ \\
\hline \multirow{3}{*}{ Ontario } & EF & $\$ 5,800$ & $2.04 \%$ \\
\cline { 2 - 4 } & EM & $\$ 8,000$ & $2.82 \%$ \\
\cline { 2 - 4 } & By-the-hour & $\$ 8,900$ & $3.13 \%$ \\
\hline Ottawa & By-the-hour & $\$ 2,900$ & $1.02 \%$ \\
\hline London & By-the-hour & $\$ 31,400$ & $11.06 \%$ \\
\hline
\end{tabular}


The major assumption in modeling the municipal frame of references is the order of technologies in which the local load is met. To verify the sensitivity of these models, the methodology was applied to all 720 possible orders. As shown in Table 3.9, the model set in Ontario is the least sensitive followed by the model set in London, leaving the model set in Ottawa as the most sensitive. The model applied to the London location is unique as it results in only two different values throughout all 720 iterations. The model set in Ottawa is most sensitive due to its nature as a net importer therefore its load is met from exports of other nodes. Note that the model set in Ottawa may be the most sensitive, however, its maximum value equals the broader model set in Ontario whereas the model set in London always reaches higher GHG emissions than the model set in Ontario. The by-the-hour carbon model only works with hourly and sub hourly results.

Table 3.9: GHG sensitivity based on model assumptions

\begin{tabular}{|l|l|l|l|}
\hline Tonne of CO2e & Ontario & Ottawa & London \\
\hline Max Value & 183 & 183 & 695 \\
\hline Min Value & 164 & 57 & 628 \\
\hline Median & 174 & 112 & 662 \\
\hline
\end{tabular}

\subsection{Conclusion}

The methodology to derive more accurate and higher resolution estimates of GHG emissions associated with electricity use is useful for government, utilities, building owners, and researchers to quantify the real carbon content of electricity use. This methodology will be used in the rest of the thesis to quantify GHG savings using devices such as electrical and thermal storage. The by-the-hour methodology would be relevant to any region with mixed electrical generation as seen in the province of Ontario and irrelevant in homogeneous generation areas such as the province of Québec. The case study 
found that in an Ontario frame of reference, Environment Canada's EF method underestimated the carbon cost of a building by $\$ 3,100$ compared to the by-the-hour method proposed in this chapter. Furthermore, it was found that the sub regions of Ontario can create a large discrepancy in carbon cost showing that if the building was in London, Ontario it would have a carbon cost of $\$ 31,400$ whereas the same building in Ottawa would have a carbon cost of $\$ 2,900$. Using this methodology, real opportunity for district energy systems to utilize energy storage arises to lower demand during system wide peaks. This chapter presents that location and timing of an electrical load is important in calculating the end user's emissions. It should be noted that because Ottawa has the lowest emissions of the municipal regions, this does not mean that we should ignore efficiency measures in this zone as it affects the province. Decarbonization of electricity generation and reducing building peak energy demand are both needed to lower overall GHG. It is unclear whether hourly data offer the best results and the content of this chapter should be utilized as a reference for comparing the various carbon models. This approach can be translated into policy at the provincial and municipal levels of government. Future work to refine the model may involve applying generator-specific GHG intensity, consideration of generator available capacity, consideration of electrical pricing, consideration of grid losses, consideration of grid line capacity, and consideration of heating loads. 


\section{Chapter: Electrical Bill Minimization via Battery Energy Storage}

\section{Systems}

\subsection{Overview}

This chapter presents a linear programming methodology to minimize an electrical grid end user's monthly electrical bill using electrical storage and demonstrates it with a case study of an eight-building cluster.

\subsection{Background}

To lower electrical bills, simply using less energy by implementation of energy efficiency measures may not be the most beneficial $[55,56]$. Furthermore, avoiding peak pricing is a net benefit for both consumer and the grid, as peak pricing is linked to peak market demands which in turn signal that peaking plants must be activated.

This chapter presents a methodology of creating a model allowing an end user to lower their electrical bill via publicly available data in an automated process. MohsenianRad et al. points out that both users and building automation systems lack effectiveness to fully benefit from RTP [55].

Previous studies have often concentrated on lowering the costs of one of the electrical bill sections with battery energy storage systems (BESS) via either peak shaving or load shifting applications exclusively $[6,55,56,57,58,59,60,61,62]$.

Mishra et al. explored the lowering of electric bills without consumer involvement by storing low cost energy for high cost periods using a charging system they call "SmartCharge" [6]. This previous study used linear regression (LR) and support vector machines (SVMs) using historic household load data and weather data to predict next-day electrical loads. This predicted load was then fed into a linear optimization method with 
day-ahead market pricing to minimize the household's electrical bill with a battery chargedischarge schedule. Due to the nature of the problem, this study concentrated on load shifting applications exclusively. Mishra et al. developed a methodology which showed a $10-15 \%$ reduction in electric bill and $20 \%$ grid peak demand reduction when widely deployed across the electric grid [6].

Mohsenian-Rad et al. utilized linear programming to create a trade-off between minimizing electricity payment and minimizing wait time for appliance operation in households [55]. The study utilized DR to create a residential energy consumption scheduling framework having RTP with an added inclining block rate pricing where marginal price increased by the total energy quantity consumed. Mohsenian-Rad et al.'s DR methodology was successful in peak shaving applications by reducing peak to average load ratio by $22 \%$ [55]. Cui et al. aimed to close the gap between profit maximization for utility companies and cost minimization for customers by maximizing economic social welfare in a day-ahead market [56]. Using DR techniques like Mohsenian-Rad et al., Cui et al. household's electrical cost has been reduced by $13.3 \%$ on average $[55,56]$.

Oudalov et al. proposed a BESS sizing and operation strategy for peak shaving applications [57]. This study utilized a dynamic programming algorithm which maximized net benefit defined as the potential savings minus the cost of BESS. Oudalov et al. reaches an $8 \%$ reduction in the demand portion of the electrical bill with prior knowledge of customer load and a static reference peak demand value that cannot be passed [57].

Carpenter et al. studied the impact of different TOU pricing schemes for Ontario households utilizing BESS [61]. The study utilized game theory to envision a daily competitive Ontario household storage profile market where each agent optimized for 
electrical bill minimization. Furthermore, the study predicted an Ontario aggregate load via a feed forward neural network utilizing date, time, and outside temperature. Carpenter et al. concluded that as of date of publishing (2012), storage was not profitable under Ontario's current household pricing scheme and could cause an increase in province peak load with high storage penetration [61].

This chapter proposes a methodology to minimize an Ontario industrial/campus realworld monthly electrical bill with use of a BESS. This is accomplished using a linear programming technique and historic hourly timestamped data. This chapter separates itself from previous work by using current established electrical rates and using both load shifting and peak shaving techniques. The proposed methodology will load shift taking advantage of RTP and peak shave with no prescribed maximum value.

\subsection{Methodology}

The proposed methodology is relevant for any electric market where users pay RTP and is demonstrated using Ontario, Canada data as a case study. A case study of an eightbuilding cluster on a university campus will showcase the potential savings from utilizing this methodology. The decision to utilize eight buildings instead of a single building was made to analyze any differences in the solution if looking at individual buildings versus a cluster of buildings.

The proposed methodology approaches a grid-battery-load system as a MATLABbased linear program using dual-simplex algorithm explained in Appendix A minimizing for the lowest possible monthly electrical bill by taking advantage of hourly RTP of electricity with load shifting and managing the BESS for peak shaving opportunities. The linear program is applied to historic hourly data of the electrical demand and RTP to create 
a simulated charge/discharge model of the BESS.

The Grid-Battery-Load system demonstrated in Figure 4.1 is transformed into a linear program via the equations and constraints shown in Table 4.1. Nomenclature for this linear program can be found in Table 4.2 as it is only used in this chapter. The equality constraints displayed in Table 4.1 create energy balances in which the optimization must adhere to such as the energy in storage at the end of timestep i must be equal to the amount of energy in storage at the beginning of the following hourly timestep. Comparatively, the inequality constraints limits energy transfers dependent on equipment limitations such as the storage maximum allowed discharge rate.

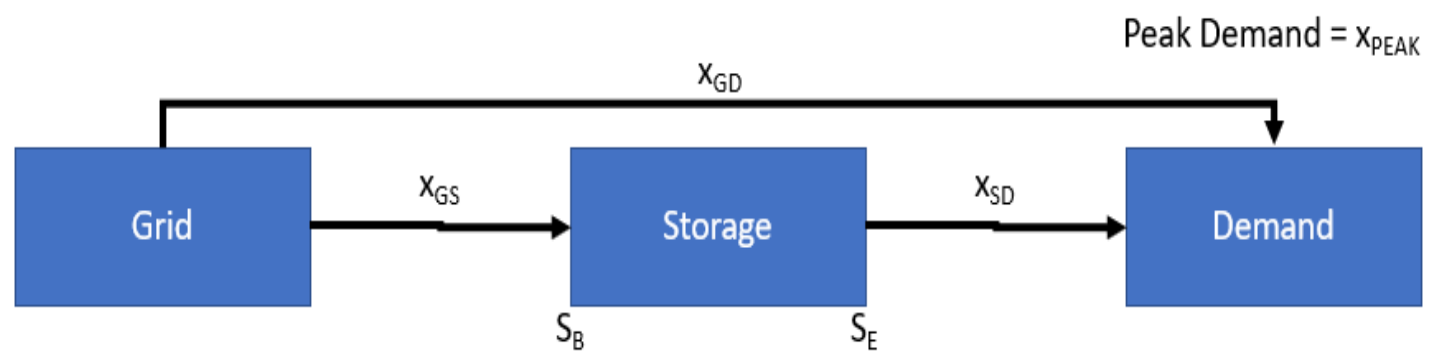

Figure 4.1: BESS Model

Table 4.1: BESS Model Linear Program Constraints

\begin{tabular}{|l|c|}
\hline & Equation \\
\hline Demand Restriction & $x_{G D i}+x_{S D i}=$ Demand $_{i}$ \\
\hline Storage Continuity & $S_{B(i+1)}+S_{E i}=0$ \\
\hline Storage Balance & Battery Efficiency $* x_{G S i}+S_{B i}-x_{S D i}-S_{E i}=0$ \\
\hline Storage Priming & $S_{B 1}=0 \& S_{E n}=0$ \\
\hline Peak Demand Constraint & $x_{G D i}+x_{G S i}-x_{P E A K} \leq 0$ \\
\hline Storage Size Constraint & $S_{E i} \leq$ Storage Size \& $S_{B i} \leq$ Storage Size \\
\hline Charging Constraint & $x_{G S i} \leq$ Charge Rate \& $x_{S D i} \leq$ Discharge Rate \\
\hline
\end{tabular}




\begin{tabular}{|l|r|}
\hline Minimization & $\begin{array}{r}\text { Price of Electricity } *\left(x_{G D i}+x_{G S i}\right) \\
+ \text { Price of Demand } * x_{P E A K}\end{array}$ \\
\hline
\end{tabular}

Table 4.2: BESS Model Linear Program Nomenclature

\begin{tabular}{|c|l|}
\hline Symbols & Full Name \\
\hline$x_{G D i}$ & Energy from Grid satisfying Electrical Demand at timestep $i$ \\
\hline$x_{S D i}$ & Energy from BESS satisfying Electrical Demand at timestep $i$ \\
\hline$x_{G S i}$ & Energy from Grid charging BESS at timestep $i$ \\
\hline$x_{P E A K}$ & Peak Demand of all timesteps $i$ \\
\hline$S_{B i}$ & Energy in BESS at beginning of timestep $i$ \\
\hline$S_{E i}$ & Energy in BESS at end of timestep $i$ \\
\hline
\end{tabular}

The linear program is set to minimize the monthly electrical bill of a given demand.

To demonstrate the linear program, the historic load profile of eight buildings from Carleton University from 2015 was used. The eight buildings were the Canal Building, Minto Centre, Mackenzie Building, Paterson Hall, Richcraft Hall, Southam Hall, Steacie Building, and University Centre. The load profile in 2015 of this building cluster can be seen in Appendix B . As previously mentioned in Section 2.4, electrical bills can be separated in a fixed charge, delivery charge and electricity charge. Due to location of the buildings, Hydro Ottawa's rates will be used in the case study as a Class B customer. The rates effective since May 1, 2018 for a customer under 5,000 kW peak are displayed in Table 4.3. However, as the buildings are located on a university campus which reaches a peak of over 5,000 kW and for better comparison with later chapters, this thesis will use the over $5,000 \mathrm{~kW}$ peak charges displayed in Table 4.4 For better visualization on the distribution of the varying electricity charge refer to Figure 4.2. 
Table 4.3: Hydro Ottawa's Rates under 5,000 kW Peak [63]

\begin{tabular}{|l|l|l|}
\hline \multicolumn{2}{|l|}{ Charge } & Price \\
\hline \multicolumn{2}{|l|}{ Fixed Charge } & $\$ 4,193.93 / \mathrm{month}$ \\
\hline Electricity Charge & Market Price & HOEP + GA \\
\cline { 2 - 3 } & Regulatory Charge & $\$ 0.0039 / \mathrm{kWh}$ \\
\hline Delivery Charge & Transmission Network & $\$ 2.8472 / \mathrm{kW}$ \\
\cline { 2 - 3 } & Transmission Connection & $\$ 2.0414 / \mathrm{kW}$ \\
\cline { 2 - 3 } & Low Voltage Service Charge & $\$ 0.02564 / \mathrm{kW}$ \\
\hline
\end{tabular}

Table 4.4: Hydro Ottawa's Rates over 5,000 kW Peak [63]

\begin{tabular}{|l|l|l|}
\hline \multicolumn{2}{|l|}{ Charge } & Price \\
\hline \multicolumn{2}{|l|}{ Fixed Charge } & $\$ 15,231.32 /$ month \\
\hline Electricity Charge & Market Price & HOEP + GA \\
\cline { 2 - 3 } & Regulatory Charge & $\$ 0.0039 / \mathrm{kWh}$ \\
\hline Delivery Charge & Transmission Network & $\$ 3.1563 / \mathrm{kW}$ \\
\cline { 2 - 3 } & Transmission Connection & $\$ 2.2989 / \mathrm{kW}$ \\
\cline { 2 - 3 } & Low Voltage Service Charge & $\$ 0.02887 / \mathrm{kW}$ \\
\hline
\end{tabular}




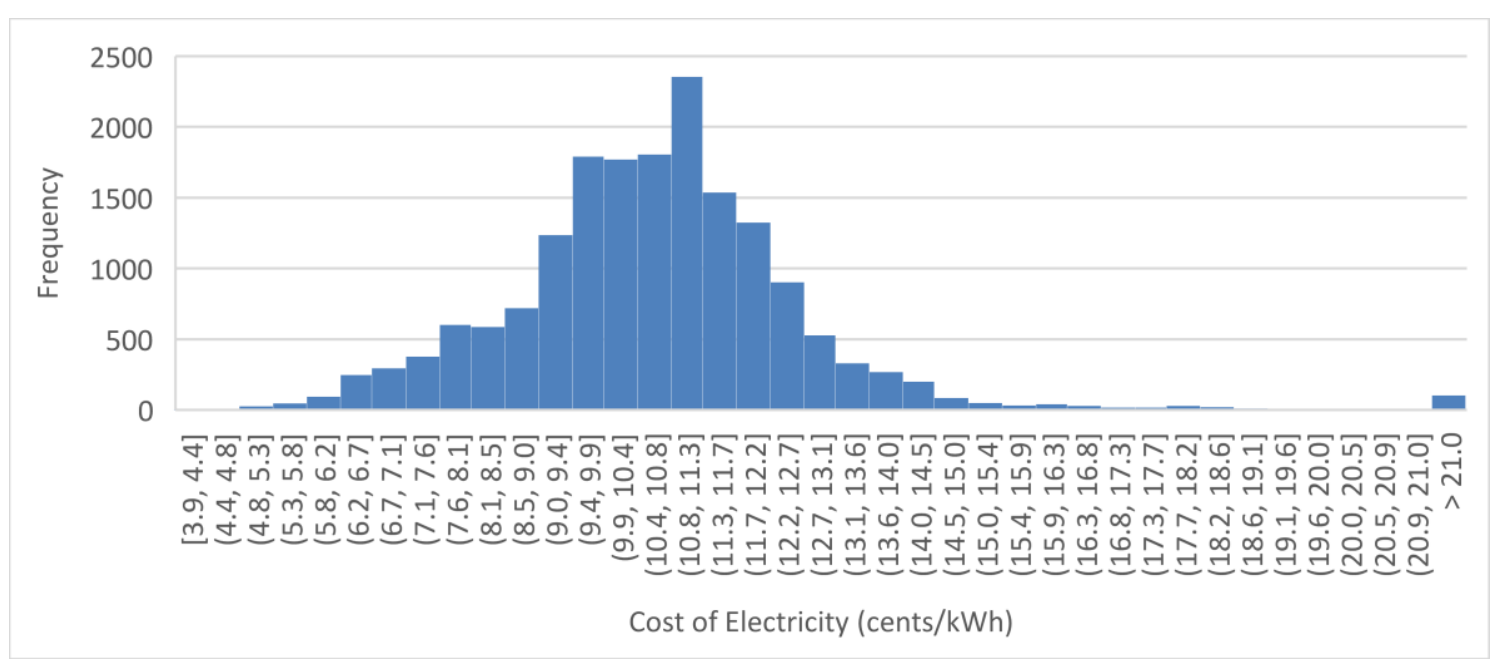

Figure 4.2: Electricity Charge 2015-2016

Furthermore, real world constraints must be set to the battery for the case study. Due to its modularity, specifications for Tesla's Powerpack 2 seen in Table 4.5 was used.

Table 4.5: Tesla's Powerpack 2 Specs [64]

\begin{tabular}{|l|l|}
\hline Constraint & Value \\
\hline Battery Efficiency & $89 \%$ \\
\hline Storage Size & $210 \mathrm{kWh} /$ Powerpack \\
\hline Charge and Discharge Rate & $50 \mathrm{~kW} /$ Powerpack \\
\hline Technology & Lithium-ion4 \\
\hline
\end{tabular}

\subsection{Results and Discussion}

Our case study took the eight-building cluster and assumed each building was equipped with its own Powerpack for a total system storage size of 1,680 kWh with a maximum charge/discharge rate of $400 \mathrm{~kW}$. The system was analyzed as a minimization of a central BESS system for a demand which added up all eight buildings' load to receive a yearly electrical bill savings of $1.5 \%$ or approximately $\$ 36,000$ as seen in Table 4.6. Alternatively, the system was also analyzed for each individual building minimizing their 
own bill with their own BESS to receive a total yearly electrical bills savings for the eight buildings approximately $\$ 37,000$. Due to the minimal savings of individual systems of approximately $\$ 1,000$ and real-world implementation complications, this thesis concentrates on single load view where the individual buildings loads are added up. The case study shows that if you optimize for electrical bill minimization in an Ontario RTP environment, the added goal of peak shaving is also met because of the current structure in electrical bill charges. Table 4.7 shows that while minimizing the electrical bill, the average peak load was reduced by approximately 10 to $15 \%$ for each month in 2015 .

Table 4.6: 2015 Minimized Electrical Bills

\begin{tabular}{|c|c|c|c|c|}
\hline Month & Original Bill & Optimized Bill & Bill Dif & ence \\
\hline January & $\$ \quad 158,600$ & $\$ \quad 155,600$ & $\$$ & 3,000 \\
\hline February & $\$ \quad 159,900$ & $\$ \quad 155,600$ & $\$$ & 4,300 \\
\hline March & $\$ \quad 173,900$ & 170,700 & $\$$ & 3,200 \\
\hline April & $\$ \quad 201,300$ & $\$ \quad 198,700$ & $\$$ & 2,600 \\
\hline May & $\$ \quad 215,600$ & $\$ \quad 212,100$ & $\$$ & 3,500 \\
\hline June & $\$ \quad 207,000$ & 204,300 & $\$$ & 2,700 \\
\hline July & $\$ \quad 217,800$ & $\$ \quad 215,300$ & $\$$ & 2,500 \\
\hline August & $\$ \quad 225,800$ & $\$ \quad 222,500$ & $\$$ & 3,300 \\
\hline September & $\$ \quad 223,700$ & 220,700 & $\$$ & 3,000 \\
\hline October & $\$ \quad 196,600$ & $\$ \quad 193,300$ & $\$$ & 3,300 \\
\hline November & $\$ \quad 228,300$ & $\$ \quad 225,900$ & $\$$ & 2,400 \\
\hline December & $\$ \quad 189,600$ & 187,400 & $\$$ & 2,200 \\
\hline Total & $\$ 2,398,100$ & $\$ 2,362,100$ & $\$$ & 36,000 \\
\hline
\end{tabular}


Table 4.7: 2015 Minimized Peak Demand

\begin{tabular}{|l|c|c|c|}
\hline Month & Peak Demand (kW) & Optimized Peak Demand (kW) & Peak Difference (kW) \\
\hline January & 2,900 & 2,600 & 300 \\
\hline February & 2,800 & 2,600 & 200 \\
\hline March & 2,900 & 2,600 & 300 \\
\hline April & 2,900 & 2,600 & 300 \\
\hline May & 3,200 & 2,900 & 300 \\
\hline June & 3,100 & 2,800 & 300 \\
\hline July & 3,600 & 3,300 & 400 \\
\hline August & 3,600 & 3,200 & 300 \\
\hline September & 3,700 & 3,400 & 400 \\
\hline October & 3,100 & 2,700 & 300 \\
\hline November & 2,900 & 2,600 & 300 \\
\hline December & 2,800 & 2,500 & \\
\hline
\end{tabular}

The case study also demonstrates that optimizing for electrical bill also reduces GHG emissions. If utilizing the imprecise methodology of simply using an emission factor (EF), adding a BESS to your system will always cause an increase in GHG emissions due to an increase in energy consumption due to BESS inefficiencies. For the case study, using a BESS caused an increase of approx. $11 \mathrm{t} \mathrm{CO}_{2 \mathrm{e}}$ using the EF methodology. However, if using the time-sensitive methodology explained in Chapter 3, the case study showed a decrease of approx. $5 \mathrm{t} \mathrm{CO}_{2 \mathrm{e}}$ while using a BESS to minimize electrical bill. The optimization from the methodology section was run once more with a $50 \$ / \mathrm{tCO}_{2 \mathrm{e}}$ carbon price attached to the RTP and caused little to no difference in electrical bill savings as the 
carbon price varied only between 0.1 to $0.8 \notin / \mathrm{kWh}$.

Figure 4.3 displays the frequency in which the BESS is optimally charging or discharging over a year. The negative bin numbers in Figure 4.3 represent discharge as a percentage of the maximum allowed discharge rate $(400 \mathrm{~kW})$ and the positive bin numbers represent the charge as a percentage of the maximum allowed charge rate $(400 \mathrm{~kW})$. Approximately $55 \%$ of the time, the BESS system stands idle. The charge rate for the BESS system seems mostly bimodal as it either stands idle or charges at a $100 \%$ rate compared to the discharge rate which is more finite in its discharge profile. The charge rate would be easier to predict with the detection of an upcoming peak and lower cost of electricity. On the other hand, the discharge rate will need a finer prediction model to attain the demand response as optimally solved.

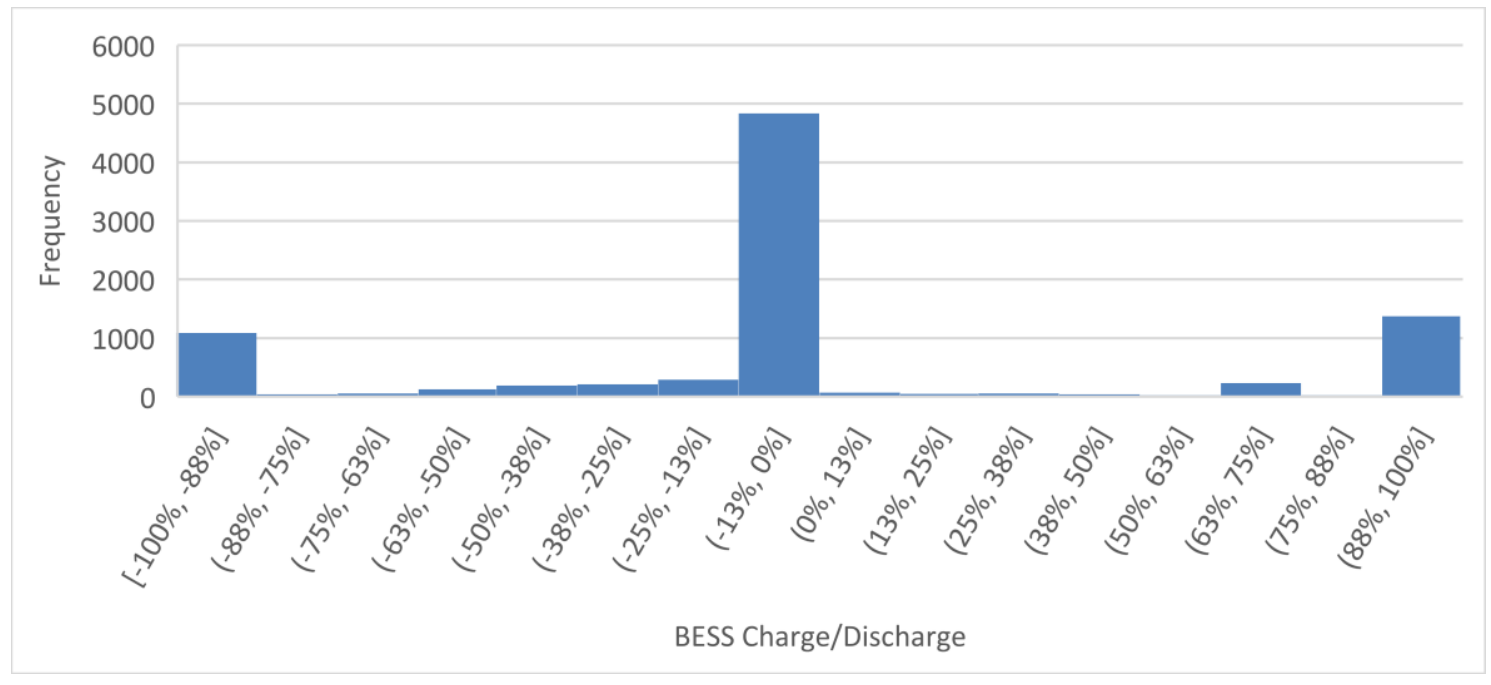

Figure 4.3: BESS Charge/Discharge Histogram

In terms of economic feasibility, the simple payback of the system is attached heavily to the cost of the BESS as displayed in Figure 4.4. Iterating the methodology with the number of Powerpacks installed, electrical bill savings grow to a maximum amount of $\$ 120,000$ as seen in Figure 4.5. Figure 4.5 also displays the simple payback dependent on 
number of Powerpacks assuming a cost of $400 \$ / \mathrm{kWh}$ [65]. Due to high price of BESS systems, the lowest simple payback independent of price per $\mathrm{kWh}$ is always seen with a single Powerpack installed. The diminishing returns is most likely due to the nature of the electrical load profile of the case study, specifically its peak demand. In the following chapter, a larger load profile will be investigated to analyze whether the single Powerpack remains the lowest simple payback. In the current electrical bill environment in Ontario, a large customer wanting to lower their electrical bill should focus on peak shaving applications as opposed to load shifting.

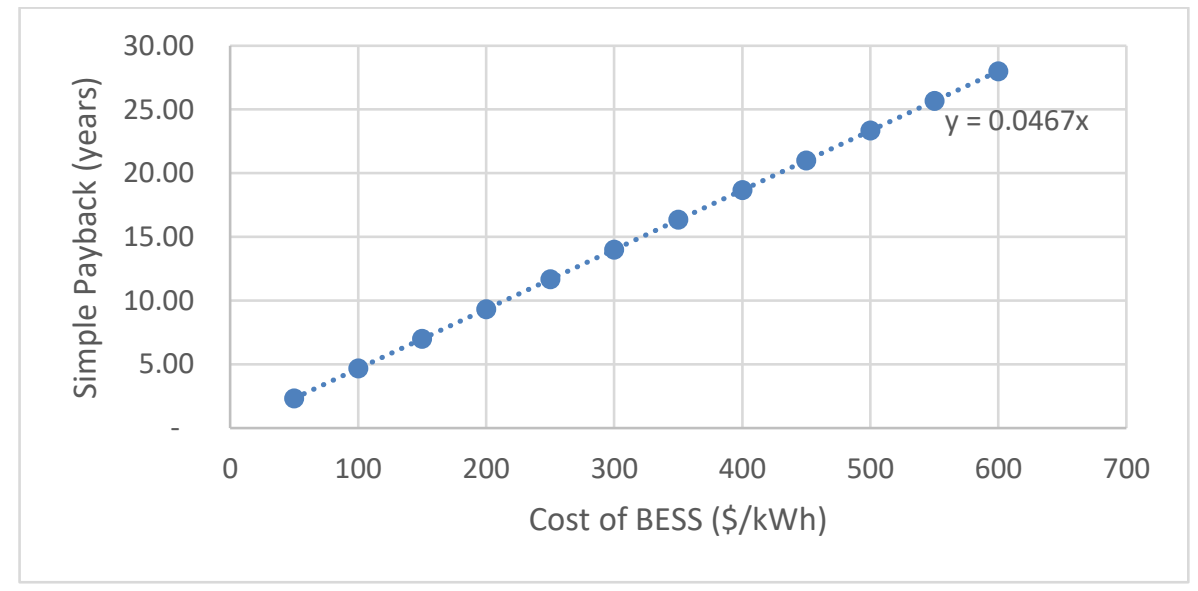

Figure 4.4: BESS Simple Payback versus Cost of BESS

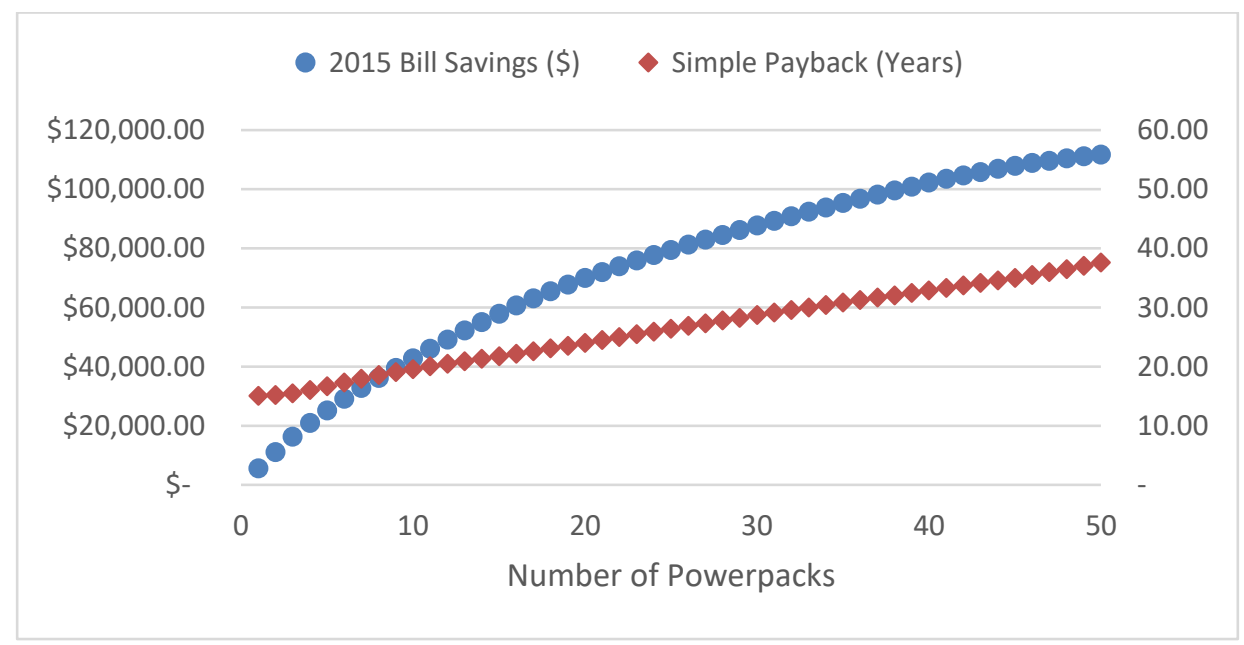

Figure 4.5: Bill Savings and Simple Payback Dependent on Amount of Powerpacks 


\subsection{Conclusion}

In conclusion, using a BESS while minimizing electrical bill in an RTP environment not only saves on the customer's bill but also lowers peak demand that can help reduce the eight-building cluster's need for added capacity and GHG emissions. Future work will involve adding system costs to the optimization for a floating BESS size while also extending BESS lifetime by limiting charge-discharge cycles. 


\section{Chapter: Energy Bills Minimization via On-Site Generator and}

\section{Storage}

\subsection{Overview}

This chapter presents a linear programming methodology minimizing energy cost over a year while meeting both heating and electrical demands and is demonstrated with a case study of a whole university campus. This chapter will concentrate on the addition of a BESS as demonstrated in Chapter 4 and a preliminary view of this methodology on a yearly scale while also speaking further on carbon emissions. Due to it's high heat transfer rate, this chapter will concentrate on SHS systems for TES.

\subsection{Background}

Campuses are believed to be "low-hanging fruit" in the implementation of community energy systems. IEEE argues that campuses can add and manage their own power generation while also establishing academic research [66]. IEEE claims benefits may include the ability to improve grid reliability, ability to better manage costs, and potentially new revenue streams for customers while still being wary of consumer buy-in, creation of new policies, and scheduling of the various devices [66].

University of California in San Diego has a campus wide CES which supplies electricity, heating and cooling via two $13.5 \mathrm{MW}$ gas turbines, one $3 \mathrm{MW}$ steam turbine and a 1.2 MW solar installation [67]. Sreedharan et al. studied this project by modeling the dispatch and computing costs based on mixed integer linear programming [68]. The study comprised of utilizing a first stage estimate on a monthly scale and a second stage which recursively optimizes on a daily scale showing results for August (summer) and December (winter) months. Sreedharan et al. concludes that participation in the ancillary services 
market does not provide enough incentives and that further studies on carbon emissions should be completed [68].

Further studies have investigated the operations of a CES with CHP and TES such as Sartor et al. which found that a biomass CHP connected to a district heating network (DHN) with a TES increases CHP plant efficiency and reduces GHG emissions [16]. Furthermore, Sartor et al. concluded that seasonal storage should not be considered due to large capital investments for a few operating hours [16].

Siewierski et al. suggested a Mixed Integer Linear Programming method to maximize the profit of a CHP system connected to a DHN with thermal storage [21]. The CHP in Siewierski et al. is linearized by its operating characteristics of power to heat ratio [21]. Their results show that scheduling using the methodology proves to reach better financial results when comparing to traditional manual dispatch.

Tveit et al. presented a methodology for long term TES with a CHP attached to a DHN using Mixed Integer Nonlinear Programming to take account non-linear behavior of the CHP plant [22]. The methodology has issues with its non-convex nature making it sensitive to its initial values.

One of the main concerns for the linear programming of the TES is its capacity, heat transfer rate, and efficiency. Sarbu et al. reviewed TES systems giving Table 5.1 of typical TES parameters [69]. 
Table 5.1: Typical TES Parameters [69]

\begin{tabular}{|l|l|l|l|l|l|}
\hline TES System & $\begin{array}{l}\text { Capacity } \\
(\mathrm{kWh} / \mathrm{t})\end{array}$ & $\begin{array}{l}\text { Heat Transfer } \\
(\mathrm{kW})\end{array}$ & $\begin{array}{l}\text { Efficiency } \\
(\%)\end{array}$ & Storage Period & $\begin{array}{l}\text { Cost } \\
(\$ / \mathrm{kWh})\end{array}$ \\
\hline SHS & $10-50$ & $1-10,000$ & $50-90$ & days/months & $0.15-15$ \\
\hline LHS & $50-150$ & $1-1,000$ & $75-90$ & hours/months & $15-76$ \\
\hline TCHS & $120-150$ & $1-1,000$ & $75-100$ & hours/days & $12-152$ \\
\hline
\end{tabular}

\subsection{Methodology}

To complete the simulation, the electrical load was set as the real mean power recorded on three sub feeders located on Bronson Ave., which exclusively supply the Carleton University campus. The data was retrieved from the Schneider submeters used by Carleton University's facility team. From the same system, the heat load for the campus steam network is the hourly steam data exiting from all three on-campus boilers. It should be noted that some buildings on campus have their own boilers and these heating loads are ignored as they are not connected to the steam network and lack hourly data. Due to real world sensor issues, the data had to be manipulated to fill data gaps with further details seen in Appendix $\mathrm{C}$. As it required the least amount of interpolation and both lead to similar outcomes, the yearly data of 2016 is utilized in this chapter.

To simplify the problem, all loads were converted into energy on a $\mathrm{kWh}$ eq $\mathrm{scale}$. The high-pressure steam data was recorded as a cumulative amount in pounds of steam and utilized assumptions of the steam network boilers from Carleton University's Energy Master Plan [70] in Table 5.2 to transform steam into $\mathrm{kWh}_{\text {eq. }}$ Using these assumptions, [70] saw a $0.1 \%$ deviation in 2009 and a $2.5 \%$ deviation in 2012 in correlation with total billed natural gas consumption in the central boilers. These parameters will also be used to 
define the system's auxiliary boiler. Therefore, the hourly steam data was transformed into the desired format of $\mathrm{kWh}$ eq using Equation 5.1. The electrical and heat load profile can be seen in Appendix D

Table 5.2: Boiler Assumptions

\begin{tabular}{|l|c|}
\hline Assumption & Value \\
\hline Boiler Seasonal Plant Efficiency & $70 \%$ \\
\hline Steam consumed within Boiler & $15 \%$ of total steam output \\
\hline Natural Gas to Energy & $1 \mathrm{~m}^{3}$ of natural gas = $0.03584 \mathrm{MMBtu}$ \\
\hline Steam to Energy & 1 klbs of steam = $1 \mathrm{MMBtu}$ \\
\hline
\end{tabular}

$$
\begin{gathered}
\text { Heat Load }(\mathrm{kWheq})= \\
\text { Steam Data }(\mathrm{lbs}) * \frac{1 \mathrm{klbs}}{1000 \mathrm{lbs}} * \frac{1 \mathrm{MMBtu}}{1 \mathrm{klbs}} * \frac{293.2972 \mathrm{kWh}}{1 \mathrm{MMBtu}} \quad \text { Equation } 5.1
\end{gathered}
$$

Due to the steam network being already established and current plans for the installation of a 4.6 MW natural gas-fired turbine on our case study of Carleton University's campus, this thesis concentrated on gas turbine CHP. Gas turbines systems range typically in electrical output of $250 \mathrm{~kW}$ to $200 \mathrm{MW}$ with gas exiting the turbine at temperatures between 450 and $550{ }^{\circ} \mathrm{C}$ to meet onsite thermal demand [14]. To represent on-the-ground reality and limitations this study uses data from Centaur 50 Gas Turbine Generator Set shown in Table 5.3. Assuming the lower end efficiency for CHP gas turbines of 70\%, the current CHP system will have a heat engine efficiency of $40.7 \%$ [14]. 
Table 5.3: CHP System Parameters [71]

\begin{tabular}{|l|l|}
\hline & Value \\
\hline Cogeneration System & Gas Turbine \\
\hline Frequency & $60 \mathrm{~Hz}$ \\
\hline Output Power & $4600 \mathrm{kWe}$ \\
\hline Heat Rate & $12,270 \mathrm{~kJ} / \mathrm{kWe} \cdot \mathrm{hr}$ \\
\hline Electrical Engine Efficiency & $29.3 \%$ \\
\hline
\end{tabular}

For the cost of gas, this chapter will use the volumetric price in Table 2.4. Due to its relative stable price and the peak volumetric demand of $1,500 \mathrm{~m}^{3}$ for the case study, the natural gas delivery charge will be estimated to $8.9 \phi / \mathrm{m}^{3}$ creating a flat volumetric gas price of $22.9021 \phi / \mathrm{m}^{3}$ on the yearly scale. To transform the volume of gas into energy, Equation 5.2 is used with the given values from Honeywell [70]. For the cost of electricity, this chapter will use full electrical bill method as seen in Chapter 4. However, for sellback to the grid, simply the HOEP price will be used to represent the electrical market.

$$
\begin{gathered}
\text { Energy Conversion }(\mathrm{kWheq})= \\
\text { Volume }\left(\mathrm{m}^{3}\right) * \frac{0.03584 \mathrm{MMBtu}}{1 \mathrm{~m}^{3}} * \frac{293.2972 \mathrm{kWh}}{1 \mathrm{MMBtu}}
\end{gathered}
$$

The complete CES system is demonstrated in Figure 5.1 and is transformed into a linear program via the equations and constraints shown in Table 5.4. The equality constraints displayed in Table 5.4 create energy balances in which the optimization must adhere to such as the distribution between heat and electrical energy from the CHP 
dependent on the gas inputted. Comparatively, the inequality constraints limits energy transfers dependent on equipment limitations such as the electrical capacity of the CHP.

The linear program is solved using the dual-simplex algorithm explained in Appendix A. For ease of use and as it is only used in this chapter, the nomenclature for this linear program can be found in Table 5.5. It should be noted that some components will be removed to create sub-models for further discussion. The linear program is set to minimize the monthly electrical and gas bill of a the given electrical and heating demand. To demonstrate the linear program, the historic load profile of Carleton University from 2016 was used. The load profile in 2016 of this CES can be seen in Appendix D.

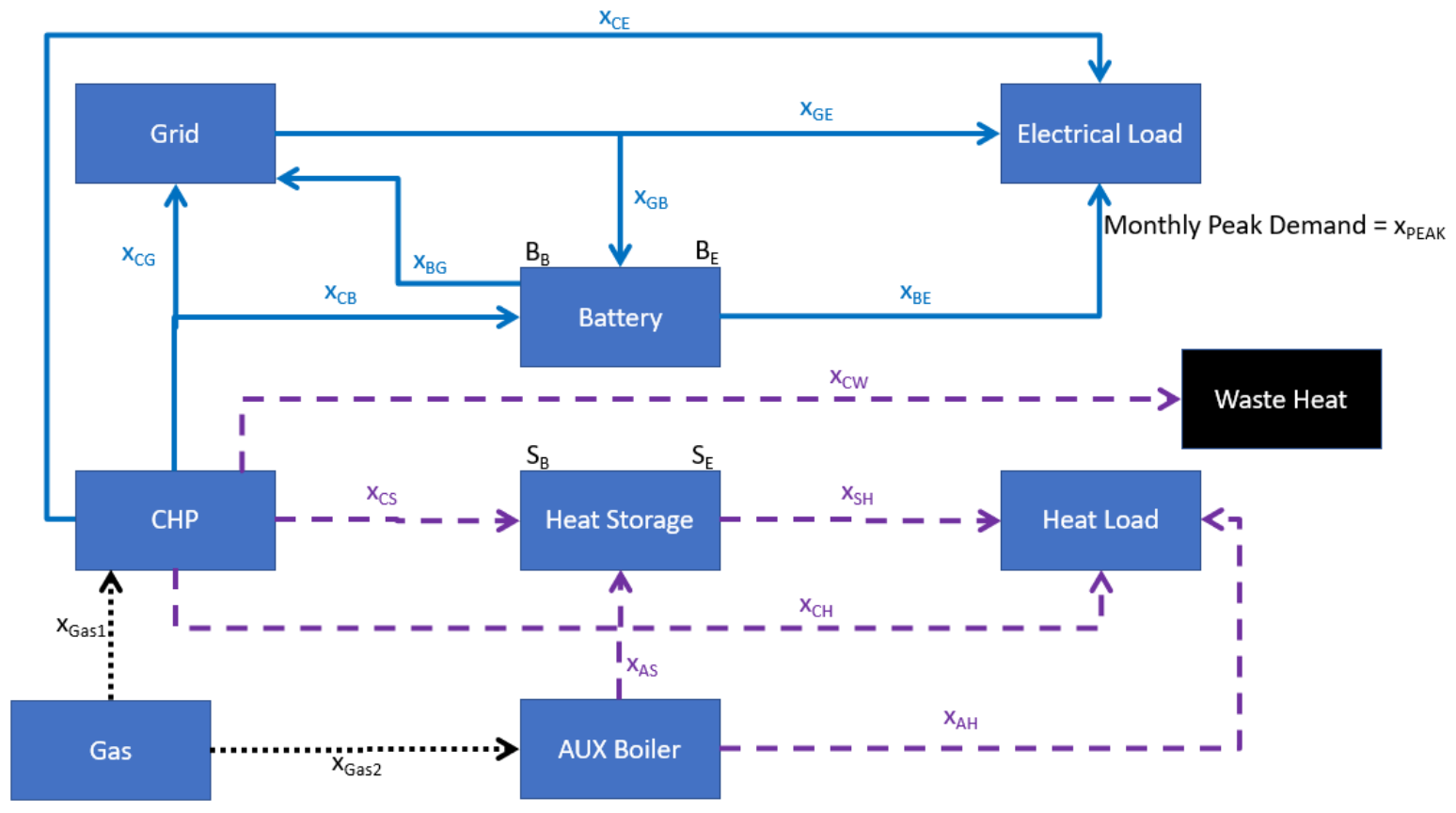

Figure 5.1: CHP and Storage Model

Table 5.4: CES Linear Program Constraints

\begin{tabular}{|l|c|}
\hline & Equation \\
\hline Electrical Load Restriction & $x_{G E_{i}}+x_{C E_{i}}+x_{B E_{i}}=$ Electrical Load \\
\hline Heating Load Restriction & $x_{C H_{i}}+x_{S H_{i}}+x_{A H_{i}}=$ Heat Load $_{i}$ \\
\hline
\end{tabular}




\begin{tabular}{|c|c|}
\hline Storage Continuity & $\begin{array}{l}B_{B_{i+1}}-B_{E_{i}}=0 \\
S_{B_{i+1}}-S_{E_{i}}=0\end{array}$ \\
\hline Storage Balance & $\begin{array}{c}\text { BESS Efficiency* }\left(x_{G B_{i}}+x_{C B_{i}}\right)-x_{B E_{i}}-x_{B G_{i}}+B_{B_{i}} \\
-B_{E_{i}}=0 \\
\text { TES Efficiency* }\left(x_{C S_{i}}+x_{A S_{i}}\right)-x_{S H_{i}}+S_{B_{i}}-S_{E_{i}}=0\end{array}$ \\
\hline Storage Priming & $B_{B 1}=$ BESS Size \& $S_{B 1}=$ TES Size \\
\hline CHP System Electrical & $\begin{array}{c}\text { Electrical Efficiency } * \text { Energy Conversion } * x_{G A S 1_{i}} \\
-x_{C E_{i}}-x_{C G_{i}}-x_{C B_{i}}=0\end{array}$ \\
\hline CHP System Heating & $\begin{array}{l}\text { Heat Efficiency } * \text { Energy Conversion } * x_{G A S 1_{i}} \\
-x_{C W_{i}}-x_{C S_{i}}-x_{C H_{i}}=0\end{array}$ \\
\hline Auxiliary Boiler Heating & $\begin{array}{c}\text { Boiler Efficiency } * \text { Energy Conversion } * x_{G A S 2_{i}} \\
-x_{A S_{i}}-x_{A H_{i}}=0\end{array}$ \\
\hline Peak Demand Constraint & $x_{G E_{i j}}+x_{G B_{i j}}-x_{\text {Peakj }} \leq 0$ \\
\hline Storage Size Constraint & $\begin{array}{l}B_{E i} \leq \text { Battery Size \& } B_{B i} \leq \text { Battery Size } \\
S_{E i} \leq \text { Storage Size \& } S_{B i} \leq \text { Storage Size }\end{array}$ \\
\hline Charging Constraint & $\begin{array}{c}x_{G B_{i}}+x_{C B_{i}} \leq \text { Battery Charge Rate } \\
x_{B E_{i}}+x_{B G_{i}} \leq \text { Battery Discharge Rate } \\
x_{C S_{i}}+x_{A S_{i}} \leq \text { Heat Storage Charge Rate } \\
x_{S H_{i}} \leq \text { Heat Storage Discharge Rate }\end{array}$ \\
\hline CHP Electrical Capacity & $\begin{aligned} x_{C E_{i}}+x_{C G_{i}}+ & x_{C B_{i}} \\
& \leq \text { CHP Nominal Electrical Capacity }\end{aligned}$ \\
\hline
\end{tabular}




\begin{tabular}{|c|c|}
\hline Auxiliary Boiler Capacity & $x_{A S_{i}}+x_{A H_{i}} \leq$ Boiler Nominal Capacity \\
\hline Minimization & $\begin{aligned} &{\text { Min: } \text { Cost }_{\text {Elec }_{i}}} *\left(x_{G E_{i}}+x_{G B_{i}}\right)-\operatorname{Cost}_{\text {HOEP }_{i}} \\
& *\left(x_{C G_{i}}+x_{B G_{i}}\right)+\operatorname{Cost}_{\text {Demand }} * x_{\text {Peak }_{j}} \\
&+\operatorname{Cost}_{\text {Gas }} *\left(x_{\text {Gas }_{i}}+x_{\text {Gas }_{i}}\right)\end{aligned}$ \\
\hline
\end{tabular}

Table 5.5: CES Linear Program Nomenclature

\begin{tabular}{|c|c|}
\hline Symbols & Full Name \\
\hline$x_{G E i}$ & Energy from Grid satisfying Electrical Demand at timestep i \\
\hline$x_{B E i}$ & Energy from BESS satisfying Electrical Demand at timestep i \\
\hline$x_{G B i}$ & Energy from Grid charging BESS at timestep i \\
\hline$x_{B G i}$ & Energy sold back to Grid from BESS \\
\hline$x_{C E i}$ & Energy from CHP satisfying Electrical Demand at timestep i \\
\hline$x_{C B i}$ & Energy from CHP charging BESS at timestep i \\
\hline$x_{C G i}$ & Energy sold to Grid from CHP at timestep i \\
\hline$x_{\text {Peak }_{j}}$ & Monthly Peak Demand of month $\mathrm{j}$ \\
\hline$B_{B i}$ & Energy in BESS at beginning of timestep i \\
\hline$B_{E i}$ & Energy in BESS at end of timestep i \\
\hline$x_{C S i}$ & Energy from CHP charging TES at timestep i \\
\hline$x_{S H i}$ & Energy from TES satisfying Heating Demand at timestep i \\
\hline$x_{C H i}$ & Energy from CHP satisfying Heating Demand at timestep i \\
\hline$x_{\text {Gas }_{i}}$ & Gas supplied to CHP at timestep i \\
\hline$x_{\text {Gas }_{i}}$ & Gas supplied to Aux. Boiler at timestep i \\
\hline$x_{A S i}$ & Energy from Aux. Boiler charging TES at timestep i \\
\hline$x_{A H i}$ & Energy from Aux. Boiler satisfying Heating Demand at timestep i \\
\hline$S_{B i}$ & Energy in TES at beginning of timestep $\mathrm{i}$ \\
\hline$S_{E i}$ & Energy in TES at end of timestep i \\
\hline
\end{tabular}




\begin{tabular}{|c|l|}
\hline Cost $_{\text {Elec }_{i}}$ & Cost of electrical energy at timestep i \\
\hline Cost $_{\text {Demand }}$ & Cost of electrical peak power \\
\hline Cost $_{\text {HOEP }}$ & Real Time Pricing of electrical energy at timestep i \\
\hline Cost $_{\text {Gas }}$ & Cost of heating energy \\
\hline
\end{tabular}

\subsection{Results and Discussion}

To discuss the results of our case study, a baseline model is created representing meeting all electrical demand with the grid and heating demand with the on-site boiler. Flat charges of electrical bills and gas bills will be ignored due to its irrelevancy in comparison. For the auxiliary boiler, a nominal capacity of $12,000 \mathrm{~kW}$ was used to meet thermal demand in the baseline model. The operation cost of the baseline model reaches a yearly cost of $\$ 9.547 \mathrm{M}$ with a yearly peak electrical demand of $13,300 \mathrm{~kW}$.

The first alteration to the baseline model will be adding the CHP previously described and will be referenced as CHP model. For the CHP model, a nominal capacity of $6,000 \mathrm{~kW}$ was used for the auxiliary boiler to meet thermal load if no TES was installed. The operation cost for the CHP model has a yearly cost of $\$ 6.605 \mathrm{M}$ creating a saving of $\$ 2.942 \mathrm{M}$ from the baseline model. Technically, adding the CHP causes the peak demand to reach levels lower than $5,000 \mathrm{~kW}$ during winter months as seen in Figure 5.2 meaning the electrical billing would fall to a lower billing rate. The difference between these billing rates can be seen in Chapter 4 under Table 4.3 and Table 4.4 respectively. For a typical day view of the grid demand for several months refer to Figure 5.3. This lower billing rate would mean a fixed charge savings of $\$ 11,000$ per month and a demand charge saving of $\$ 0.57$ per peak $\mathrm{kW}$. For example, a winter month with a peak load of $4,000 \mathrm{~kW}$ would achieve an additional saving of approx. $\$ 13,000$. This added savings is calculated postoptimization as the optimization does not consider different billing rates. 


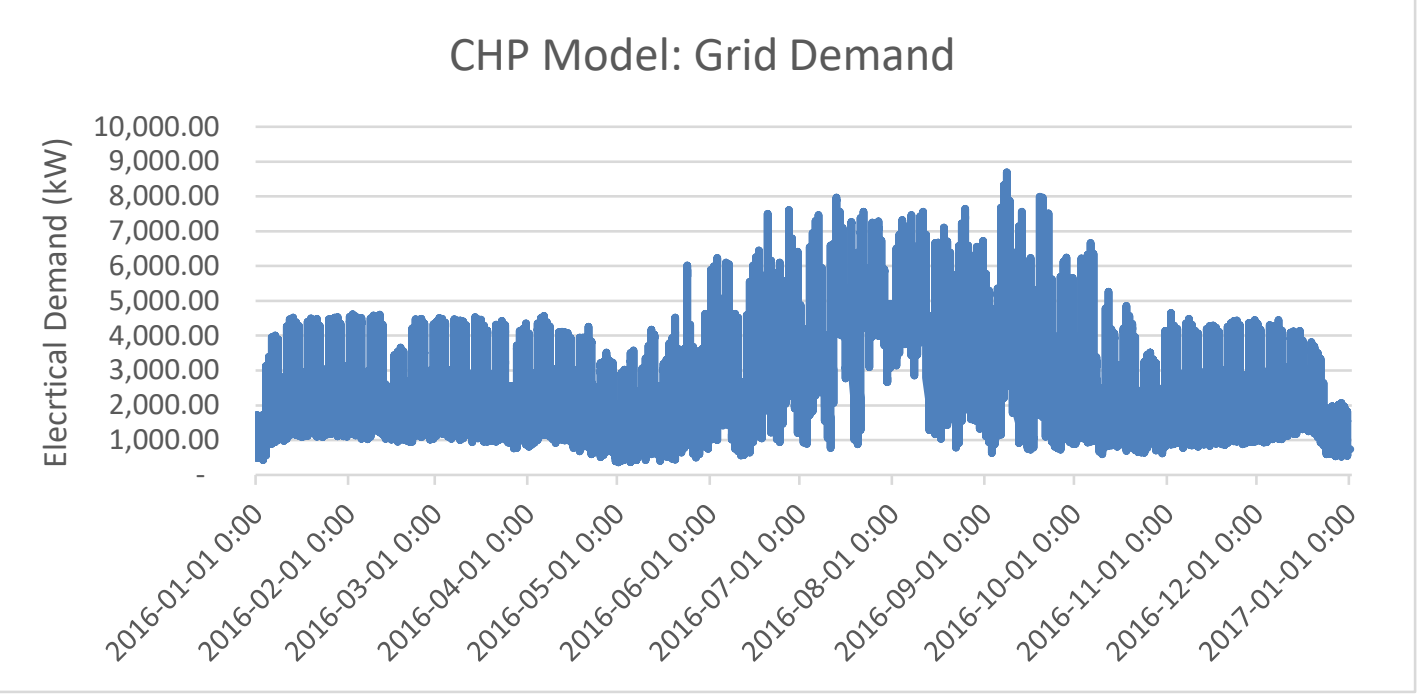

Figure 5.2: Campus Hourly Demand from Grid in CHP Model

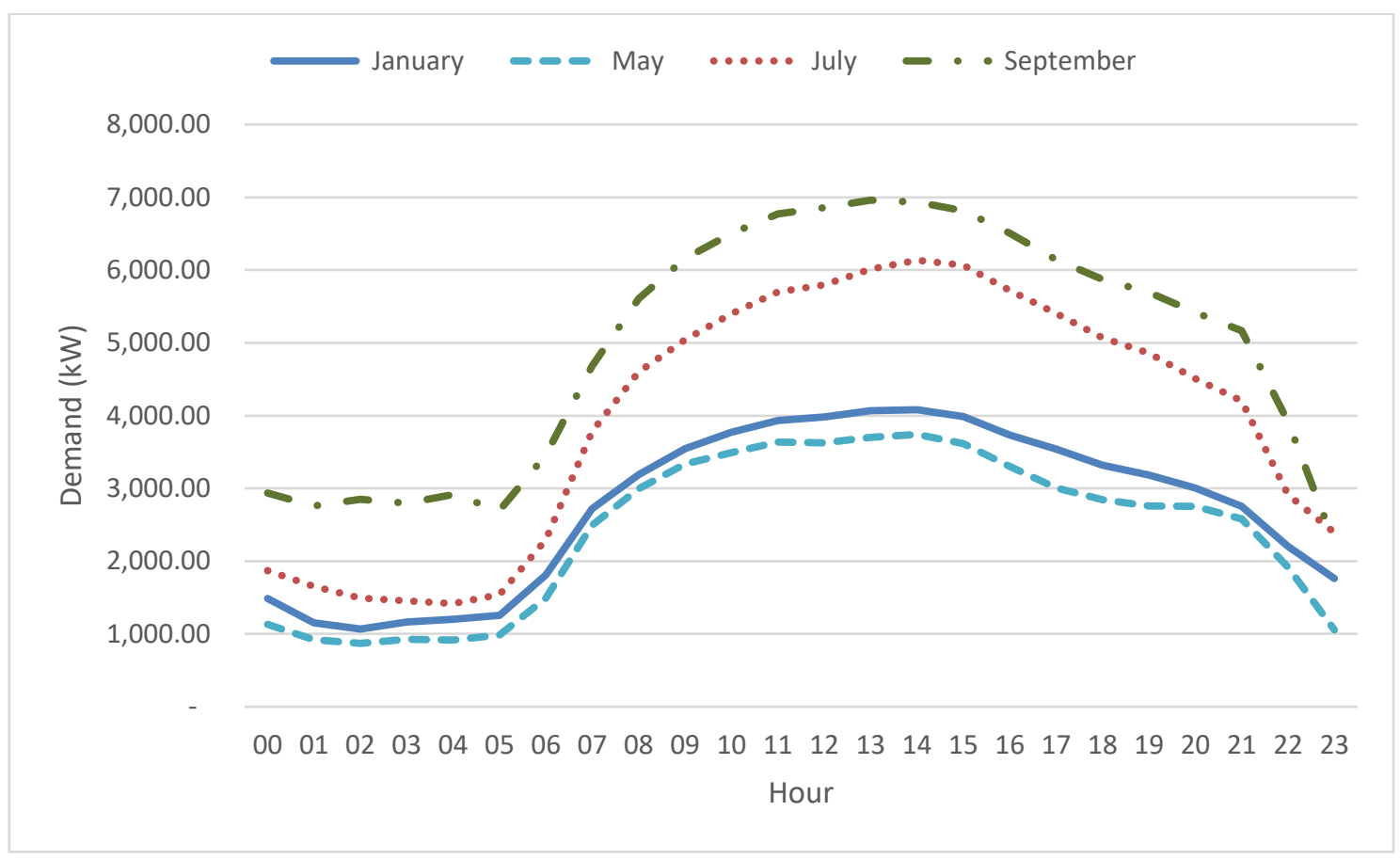

Figure 5.3: Average Weekday Campus Demand from Grid in CHP Model

The CHP model minimizes operational costs with no sales to the grid and running at constant maximum capacity except for a total of six events as seen in Figure 5.4. These events seem to corelate with a total grid electrical price of $7.365 \phi / \mathrm{kWh}$ or less. Comparatively, the average grid price is $11.625 \phi / \mathrm{kWh}$. 


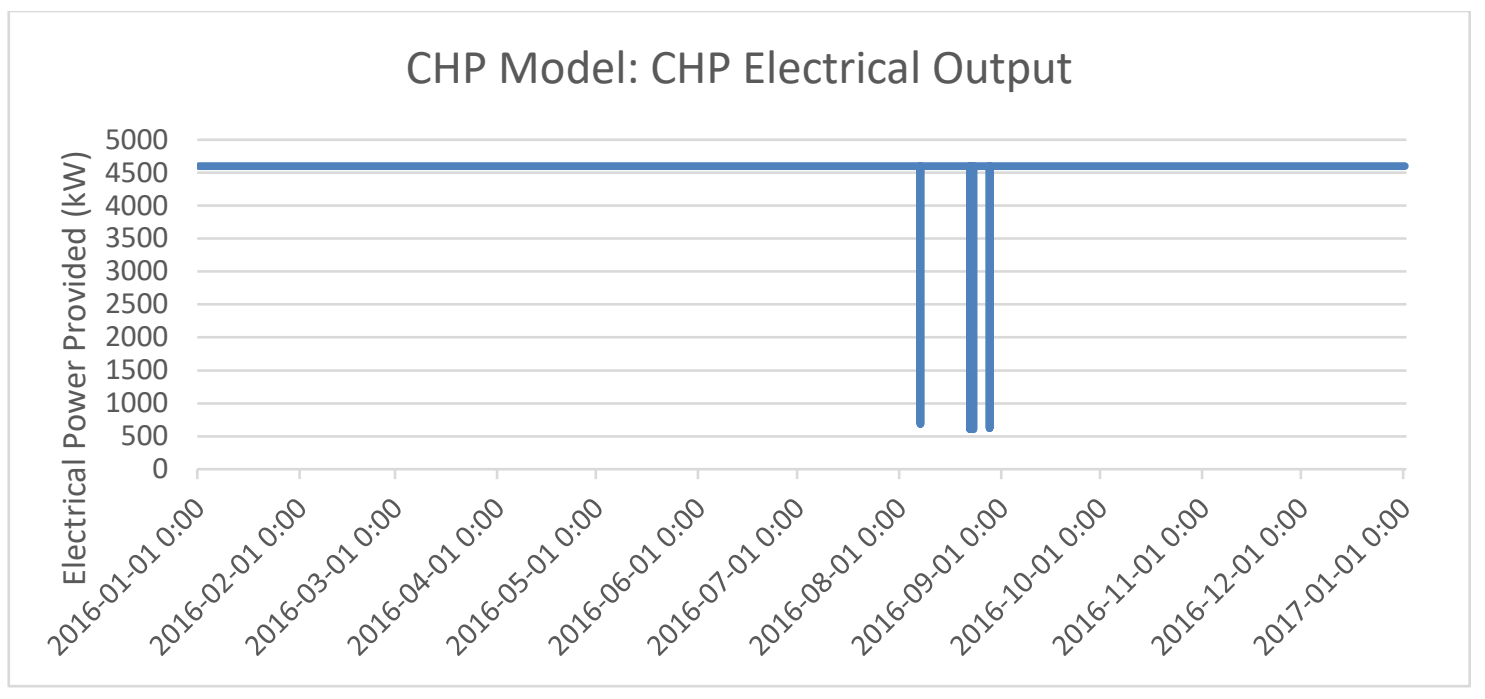

Figure 5.4: CHP Hourly Electrical Output from CHP Model

Looking deeper into the electrical side, adding a BESS system to the CHP Model can help unlock further operational savings. Carleton University has a total of 45 buildings and if each of these is assumed to be equipped with Powerpacks with specifications as defined in Table 4.5 , the operational costs drop to $\$ 6.46 \mathrm{M}$ or a further savings of $\$ 145 \mathrm{k}$ from the CHP model. The CHP + BESS model has the BESS charging at different times from both grid and CHP electrical output. The addition of the BESS keeps the six events previously seen in Figure 5.5 where the CHP was not running at maximum capabilities. Furthermore, the operational cost minimization now includes sell back to the grid from both the CHP and the BESS during two events where the electrical price reaches higher than $25.269 \not / \mathrm{kWh}$. These two events add up to approximately $1,400 \mathrm{kWh}$ being sold to the grid. As discussed in Chapter 4, the BESS adds most of its value by peak shaving the electrical demand and this can be seen in the flattening of the electrical grid demand in Figure 5.5. The addition of the BESS drops the yearly peak demand from $8,700 \mathrm{~kW}$ to 7,400 kW. Moreover, Figure 5.5 displays multiple events where the electrical demand from the grid drops to 0 and doesn't correlate fully with electrical price. This could create issues 
in the power factor of electrical power on campus creating penalty charges. For a typical day view of the grid demand for several months refer to Figure 5.6. Figure 5.6 compared to Figure 5.3 shows that the addition of the BESS requires less variance from the grid with a peak to minimum average ratio in September of approximate $3,000 \mathrm{~kW}$ versus the CHP model requiring approximately $5,000 \mathrm{~kW}$.

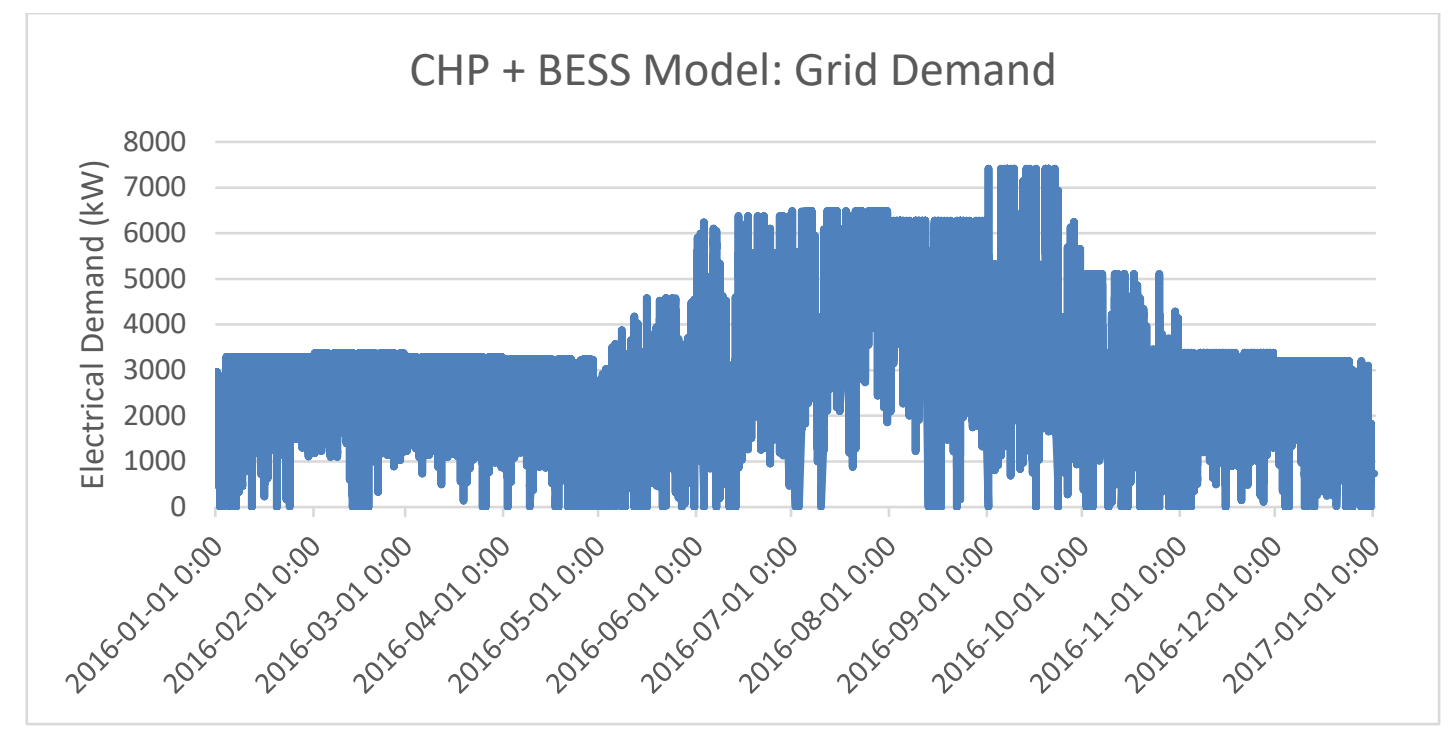

Figure 5.5: Campus Hourly Demand from Grid in CHP + BESS Model

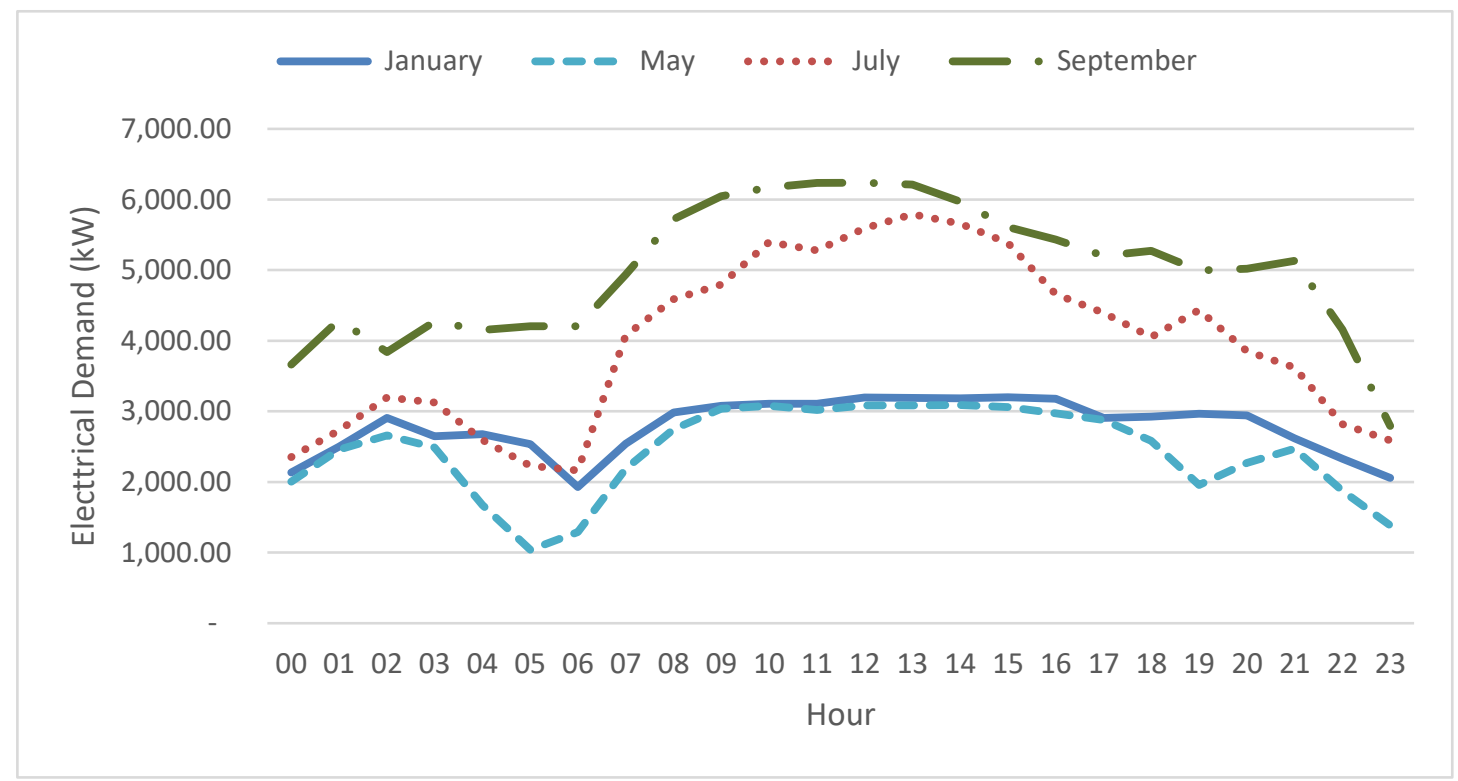

Figure 5.6: Average Weekday Campus Demand from Grid in CHP + BESS Model 
On the heating side, the CHP model requires the auxiliary boiler to meet heating load peaks during winter months as seen in Figure 5.7. The CHP model may minimize operational costs by having the CHP at constant capacity, however, could have real world issues due to the immense amount of waste heat generated during summer months as seen in Figure 5.8. To take advantage of waste heat and offset some of the auxiliary boiler demand, the next model will look at the involvement of a TES.

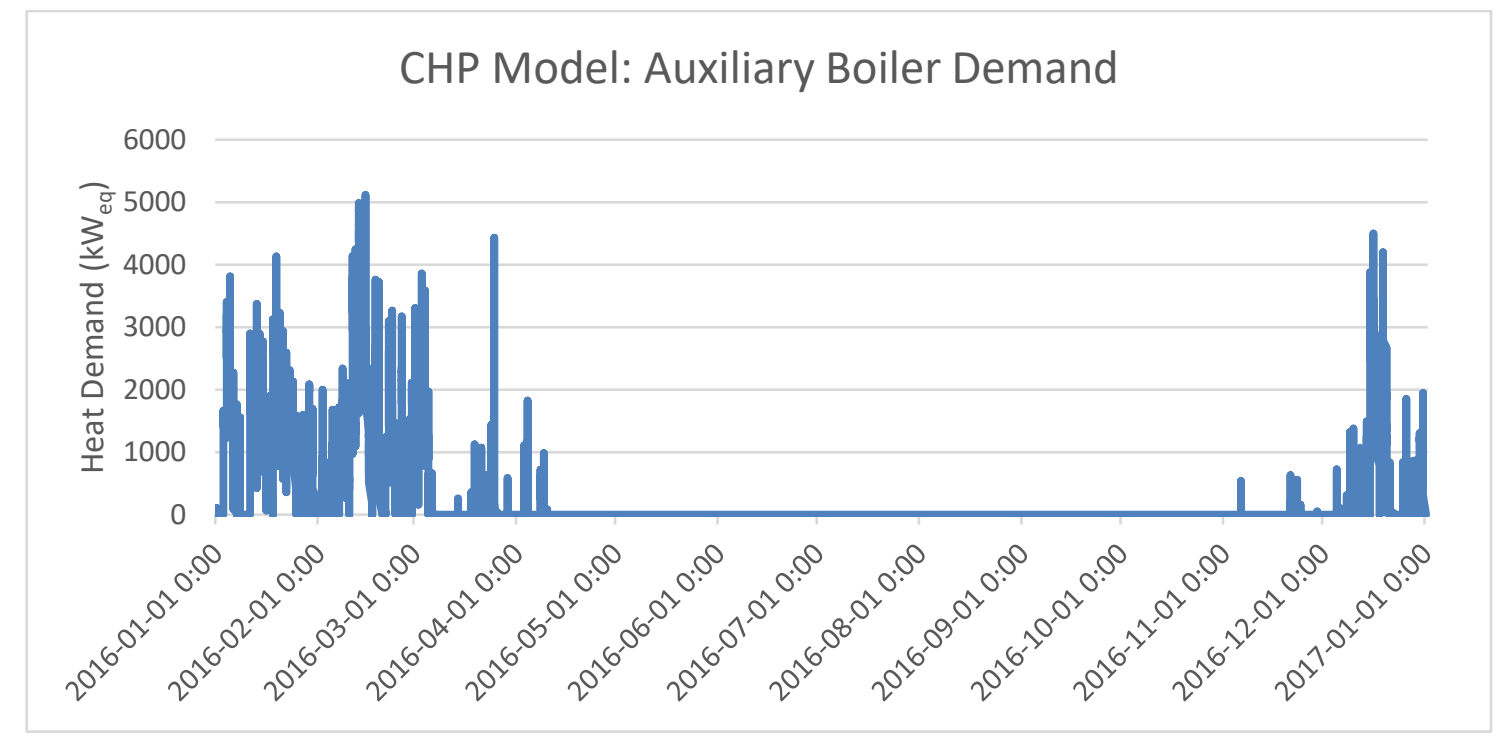

Figure 5.7: Auxiliary Boiler Hourly Heat Output in CHP Model

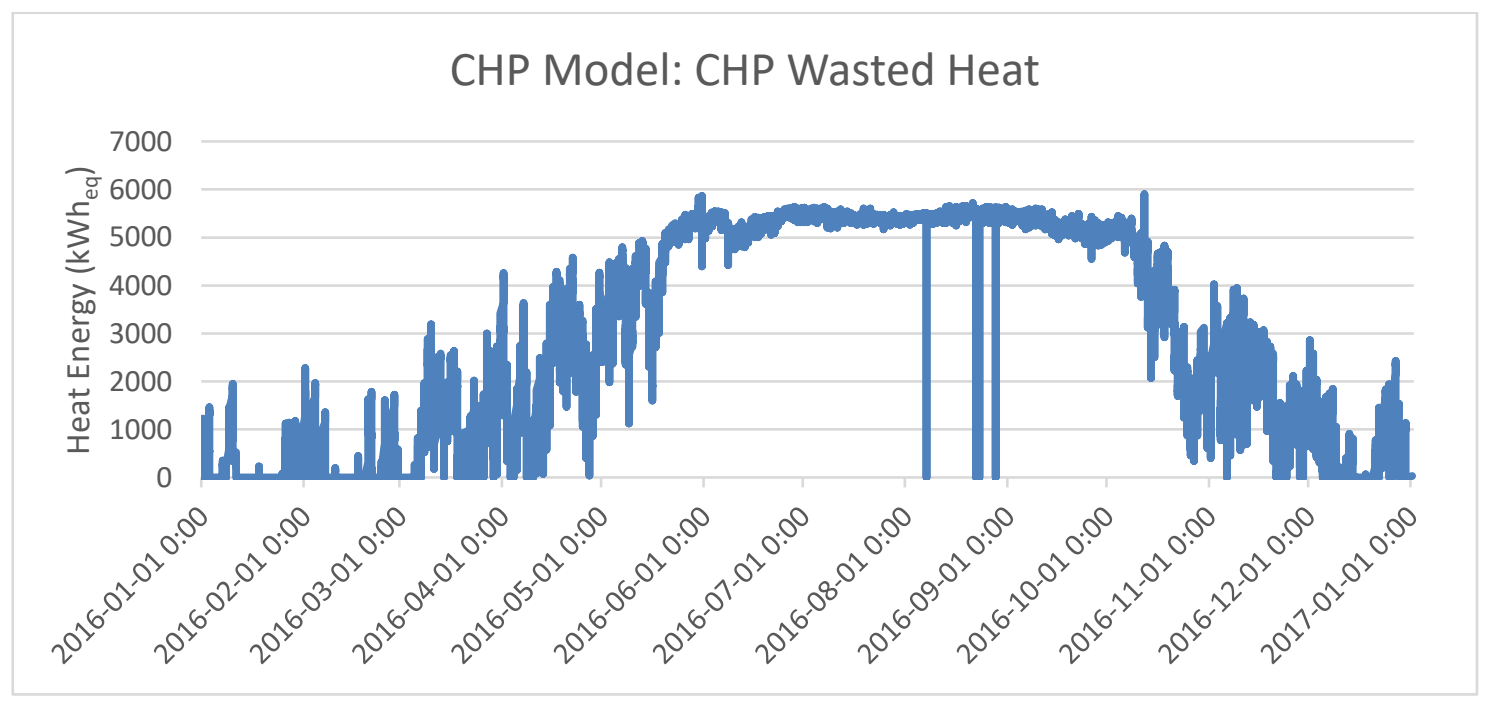

Figure 5.8: CHP Hourly Waste Heat in CHP Model 
Looking deeper into the heating side, we will add a TES system to replace the auxiliary boiler therefore the charge/discharge rate will be $6,000 \mathrm{~kW}$ with a total capacity of $3 \mathrm{GWh}$ and low-end roundtrip efficiency for a SHS system of 50\% [69]. The CHP + TES model has an operational cost of $\$ 6.529 \mathrm{M}$ which is a saving of $\$ 76 \mathrm{k}$ from the CHP model. For a 5-year simple payback, the addition of the TES makes sense if the system costs $0.13 \$ / \mathrm{kWh}$ or less which falls close to the low end of typical TES parameters of $0.15 \$ / \mathrm{kWh}$ as seen in Sarbu et al. [69]. Furthermore, the addition of the TES does remove the need for the auxiliary boiler and takes advantage of the waste heat but still has excess during summer months as seen in Figure 5.9. In reality, there would be a short-term storage for the peak demand to replace the auxiliary boiler and seasonal storage to take advantage of the waste heat. The effects of the seasonal storage can be seen in Figure 5.10 which demonstrates the proper charge and discharge cycle.

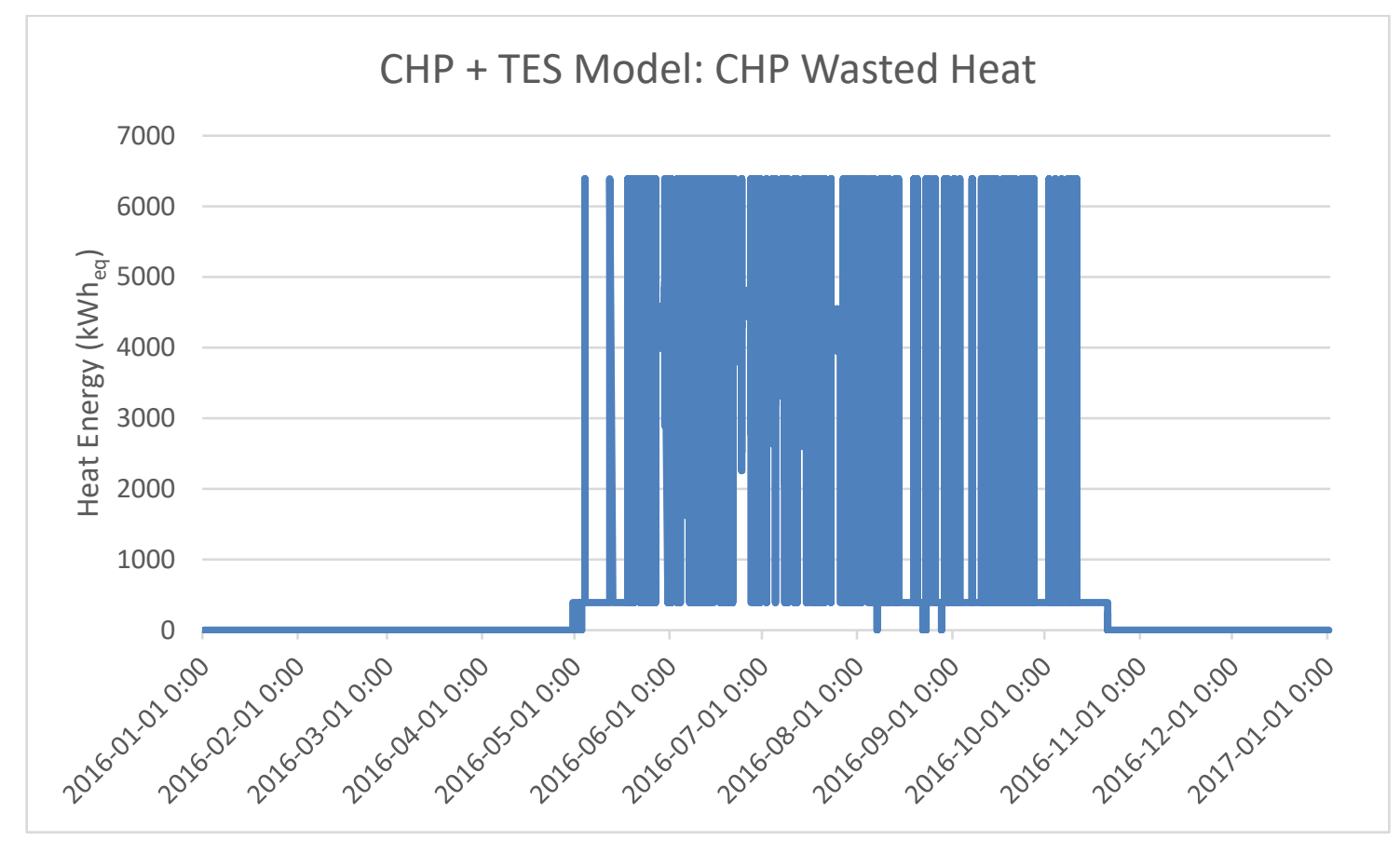

Figure 5.9: CHP Hourly Waste Heat in CHP + TES Model 


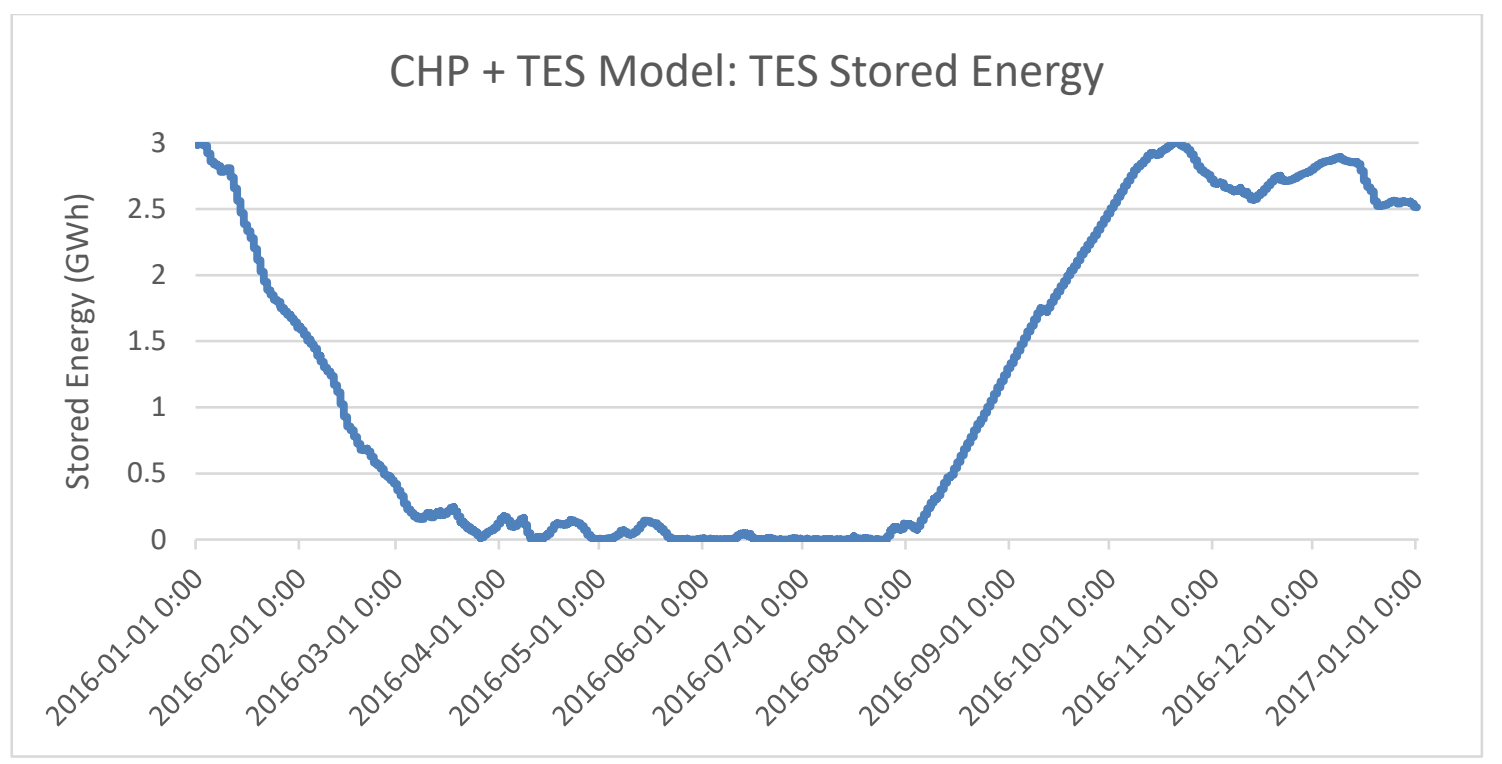

Figure 5.10: TES Stored Energy in CHP + TES Model

Adding both the TES and BESS to the CHP model (CES model), the operational costs are $\$ 6.384 \mathrm{M}$ which is a saving of $\$ 3.163 \mathrm{M}$ from the base model similarly to adding up both the CHP + BESS model and CHP + TES model savings. Using the methodology from Chapter 3 and assuming 2016 to be a similar year to 2015 in Ontario, the emissions from electrical grid use drops 2,500 $\mathrm{t} \mathrm{CO}_{2 \mathrm{e}}$ with the CES model. However, there is an increase of $8.648 \mathrm{M} \mathrm{m}^{3}$ on-site natural gas consumption due to the CHP. Using the conventual $1.9 \mathrm{~kg} \mathrm{CO} 2 \mathrm{e} / \mathrm{m}^{3}$ from [72] for natural gas, the CES model has an increased GHG intensity of approximately 14,000 t $\mathrm{CO}_{2}$. Using the 2022 proposed carbon pricing of $\$ 50 / \mathrm{t} \mathrm{CO}_{2 \mathrm{e}}[31]$, this creates an added cost of $\$ 700 \mathrm{k}$ dropping the CES model total operational savings of $\$ 2.464 \mathrm{M}$. How the electrical and thermal demand is met on a yearly scale can be seen in the Sankey diagram of Figure 5.11. 


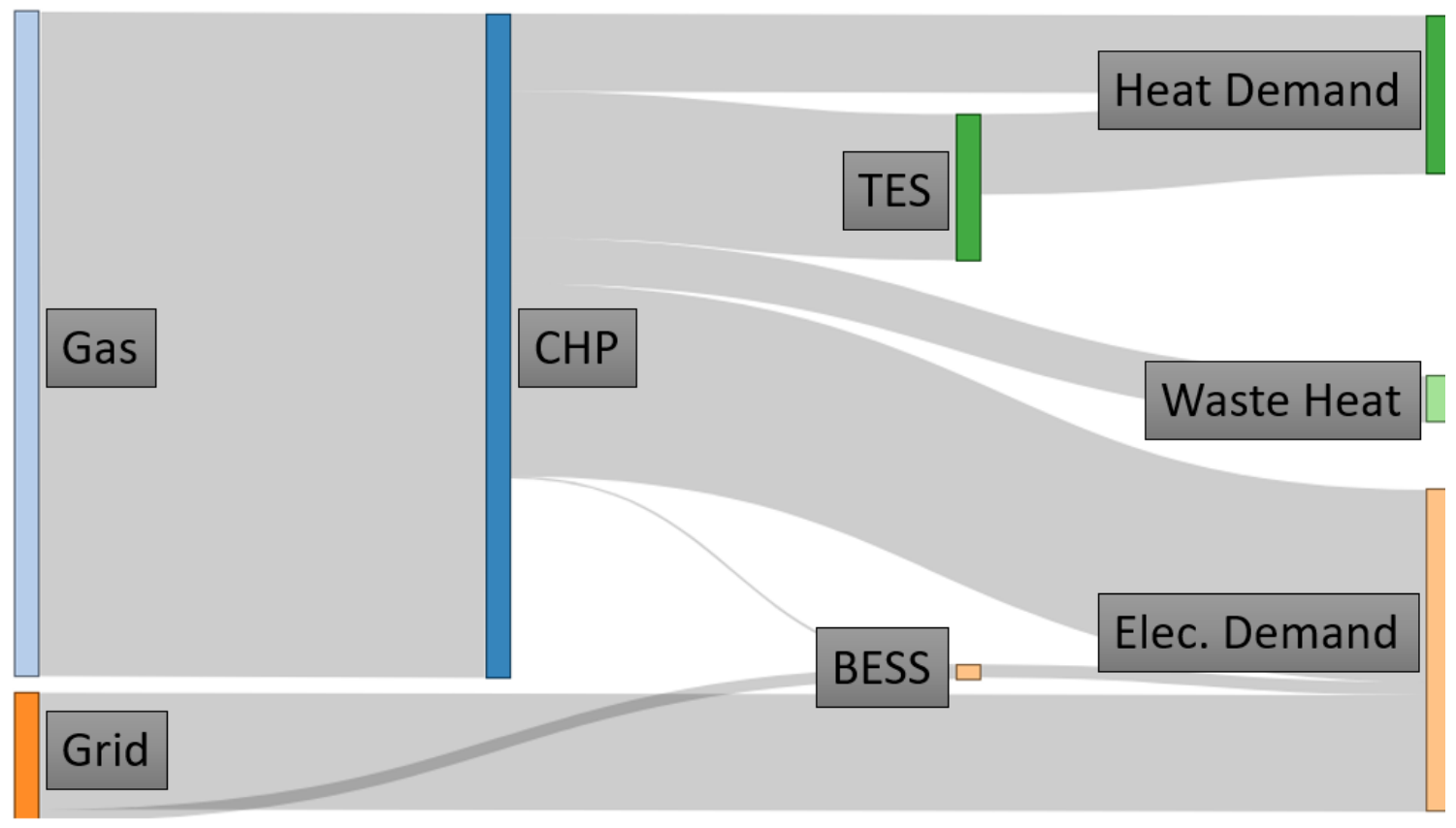

Figure 5.11: Sankey Diagram of CES on a Yearly Scale

One of the advantages of using MATLAB is the additional outputs when optimizing. One of these outputs is a structure named "lambda" which is the Lagrange multipliers at the solution separated into four vector fields; lower bounds, upper bounds, linear inequalities, and linear equalities. Lagrange multipliers, often referred to as the shadow price in economics, is the change in the operational cost due to the relaxation of a constraint such as the size of the BESS. For this chapter, we will concentrate on the linear inequalities as these constraints are dependent on equipment sizing compared to the linear equalities which sets up energy balance equations for the system. At a high level, the TES size, TES charge, TES discharge, and auxiliary boiler size produced Lagrange multiplier vectors of zeroes meaning they were not sensitive. The auxiliary boiler can be explained as it was not needed in the solution and was a redundant piece of equipment in this case as for the TES insensitivity will be explored further with an initial theory that it is optimally sized. Alternatively, the BESS size, BESS charge rate, BESS discharge rate, and CHP capacity 
are sensitive to the solution and varies with each hourly timestep. This variation can be seen in Figure 5.12 to Figure 5.15.

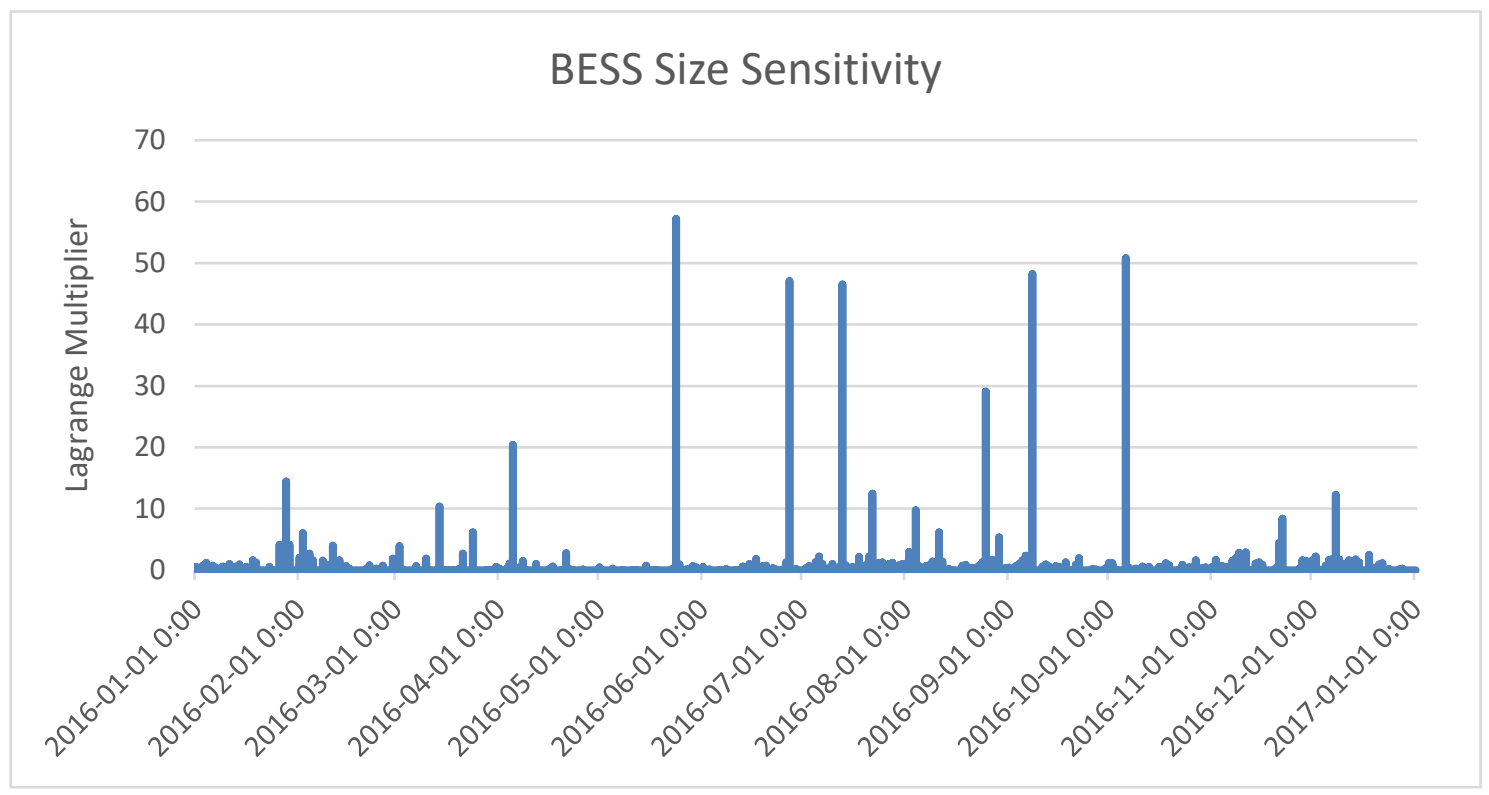

Figure 5.12: Lagrange Multiplier for BESS Size in CES Model

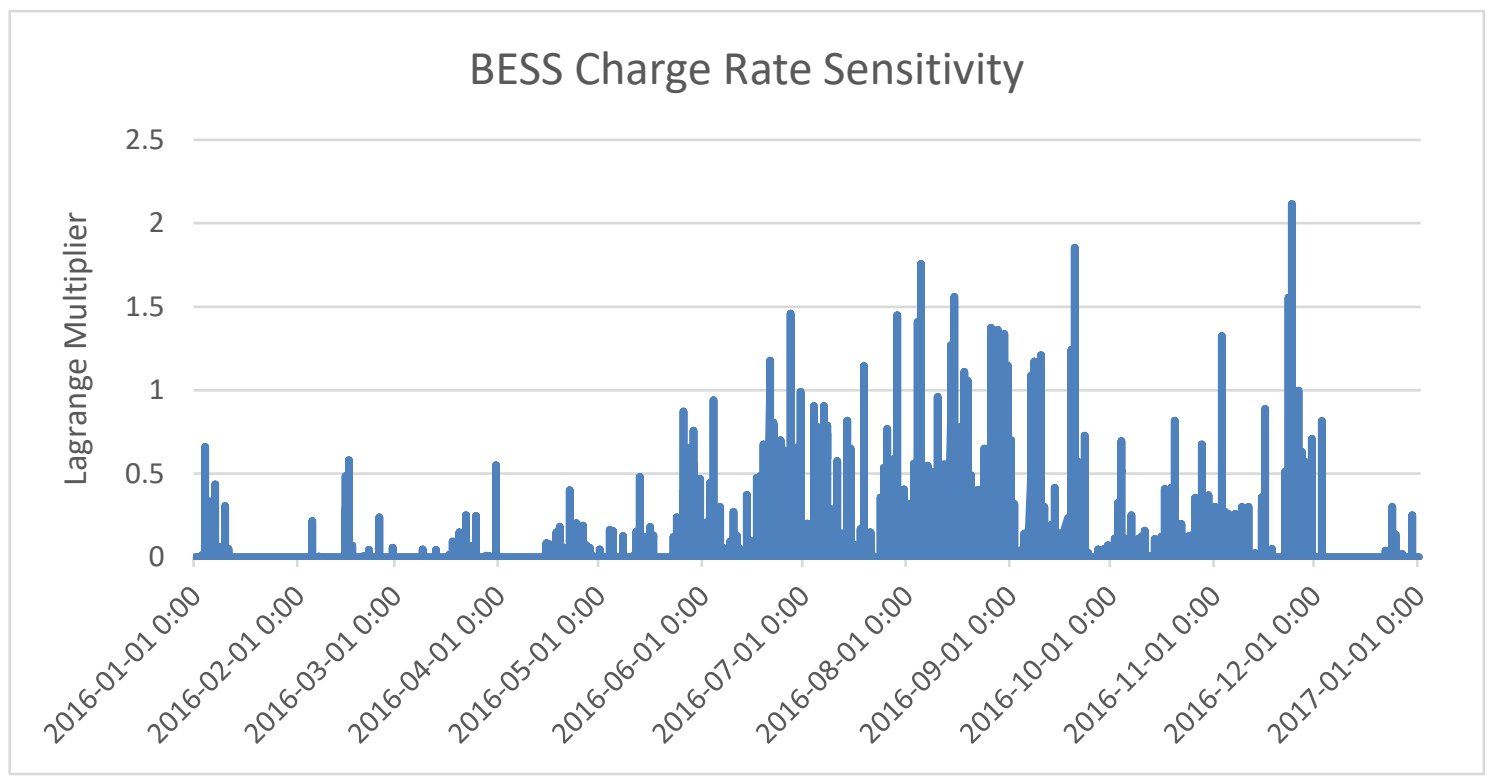

Figure 5.13: Lagrange Multiplier for BESS Charge Rate in CES Model

Figure 5.13 representing the Lagrange multiplier of the BESS's charge rate is the least sensitive. In Chapter 4, it was discussed how the charge rate of a BESS system when 
optimized to lower electrical bill was of bimodal distribution which may explain the lesser sensitivity compare to the Lagrange multiplier for the BESS's discharge rate in Figure 5.14.

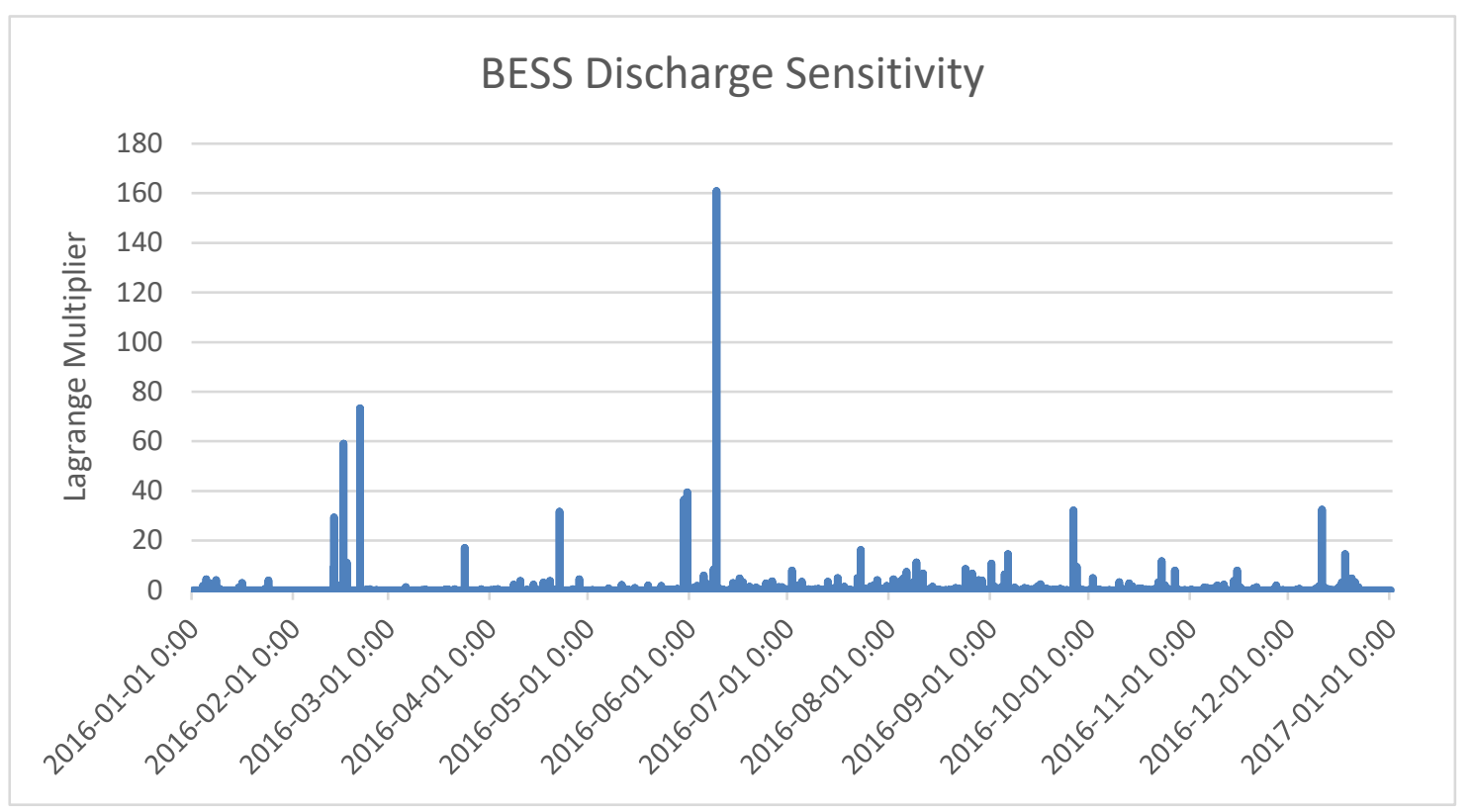

Figure 5.14: Lagrange Multiplier for BESS Discharge Rate in CES Model

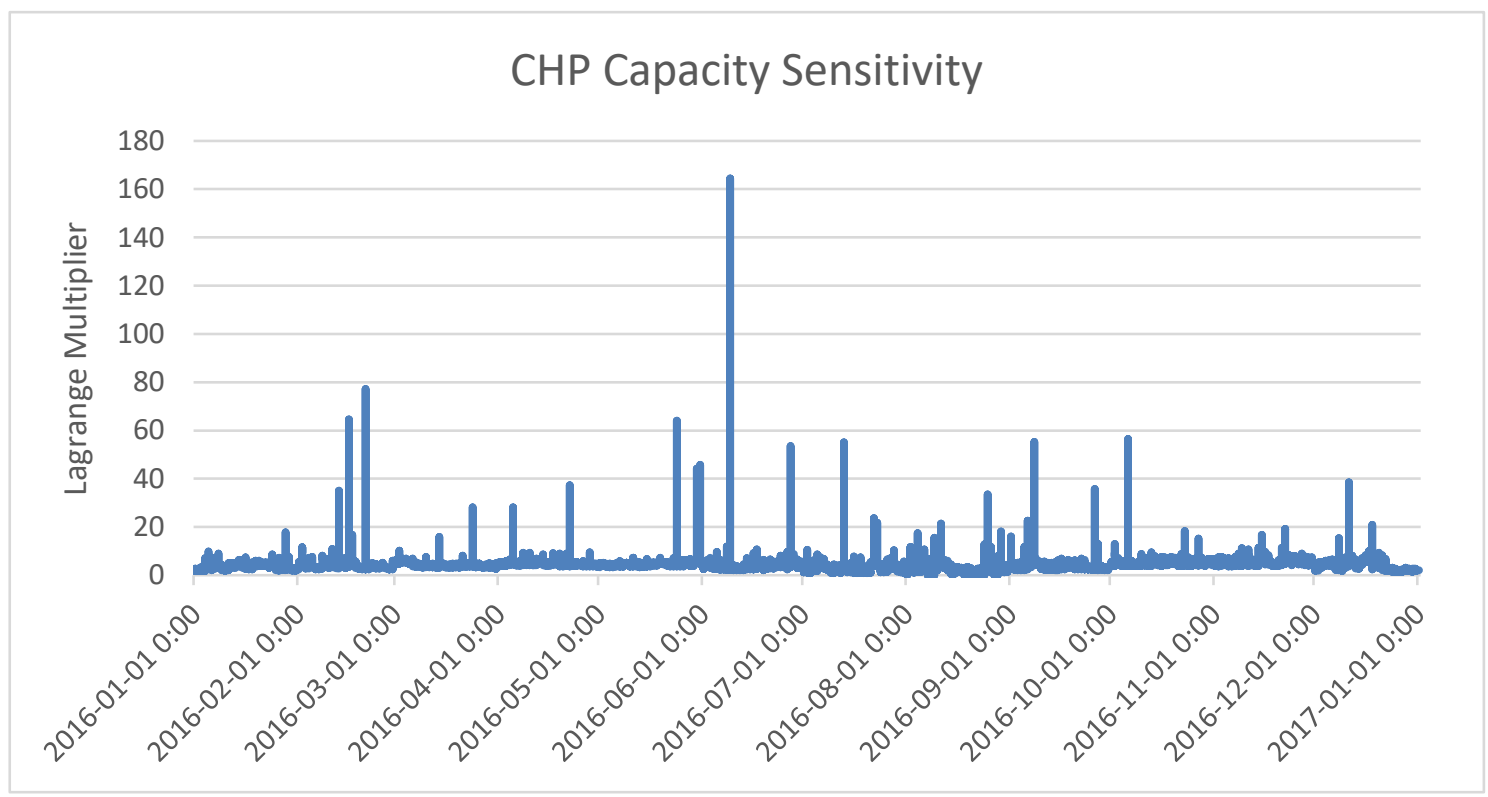

Figure 5.15: Lagrange Multiplier for CHP Capacity in CES Model

Figure 5.14 and Figure 5.15 displays that both the BESS discharge rate and CHP capacity are the most sensitive as they affect the electrical peak the most. Together, the 
Lagrange multiplier for BESS discharge and CHP capacity have a correlation of approximately 0.5 which indicates they are reacting to similar signals. Moving forward for sensitivity analysis, we will analyze the BESS size and TES size independently.

To test the sensitivity of the TES size from the CES model, the MATLAB code was run multiple times while varying the storage size while keeping the heat transfer rate also fluctuating at 1:1000 rate with storage size. Figure 5.16 displays the yearly operational savings from the TES solely max out at approximately \$76k like the CES model even if we were to size the TES even larger. Therefore, a recommendation of using a TES of similar capacity and heat transfer rate should be used in CES of this size. Figure 5.16 also displays the simple payback of the TES assuming a cost of $0.15 \$ / \mathrm{kWh}$ [69]. The TES in the CES model has an approximate simple payback of 6 years.

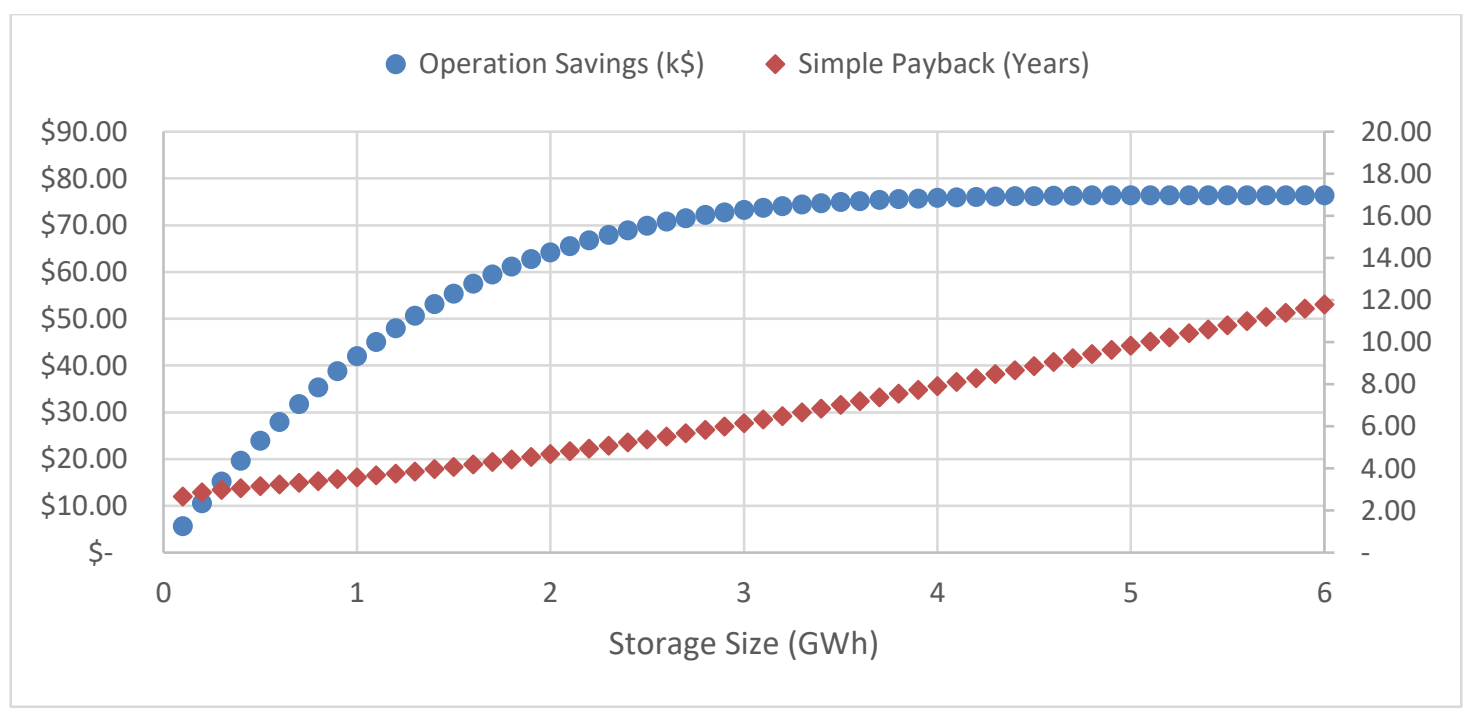

Figure 5.16: Sensitivity Analysis of TES Size for Operational Savings

To test the sensitivity of the BESS size from the CES model, the MATLAB code was run multiple times while varying the amount of Powerpacks installed. Figure 5.17 displays that the operational savings from the BESS solely continuously rises with the number of Powerpacks except with diminishing return. As shown in Chapter 4, it is assumed that the 
savings are eventually going to converge to a maximum value but due to the high price of BESS technologies should be kept at minimal amount of Powerpacks. Assuming a cost of $400 \$ / \mathrm{kWh}$ for BESS system, the simple payback dependent on the amount of Powerpacks is also seen in Figure 5.17 [65]. Looking for the lowest simple payback, a total of four powerpacks should be installed. As theorized in Chapter 4, with a whole campus electrical load having a larger peak demand, it is now beneficial to invest in more than a single Powerpack. The minimum simple payback being approximately 17 years is high than the 15 years simple payback from the previous chapter due to the CHP taking saving potential away from the BESS. The International Renewable Energy Agency estimates that the cost of Li-ion BESS system could reach a cost of $100 \$ / \mathrm{kWh}$ by 2030 which would change the simple payback to approximately 5 years [65].

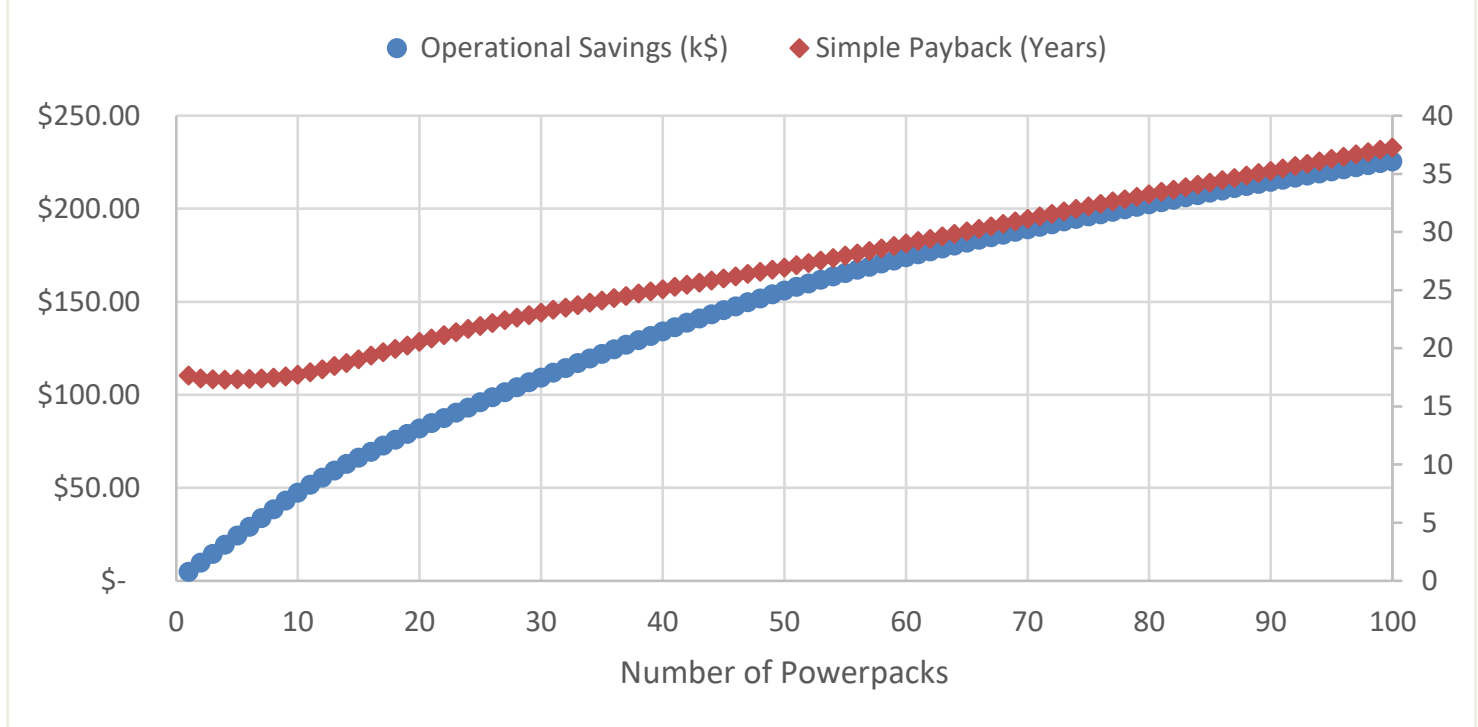

Figure 5.17: Sensitivity Analysis of BESS Size for Operational Savings

\subsection{Conclusion}

In conclusion, CES with a large demand such as the one seen in our case study can benefit greatly from energy bill savings with the addition of a CHP, TES and, BESS of 
approximately $33 \%$. Further savings could be calculated with the added benefit of receiving a lower billing rate and displacement of capital investments such as an auxiliary boiler. The advantage of having such devices on-site can allow the CHP to run continuously while optimizing the storage technologies. It should be noted that grid sellback is unimportant in such systems and should be ignored due to the low number of events and energy compared to the equipment cost one would need installed to create these opportunities. Furthermore, the addition of the technologies does increase GHG intensity on-site but adding a cost to carbon still gives a worthwhile monetary saving. Future work involves minimum load demanded from grid to keep a power factor in the correct range, the addition of CES's cooling loads to further take advantage of waste heat via chiller devices and the use of the thermal distribution system as a form of storage itself. 


\section{Chapter: Conclusions and Future Work}

\subsection{Conclusions}

The work of this thesis showed a holistic modelling approach to integrated supply, demand, storage, and collaborative management and control. Collaborative management and control were demonstrated via optimization methodologies using linear program techniques to save a CES on operational costs such as electrical and gas bills. Furthermore, the thesis not only presented the operational costs but also the GHG emissions from such systems.

The case studies of this thesis were presented with historic data but could be completed with predictions for both electrical and thermal loads. Furthermore, the optimization methodology presented in this thesis could be used on different time scales such as year, month, and day and trained into machine learning techniques such as neural networks to provide optimal real-world control of a CES.

Chapter 3 filled a gap in GHG emissions calculations by presenting a methodology to calculate an electrical grid user's carbon emission via real-world publicly available generator data using hourly timesteps. This hourly based method of calculating GHG emissions penalizes peak electrical user's instead of spreading it equally to all end users. The case study for this chapter was a single building on a university campus which demonstrated an increase in GHG emissions costs of 53\% when comparing the traditional annual model versus the proposed hourly method on a provincial level. This thesis found that decarbonization of electricity generation and reducing building peak energy demand are both needed to lower overall GHG.

Chapter 4 utilizes electrical storage to minimize an end user's electrical bill proving 
that doing so also drops peak demand, therefore lowering the need for peaking plant capacity on the electrical grid. It was also found that utilizing the hourly method presented in Chapter 3 showed an added benefit of lowering of GHG emissions. The case study of an eight-building cluster on a university campus showed a yearly electrical bills savings of $1.5 \%$, a monthly peak demand reduction of $10 \%$, and a reduction in emissions from electrical grid use by $5 \mathrm{t} \mathrm{CO}_{2 \mathrm{e}}$.

Chapter 5 takes the lessons learned from the previous two chapters and adds on-site generators, thermal demand, thermal supply and thermal storage to be applied as a case study for a whole university campus environment. The case study of a university campus showed the addition of a CHP created a minimum annual savings of $\$ 2.942 \mathrm{M}$. The addition of a BESS created further savings of $\$ 145 \mathrm{k}$ while the addition of a TES created further savings of $\$ 76 \mathrm{k}$. This thesis concludes that the addition of a CHP, TES and BESS to a community energy system can greatly benefit energy bill savings. The addition of storage devices can maximize CHP run-time at their optimal levels and offset some of the added GHG emissions. Furthermore, the addition of the technologies does increase GHG intensity on-site but adding a cost to carbon still gives a worthwhile monetary saving.

The thesis contributions include a methodology to compute GHG emissions from electrical grid which moves towards a realistic carbon intensity view of the grid based on publicly available generator data. The thesis contributed in showcasing that managing a BESS to lower electrical bill would not increase your GHG emissions using annual calculation methods but rather lower GHG emissions when considering an hourly timescale. Finally, this thesis presented that a holistic control approach to a CES using distributed generation, electrical storage, and thermal storage can lead to significant 
savings in a campus environment. The contributions of the thesis were completed with custom MATLAB script to create decision points at every hourly timestep all while minimizing operational costs globally. This custom MATLAB script removed any black box simulation process to allow for further analysis of outputs.

\subsection{Recommendations for Future Work}

Future work from this thesis includes mostly model refinement and prediction modelling. For the hourly GHG emissions methodology presented in Chapter 3, the involvement of generator-specific GHG intensity could help gives us a closer "true" answer to the amount of carbon on the electrical grid while consideration of grid line capacities could help in demonstrating how the electricity flows throughout the grid.

For model refinement for both Chapter 4 and 5, a model starting from first principles instead of assumptions or "rules of thumb" could allow for real-world implementation. These models could include further distributed generators such a solar photovoltaics and the use of a thermal distribution system as a form of storage. The methodology could also take advantage of using higher resolution timesteps at a 1-minute scale to better represent peak demands, manage electrical power factor, and take part in the electrical market. Furthermore, the methodology could be made energy holistic by considering cooling loads and water use while also adding controllable loads for further demand response.

The largest available contribution for future work will be the prediction modelling to enable historic data for real-world controls of these devices. The initial prediction models could utilize machine learning techniques such as linear regression and support vector machines from previous studies in predicting building electrical and thermal load while applying these same concepts to the electrical grid generator data to predict grid mixture. 
The secondary prediction models could utilize neural networks trained by the methodologies presented using the predicted demands as inputs. Nonlinear autoregressive network with exogenous input could be use using historical actions taken in the previous timesteps to forecast the optimal decision in the next timestep. Furthermore, studying the strategic interaction between multiple CES optimizing to lower operational costs using signals from the same market could help showcase a grid-wide net benefit or deficit from such actions. Research in the widespread use of these methodologies using research in areas such as game theory would be beneficial to society. 


\section{Appendices}

\section{Appendix A : Dual-Simplex Algorithm}

This appendix is a snipping from MATLAB's documentation [73].

At a high level, the linprog 'dual-simplex' algorithm essentially performs a simplex algorithm on the dual problem.

The algorithm begins by attempting to simplify the problem by removing redundancies and simplifying constraints. The tasks performed during the pre-solve step include:

- Check if any variables have equal upper and lower bounds. If so, check for feasibility, and then fix and remove the variables.

- Check if any linear inequality constraint involves just one variable. If so, check for feasibility, and change the linear constraint to a bound.

- Check if any linear equality constraint involves just one variable. If so, check for feasibility, and then fix and remove the variable.

- Check if any linear constraint matrix has zero rows. If so, check for feasibility, and delete the rows.

- Check if the bounds and linear constraints are consistent.

- Check if any variables appear only as linear terms in the objective function and do not appear in any linear constraint. If so, check for feasibility and boundedness, and fix the variables at their appropriate bounds.

- Change any linear inequality constraints to linear equality constraints by adding slack variables.

If algorithm detects an infeasible or unbounded problem, it halts and issues an appropriate exit message. 
The algorithm might arrive at a single feasible point, which represents the solution.

If the algorithm does not detect an infeasible or unbounded problem in the pre-solve step, it continues, if necessary, with the other steps. At the end, the algorithm reconstructs the original problem, undoing any pre-solve transformations. This final step is the postsolve step.

For simplicity, the algorithm shifts all lower bounds to zero.

While these preprocessing steps can do much to speed up the iterative part of the algorithm, if the Lagrange multipliers are required, the preprocessing steps must be undone since the multipliers calculated during the algorithm are for the transformed problem, and not the original. Thus, if the multipliers are not requested, this transformation back is not computed, and might save some time computationally.

The preprocessing reduces the original linear programming problem to the form of Equation 6.1.

$$
\min _{x} f^{T} x \text { such that }\left\{\begin{aligned}
A \cdot x & =b \\
0 & \leq x \leq u
\end{aligned}\right.
$$

Equation 6.1

Example of how to calculate a simplex problem is provided in by HEC Montréal with the logic demonstrated in Figure 6.1 [74].

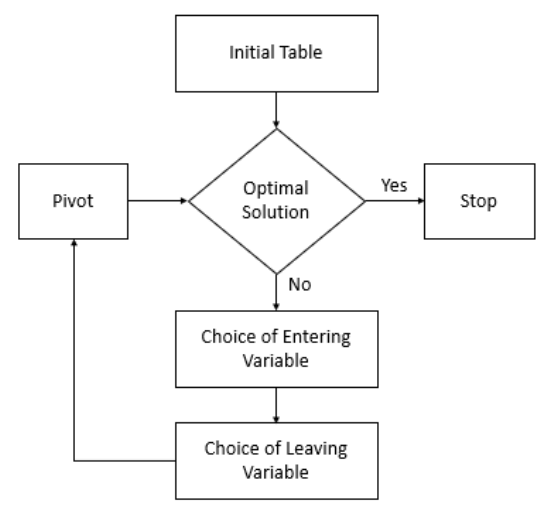

Figure 6.1: Logic Map to Calculate Simplex Problem 


\section{Appendix B : Carleton Eight Building Cluster Load Profile}

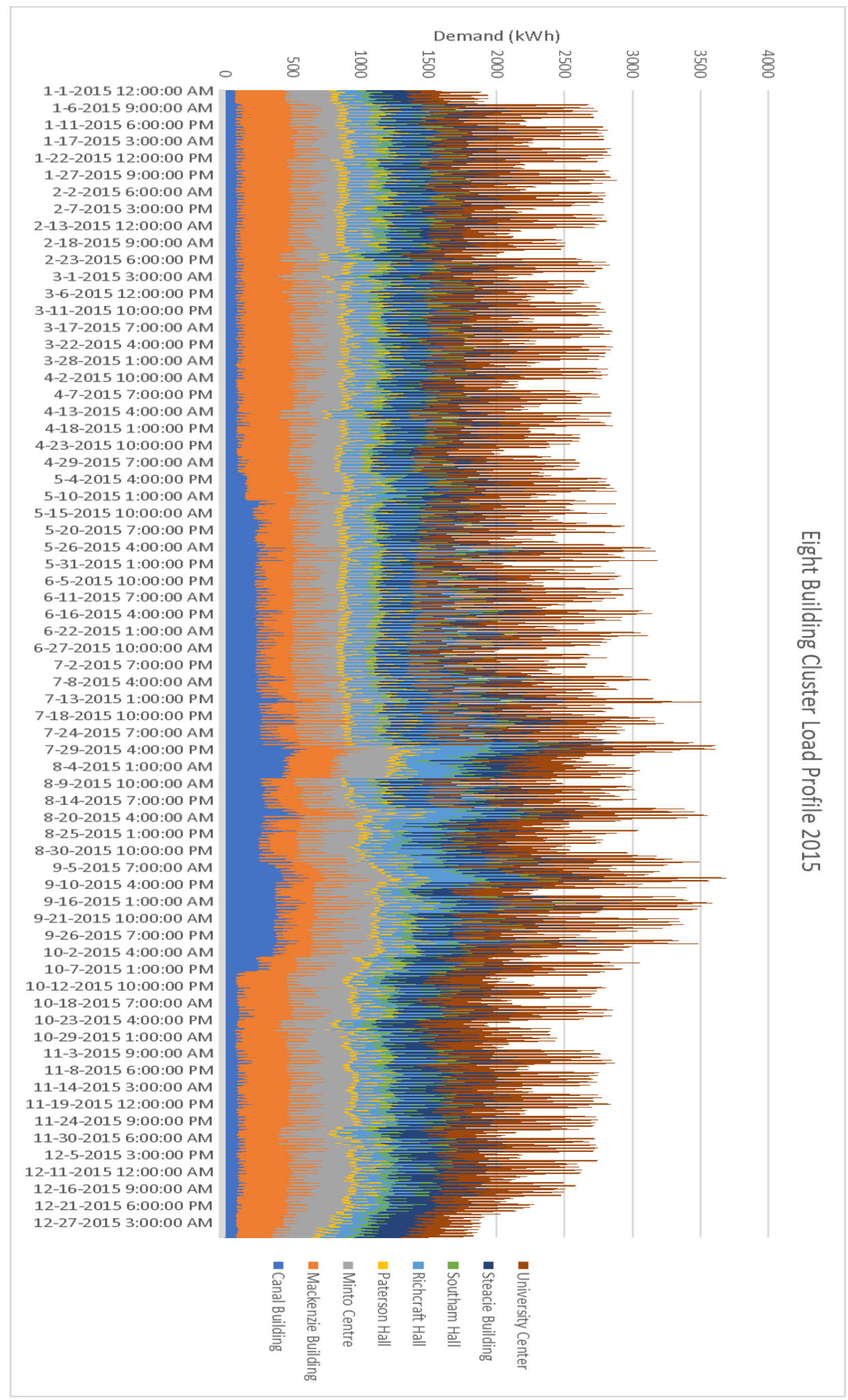

Figure 6.2: Carleton University Eight Building Cluster Stacked Load Profile 


\section{Appendix C : Carleton University Campus Load Data}

Due to the size of these files, a MATLAB code seen was scripted to filter through the data points and detect abnormalities. Table 6.1 shows the date gaps in the data and whether it'll be replaced upon further investigation. The data points that were deemed needed to be replaced, were replaced by data from the same period the previous year. For the electrical load, 540 out of 19,574 data points were replaced or $2.76 \%$. For boiler load, 1052 out of 19,573 data points were replace or $5.37 \%$.

Table 6.1: Data Abnormalities

\begin{tabular}{|c|c|c|c|}
\hline Location & From & To & Decision \\
\hline \multirow{6}{*}{ Substation 1} & 20/11/2017 2 PM & 28/11/2017 9 PM & Keep \\
\hline & 21/07/2017 12 AM & 21/07/2017 10 AM & Replace \\
\hline & 15/07/2017 12 AM & 15/07/2017 6 PM & Keep \\
\hline & 22/03/2017 9 AM & 22/03/2017 12 PM & Keep \\
\hline & 22/01/2017 2 PM & 27/01/2017 $11 \mathrm{AM}$ & Replace \\
\hline & $25 / 05 / 20166$ AM & $31 / 05 / 201610 \mathrm{PM}$ & Replace \\
\hline \multirow{8}{*}{ Substation 2} & 25/12/2017 7 PM & 02/01/2018 7 PM & Replace \\
\hline & 15/12/2017 AM & 15/12/2017 12 PM & Keep \\
\hline & 20/11/2017 2 PM & 20/11/2017 3 PM & Keep \\
\hline & $21 / 07 / 201712 \mathrm{AM}$ & $21 / 07 / 201710 \mathrm{AM}$ & Replace \\
\hline & 20/07/2017 9 PM & 20/07/20179 PM & Keep \\
\hline & 14/07/2017 11 PM & 15/07/2017 $12 \mathrm{AM}$ & Keep \\
\hline & 13/02/2017 $10 \mathrm{AM}$ & 15/02/2017 6 PM & Replace \\
\hline & 26/09/2016 5 PM & 26/09/2016 6 PM & Keep \\
\hline
\end{tabular}




\begin{tabular}{|l|l|l|l|}
\hline & $30 / 04 / 2016$ 1 AM & $30 / 04 / 20166$ AM & Keep \\
\hline \multirow{4}{*}{ Substation 3 } & $18 / 08 / 2017$ 11 AM & $18 / 08 / 2017$ 11 AM & Keep \\
\cline { 2 - 4 } & $03 / 08 / 2017$ 1 PM & $03 / 08 / 2017$ 1 PM & Keep \\
\cline { 2 - 4 } & Starts at: & $21 / 07 / 2017$ 1 PM & \\
\hline \multirow{3}{*}{ Boiler } & $08 / 10 / 2017$ PM & $09 / 10 / 20172$ AM & Keep \\
\cline { 2 - 4 } & $05 / 10 / 2017$ AM & $05 / 10 / 20171$ AM & Keep \\
\cline { 2 - 4 } & $24 / 11 / 2017$ AM & $06 / 01 / 2018$ PM & Replace \\
\hline
\end{tabular}




\section{C.1 Electrical Load Profile}
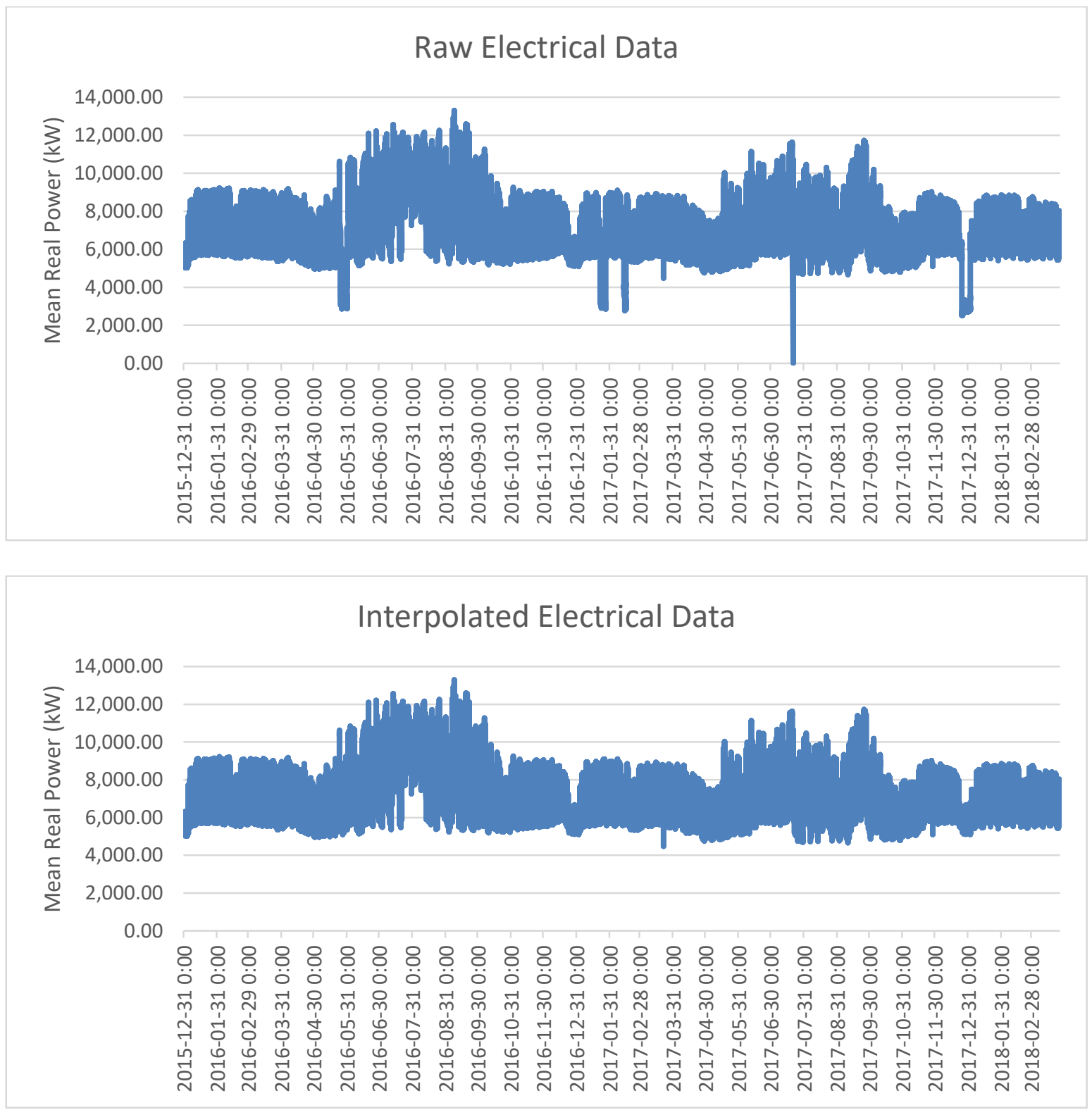

Figure 6.3: Raw vs Interpolated Hourly Electrical Data 


\section{C.2 Heating Load Profile}
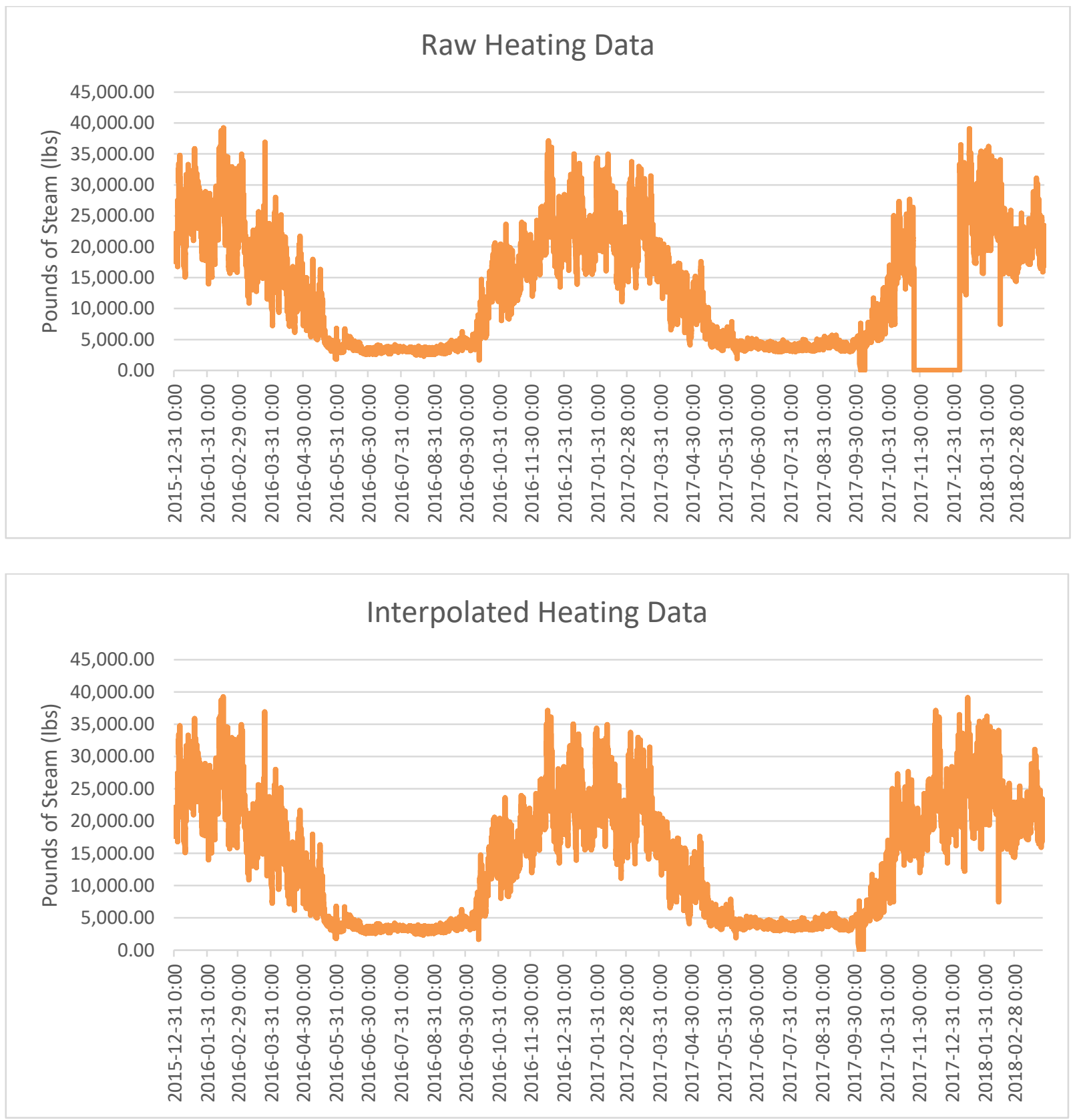

Figure 6.4: Raw vs Interpolated Hourly Heating Data 


\section{Appendix D : Carleton University's Energy System Load}

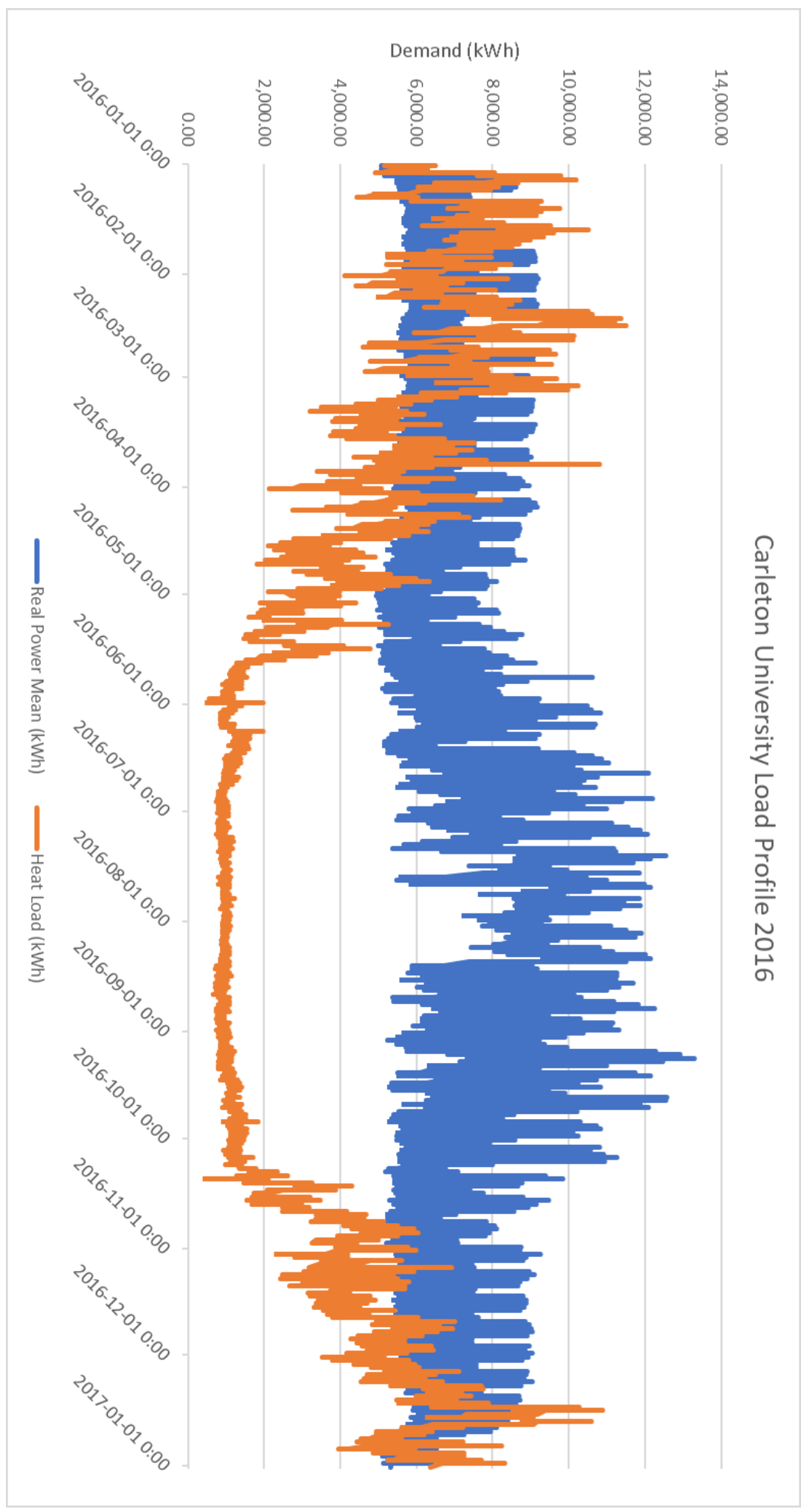

Figure 6.5: Carleton University Hourly Timestep Load Profile in 2016 


\section{References}

[1] P. Pachauri and L. Meyer, "Climate Change 2014: Synthesis Report," Intergovernmental Panel on Climate Change, Geneva, 2014.

[2] United Nations Framework Convention on Climate Change, "The Paris Agreement," United Nations Framwork Convention on Climate Change, [Online]. Available: http://unfccc.int/paris_agreement/items/9485.php. [Accessed 2017].

[3] Environment and Climate Change Canada, "Canadian Environmental Sustainability Indicator: Greenhouse Gas Emissions," Environment and Climate Change Canada, Gatineau, 2017.

[4] G. Newsham and B. Bowker, "The effect if utility time-varying pricing and load control strategies on residential summer peak electricity use: A review," Energy Policy, vol. 38, pp. 3289-3296, 2010.

[5] M. Stadler, G. Cardoso, S. Mashayekh, T. Forget, N. DeForest, A. Agarwal and A. Schonbein, "Value streams in microgrids: A literature review," Applied Energy, no. 162, pp. 980-989, 2016.

[6] A. Mishra, D. Irwin, P. Shenoy and J. Kurose, "SmartCharge" Cutting the electricity bill in smart homes with energy storage," in Future Energy Systems: Where Energy, Computing and Communications Meet, Madrid, 2012.

[7] N. R. E. Laboratory, "Renewable Electricity Futures Study," 21 January 2016. [Online]. Available: http://www.nrel.gov/analysis/re_futures/. [Accessed 20 December 2016].

[8] American Society of Civil Engineers, "2013 Report Card for Ameroca's Infrastructure," American Society of Civil Engineers, 2013. [Online]. Available: http://infrastructurereportcard.org/a/\#p/home. [Accessed January 2017].

[9] Canadian Electricity Association, "The North American Grid: Powering Cooperation on Clean Energy \& the Environment," Canadian Electricity Association, Ottawa, 2016.

[10] Schneider Electric, "Metering, Power Reliability and Microgrids," Schneider Electric, 2016. [Online]. Available: http://www.schneiderelectric.ca/en/work/services/energy-and-sustainability/metering-power-reliabilityand-microgrids/. [Accessed January 2017].

[11] M. H. Albadi and E. F. El-Saadany, "A summary of demand response in electricity markets," Electric Power Systems Research, vol. 78, no. 11, pp. 1989-1996, 2008.

[12] F. Matrin-Martinez, A. Sanchez-Miralles and M. Rivier, "A literature review of Microgrids: A functional layer based classification," Renewable and Sustainable Energy Reviews, vol. 62, pp. 1133-1153, 2016.

[13] Hydro Ottawa Limited, "TIME-OF-USE," Hydro Ottawa Limited, 2016. [Online]. Available: https://hydroottawa.com/accounts-and-billing/residential/time-of-use. [Accessed 19 December 2016]. 
[14] J. Nyboer and S. Groves, "A review of Existing Cogeneration Facilities in Canada," Canadian Industrial Energy End-Use Data and Analysis Center (CIEEDAC), Burnaby, 2012.

[15] J. P. J. Navarro, K. Kavvadias, S. Quoilin and A. Zucker, "The joint effect of centralised cogeneration plants and thermal storage on the efficiency and cost of the power system," Energy, vol. 149, pp. 535-549, 2018.

[16] K. Sartor and P. Dewallef, "Optimized Intefration of Heat Storage Into District Heating," in 11th International Renewable Energy Storage (IRES), Düsseldorf, 2017.

[17] B. Dunn, H. Kamath and J.-M. Tarascon, "Electrical Energy Storage for the Grid: A Battery of Choices," Science, vol. 334, pp. 928-935, 2011.

[18] Independant Electricity System Operator, "Price Overview," Independant Electricity System Operator, 2018. [Online]. Available: http://www.ieso.ca/power-data/priceoverview/hourly-ontario-energy-price. [Accessed 2018].

[19] Independant Electricity System Operator, "Power Data," Independant Electricity System Operator, 2016. [Online]. Available: http://www.ieso.ca/Pages/PowerData/default.aspx\#. [Accessed 20 December 2016].

[20] Independant Electricity System Operator, "Peak Tracker for Global Adjustment Class A," Independant Electricity System Operator, 2018. [Online]. Available: http://www.ieso.ca/en/sector-participants/settlements/global-adjustment-for-classa. [Accessed 2018].

[21] T. Siewierski, T. Pajak and M. Delag, "Optimisation of Gogeneration Units in Large Heating Systems," in 11th International Conference on Software, Knowledge, Information Management and Applications (SKIMA), Colombo, 2017.

[22] T.-M. Tveit, T. Savola, A. Gebremedhin and C.-J. Fogelholm, "Multi-period MINLP model for optimising operation and structural changes to CHP plants in district heating networks with long-term thermal storage," Energy Conversion and Management, vol. 50, no. 3, pp. 639-647, 2009.

[23] N. Ibrahim, F. Al-Sulaiman, S. Rahman, B. Yilbas and A. Sahin, "Heat transfer enhancement of phase change materials for thermal energy storage applications: A critical review," Renewable and Sustainable Energy Reviews, vol. 74, pp. 26-50, 2017.

[24] Y. Tao and Y.-L. He, "A review of phase change material and performance enhancement method for latent heat storage system," Renewable and Sustainable Energy Reviews, vol. 93, pp. 245-259, 2018.

[25] D. Basciotti, F. Judex, O. Pol and R.-R. Schmidt, "Sensible heat storage in disctrict heating networks: a novel control strategy using the network as storage," in 6th International Renewable Energy Storage (IRES), Berlin, 2011.

[26] Enbridge Gas Distribution Inc., "Large Volume Rates," Enbridge Gas Distribution Inc., April $2018 . \quad$ [Online]. Available: https://www.enbridgegas.com/businesses/accounts-billing/gas-rates/large-volumerates/rate-6.aspx. [Accessed May 2018]. 
[27] Ontario Energy Board, "Historical Natural Gas Rates," Ontario Energy Board, 2018. [Online]. Available: https://www.oeb.ca/rates-and-your-bill/natural-gasrates/historical-natural-gas-rates\#enbridge. [Accessed 2018].

[28] Homer Energy, "Homer Pro Version 3.7 User Manual," 2016. [Online]. Available: www.homerenergy.com/pdf/HOMERHelpManual.pdf. [Accessed 2016].

[29] T. Lambert, P. Gilman and P. Lilienthal, "Micropower System Modeling with Homer," in Integration of Alternative Sources of Energy, John Wiley \& Sons, Inc., 2006, pp. 379-418.

[30] M. St-Jacques, S. Bucking and W. O'Brien, "Quantification of high temporal and spatial scale GHG emissions from electricity generation: method and case study," in eSim 2018, Montréal, 2018.

[31] Government of Canada, "Technical paper: federal carbon pricing backstop," 187 2017. [Online]. Available: https://www.canada.ca/en/services/environment/weather/climatechange/technicalpaper-federal-carbon-pricing-backstop.html. [Accessed 2017].

[32] Environment and Climate Change Canada, "Greenhouse Gas Emissions by Canadian Economic Sector," 134 2017. [Online]. Available: https://www.ec.gc.ca/indicateurs-indicators/default.asp?lang=en\&n=F60DB708-1. [Accessed 2017].

[33] United States Environmental Protection Agency, "Air Emissions Factors and Quantification," United States Environmental Protection Agency, 2017. [Online]. Available: https://www.epa.gov/air-emissions-factors-and-quantification/basicinformation-air-emissions-factors-and-quantification. [Accessed 2017].

[34] Independent Electricity System Operator, "Ontario's Supply Mix," Independent Electricity System Operator, 2017. [Online]. Available: http://www.ieso.ca/learn/ontario-supply-mix/ontario-energy-capacity. [Accessed 2017].

[35] A. Farhat and V. Ugursal, "Greenhouse gas emission intensity factors for marginal electricity generation in Canada," International Journal of Energy Research, vol. 34, no. 15, pp. 1309-1327, 2010.

[36] C. Gordon and A. Fung, "Hourly emission factors from the electricity generation sector - A tool for analyzing the impact of renewable technologies in Ontario," Transactions of the Canadian Society for Mechanical Engineering, vol. 33, no. 1, pp. 105-118, 2009.

[37] Environment Canada, "National and provincial territorial greengouse gas emission tables," $27 \quad$ January $2016 . \quad$ [Online]. Available: http://donnees.ec.gc.ca/data/substances/monitor/national-and-provincial-territorialgreenhouse-gas-emission-tables/E-Tables-Electricity-Canada-ProvincesTerritories/?lang=en. [Accessed 2017].

[38] K. Frommann and E. DiValentino, "Calculation and application of hourly emission factors for increased accuracy in scope two emission calculations," Transactions of the Canadian Society for Mechanical Enginnering, vol. 36, no. 2, pp. 143-148, 2012.

[39] M. Brander, A. Sood, C. Wylie, A. Haughton and J. Lovell, "Technical Paper: Electricity-specific emission factors for grid electricity," August 2011. [Online]. 
Available: https://ecometrica.com/assets/Electricity-specific-emission-factors-forgrid-electricity.pdf. [Accessed 2017].

[40] M. MacCracken, "California's Title 24 \& Cool Storage," ASHRAE Journal, vol. 48, no. 10, pp. 29-33, 2006.

[41] S. Price, A. Mahone, N. Schlag and D. Suyeyasu, "Time Dependant Valuation of Energy for Developing Building Efficiency Standards," Energy and Environmental Economics, Inc., San Francisco, 2011.

[42] National Renewable Energy Laboratoty, "Climate Zone Number 3," OpenEI, 17 July 2009. [Online]. Available: https://openei.org/wiki/Climate_Zone_Number_3. [Accessed 2017].

[43] ASHRAE, "International Climate Zone Definitions," 2007. [Online]. Available: https://www.ashrae.org/File\%20Library/docLib/Public/20081111_CZTables.pdf. [Accessed 2017].

[44] J. Graff Zivin, M. Kotchen and E. Mansur, "Spatial and temporal heterogeneity of marginal emissions: Implications for electric cars and other electricity-shifting policies," Journal of Economic Behavior \& Organization, pp. 248-268, 2014.

[45] North American Electric Reliability Corporation, "Key Players," 2017. [Online]. Available: http://www.nerc.com/AboutNERC/keyplayers/Pages/default.aspx.

[46] Canadian Energy Research Instritute, "Greenhouse Gas Emissions Reductions in Canada Through Electrification of Energy Services," Canadian Energy Research Instritute, Calgary, 2017.

[47] Independant Electricity System Operator, "IESO Zonal Map," Independant Electricity System Operator, 2017. [Online]. Available: http://www.ieso.ca/localContent/zonal.map/index.html. [Accessed 2017].

[48] U.S. Energy Information Administration, "U.S. States: State Profiles and Energy Estimates," U.S. Energy Information Administration, 2017. [Online]. Available: https://www.eia.gov/state/. [Accessed 2017].

[49] Natural Resources Canada, "Energy Fact Book 2016-2017," Natural Resources Canada, Ottawa, 2017.

[50] E. Mallia and G. Lewis, "Life cycle greenhouse gas emissions of electricity generation in the province of Ontario, Canada," The International Journal of Life Cycle Assessment, vol. 18, no. 2, pp. 377-391, 2013.

[51] The MathWorks, Inc., "linprog," The MathWorks, Inc., 2017. [Online]. Available: https://www.mathworks.com/help/optim/ug/linprog.html\#description. [Accessed 2017].

[52] Carleton University, "Our Buildings," Carleton University, 2017. [Online]. Available: https://carleton.ca/campus/buildings/. [Accessed 2017].

[53] HOMER Pro Microgrid Analysis Tool x64 3.8.5, Electrical Load, 2017.

[54] Independent Electricity System Operator, "Data Directory," Independent Electricity System Operator, 2017. [Online]. Available: http://www.ieso.ca/power-data/datadirectory. [Accessed 2017]. 
[55] A.-H. Mohsenian-Rad and A. Leon-Garcia, "Optimal Residential Load Control with Price Prediction in Real-Time Electricity Pricing Environments," IEEE Transactions on Smart Grid, vol. 1, no. 2, pp. 120-133, 2010.

[56] T. Cui, H. Goudarzi, S. Hatami, S. Nazarian and M. Pedram, "Concurrent optimization of consumer's electrical energy bill and producer's power generation cost under a dynamic pricing model," in Innovative Smart Grid Technologies, Washington, 2012.

[57] A. Oudalov, R. Cherkaoui and A. Beguin, "Sizing and Optimal Operation of Battery Energy Storage System for Peak Shaving Application," in Power Tech, Lausanne, 2007.

[58] E. Telaretti and L. Dusonchet, "Battery storage systems for peak load shaving applications: Part 1: Operating strategy and modification of the power diagram," in IEEE: Environment and Electrical Engineering, Florence, 2016.

[59] E. Telaretti and L. Dusonchet, "Battery storage systems for peak load shaving applications: Part 2: Economic feasibility and sensitivity analysis," in IEEE: Environment and Electrical Engineering, Florence, 2016.

[60] G. Frank, T. Jenkin and D. Murphy, "Opportunities for Electricity Storage in Deregulating Markets," The Electricity Journal, vol. 12, no. 8, pp. 46-56, 1999.

[61] T. Carpenter, S. Sahil, P. Azimzadeh and S. Keshav, "The impact of electricity pricing schemes on storage adoption in Ontario," in Future Energy Syhstems: Where Energy, Computing and Communication Meet (e-Energy), Madrid, 2012.

[62] I. Atzeni, L. Ordonez, G. Scutari, D. Palomar and J. Fonollosa, "Demand-Side Management via Distributed Energy Generation and Storage Optimization," IEEE Transactions on Smart Grid, vol. 4, no. 2, pp. 866-876, 2013.

[63] Hydro Ottawa, Hydro Ottawa Limited, 1 May 2018. [Online]. Available: https://hydroottawa.com/accounts-and-billing/business/rates-and-conditions. [Accessed 2018].

[64] Tesla, "Tesla Press Information," Tesla, Inc., 2018. [Online]. Available: https://www.tesla.com/en_CA/presskit/teslaenergy?redirect=no. [Accessed 2018].

[65] International Renewable Energy Agency, "Electricity Storage and Renewables: Costs and Markets to 2030," International Renewable Energy Agency, Abu Dhabi, 2017.

[66] T. Mohn, "Campus microgrids: Opportunities and challenges," in IEEE Power and Energy Society General Meeting, San Diego, 2012.

[67] Berkeley Lab, "Microgrids at Berkeley Lab," Berkeley Lab, 2018. [Online]. Available: https://building-microgrid.lbl.gov/ucsd. [Accessed 2018].

[68] P. Sreedharan, J. Farbes, E. Cutter, C. Woo and J. Wang, "Microgrid and renewable generation integration: University of California, San Diego," Applied Energy, vol. 169, pp. 709 - 720, 2016.

[69] I. Sarbu and C. Sebarchievici, "A Comprehensive Review of Thermal Energy Storage," Sustainability, vol. 10, no. 1, 2018.

[70] Honeywell, "Carleton University Energy Master Plan," Carleton University, Ottawa, 2014. 
[71] Solar Turbine, "CENTAUR 50: Gas Turbine Generator Set," 2009. [Online]. Available: http://s7d2.scene7.com/is/content/Caterpillar/C10550199. [Accessed 2018].

[72] Government of Canada, "Greenhouse gas emissions: inventories and reporting," Government of Canada, Ottawa, 2018.

[73] The MathWorks, Inc., "Linear Programming Algorithms," 2018. [Online]. Available: https://www.mathworks.com/help/optim/ug/linear-programmingalgorithms.html\#budwan6. [Accessed 2018].

[74] HEC Montréal, "The Steps of the Simplex Algorithm," 2018. [Online]. Available: http://www.hec.ca/en/cam/help/topics/The_steps_of_the_simplex_algorithm.pdf. [Accessed 2018]. 